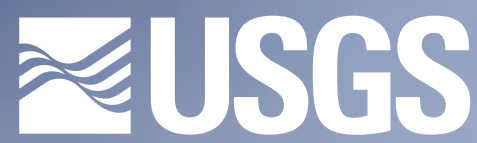

science for a changing world

Prepared in cooperation with the Bureau of Reclamation, National Park Service, and Argonne National Laboratory

\title{
Decision Analysis to Support Development of the Glen Canyon Dain Long-Term Experimental and Management Plan
}

Scientific Investigations Report 2015-5176

U.S. Department of the Interior U.S. Geological Survey

ment of tin. ) 
Covers. Front: An oar boat with university students from Northern Arizona University's Grand Canyon Semester passes river mile 61 near the confluence of the Little Colorado River and the Colorado River. This area is known for its biological and cultural significance, as the stronghold of the endangered humpback chub, and a place of importance in many tribal histories. Photograph taken by Amy S. Martin, Northern Arizona University, November 2014.

Back: Lower Beaver Falls lies approximately 4 miles up Havasu Creek from its confluence with the Colorado River at river mile 157 and is the site of ongoing endangered humpback chub translocations. Photograph taken by Amy S. Martin, National Park Service, October 2013. 


\section{Decision Analysis to Support Development of the Glen Canyon Dam Long-Term Experimental and Management Plan}

By Michael C. Runge, Kirk E. LaGory, Kendra Russell, Janet R. Balsom, R. Alan Butler, Lewis G. Coggins, Jr., Katrina A. Grantz, John Hayse, Ihor Hlohowskyj, Josh Korman, James E. May, Daniel J. O’Rourke, Leslie A. Poch, James R. Prairie, Jack C. VanKuiken, Robert A. Van Lonkhuyzen, David R. Varyu, Bruce T. Verhaaren, Thomas D. Veselka, Nicholas T. Williams, Kelsey K. Wuthrich, Charles B. Yackulic, Robert P. Billerbeck, and Glen W. Knowles

Prepared in cooperation with the Bureau of Reclamation, National Park Service, and Argonne National Laboratory

Scientific Investigations Report 2015-5176 


\title{
U.S. Department of the Interior SALLY JEWELL, Secretary
}

\section{U.S. Geological Survey \\ Suzette M. Kimball, Acting Director}

\author{
U.S. Geological Survey, Reston, Virginia: 2015
}

For more information on the USGS - the Federal source for science about the Earth, its natural and living resources, natural hazards, and the environment—visit http://www.usgs.gov or call 1-888-ASK-USGS.

For an overview of USGS information products, including maps, imagery, and publications, visit http://www.usgs.gov/pubprod/.

Any use of trade, firm, or product names is for descriptive purposes only and does not imply endorsement by the U.S. Government.

Although this information product, for the most part, is in the public domain, it also may contain copyrighted materials as noted in the text. Permission to reproduce copyrighted items must be secured from the copyright owner.

Suggested citation:

Runge, M.C., LaGory, K.E., Russell, Kendra, Balsom, J.R., Butler, R.A., Coggins, L.G., Jr., Grantz, K.A., Hayse, John, Hlohowskyj, Ihor, Korman, Josh, May, J.E., O'Rourke, D.J., Poch, L.A., Prairie, J.R., VanKuiken, J.C., Van Lonkhuyzen, R.A., Varyu, D.R., Verhaaren, B.T., Vesekla, T.D., Williams, N.T., Wuthrich, K.K., Yackulic, C.B., Billerbeck, R.P., and Knowles, G.W., 2015, Decision analysis to support development of the Glen Canyon Dam Long-Term Experimental and Management Plan: U.S. Geological Survey Scientific Investigations Report 2015-5176, 64 p., http://dx.doi.org/10.3133/ sir20155176.

ISSN 2328-0328 (online) 


\section{Acknowledgments}

A project this large owes a debt of gratitude to many people who generously offered their support, insights, and expertise. The authors thank Anne Castle and Lori Caramanian from the Department of the Interior for their vision and support for the inclusion of decision analysis methods in the development of the Environmental Impact Statement. Ted Melis (U.S. Geological Survey Grand Canyon Monitoring and Research Center) provided extensive insights during the first 2 years of this project, helping shape the design of this analysis. Jack Schmidt and Scott VanderKooi (U.S. Geological Survey Grand Canyon Monitoring and Research Center) shared their expertise and leadership, and provided access to the scientific experts at their Center.

This project required expertise from many agencies outside of the U.S. Geological Survey. Too numerous to list here, the many members of the subject-matter expert teams provided critical input to the development of performance metrics and the quantitative evaluation of alternatives. The efforts to articulate and attempt to quantify tribal viewpoints would have been impossible without the dedication and expertise of many representatives, including Kurt Dongoske (Pueblo of Zuni), Mike Yeatts (Hopi Tribe), Loretta Jackson-Kelly and Peter Bungart (Hualapai Tribe), Charley Bulletts (Southern Paiute Consortium), Robert Kirk and Tony Joe (Navajo Nation), and Sarah Rinkevich (U.S. Fish and Wildlife Service). Terry Walshe and David Smith provided insightful comments on an earlier draft of this report. Rich Valdez and Carl Walters shared their depth of knowledge and astute perspectives on many aspects of the Grand Canyon ecosystem. The authors are deeply grateful to the representatives from the stakeholder agencies who participated in the swing-weighting exercise; and worked diligently, enthusiastically, and with integrity to share their perspectives.

Funding for this project was provided by the Bureau of Reclamation. 



\section{Contents}

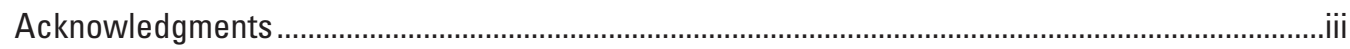

1 Abstract

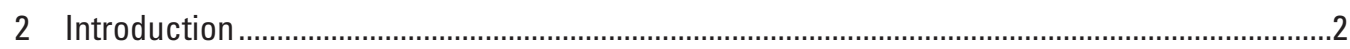

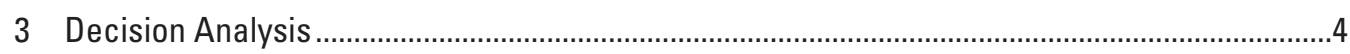

3.1 Structured Decision Making ......................................................................................

3.2 Multicriteria Decision Analysis...................................................................................

3.2.1 A Full Articulation of Resource Goals ................................................................

3.2.2 Performance Metrics ............................................................................................

3.2.3 Transparent and Quantitative Evaluation of Alternatives.......................................

3.2.4 Tradeoff Analysis .......................................................................................... 6

3.3 Uncertainty, Value of Information, and Adaptive Management.........................................

3.3.1 Adaptive Management Versus Experimental Management ....................................6

3.3.2 Articulating Uncertainty as Competing Hypotheses ............................................7

3.3.3 Deconstructing Complex Alternatives ...................................................................

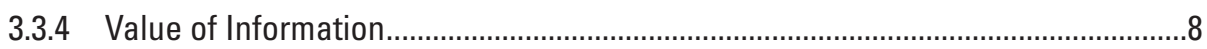

3.3.5 Experimental and Adaptive Design ....................................................................

4 Resource Goals and Performance Metrics ……................................................................

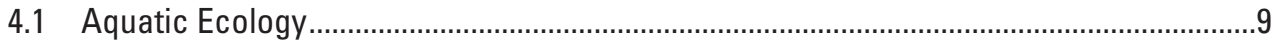

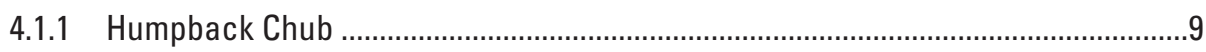

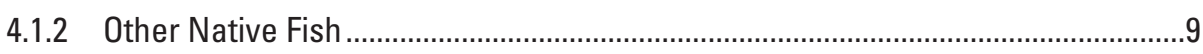

4.1.3 Rainbow Trout Fishery ................................................................................

4.1.4 Nonnative Aquatic Species .............................................................................

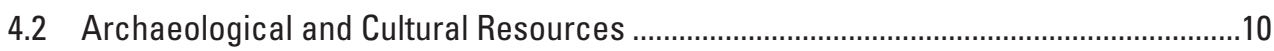

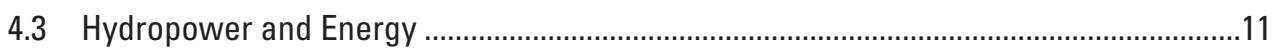

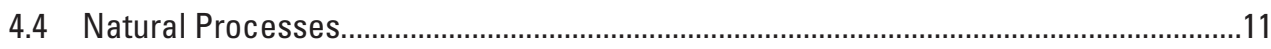

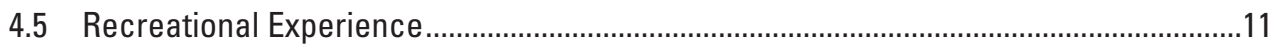

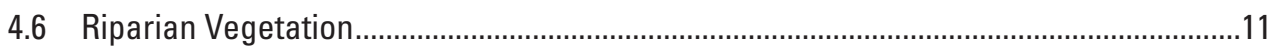

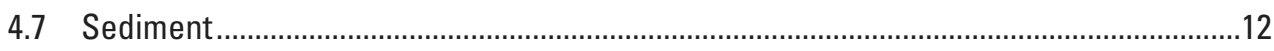

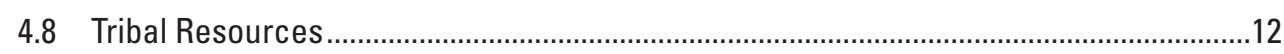

4.8.1 Health of the Ecosystem ...........................................................................

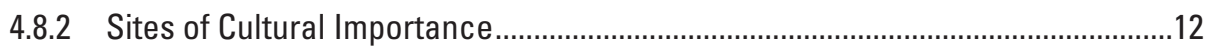

4.8.3 Respect for Life................................................................................................ 13

4.8.4 Sacred Integrity of Grand, Marble, and Glen Canyons .......................................13

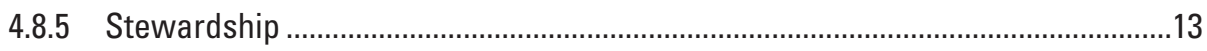

4.8.6 Tribal Connections to the Canyons.....................................................................

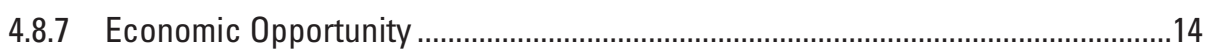

4.8.8 Tribal Water Rights and Supply.................................................................... 14

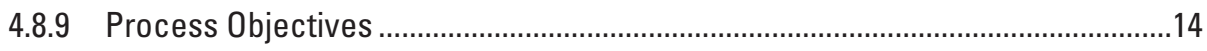

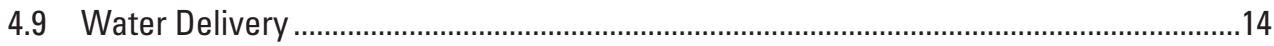

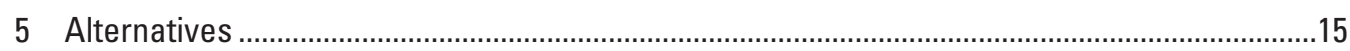

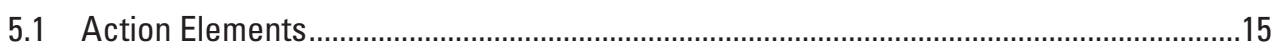

5.1.1 Monthly Release Pattern and Other Base Operations........................................15 


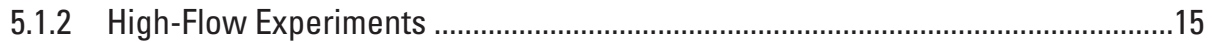

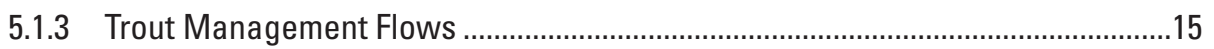

5.1.4 Other Flow Manipulations....................................................................................15

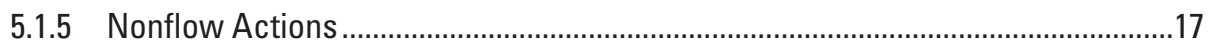

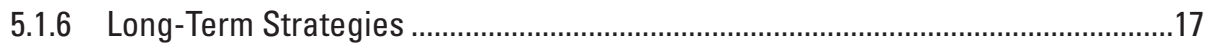

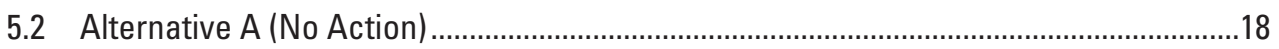

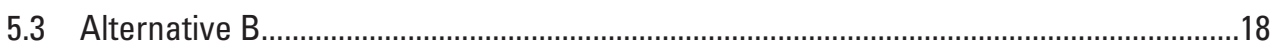

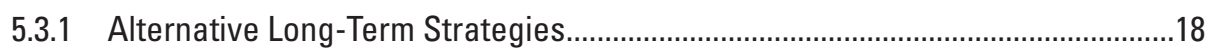

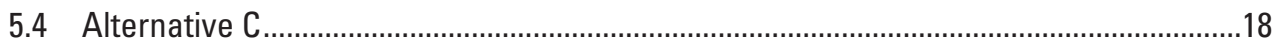

5.4.1 Alternative Long-Term Strategies...............................................................18

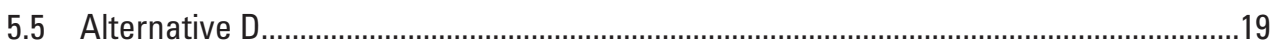

5.5.1 Alternative Long-Term Strategies..............................................................

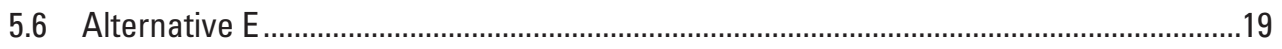

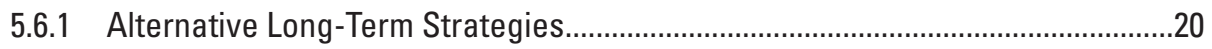

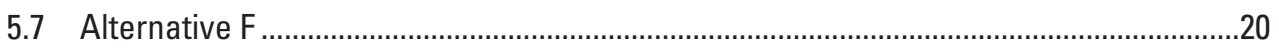

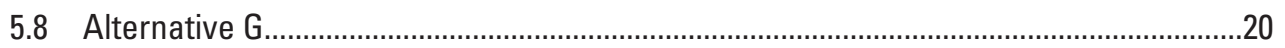

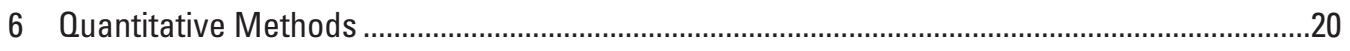

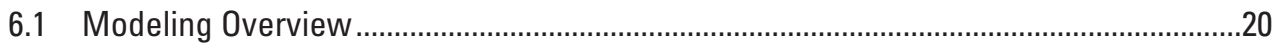

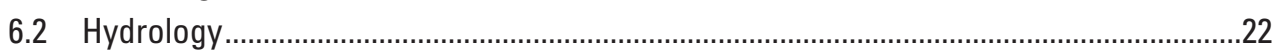

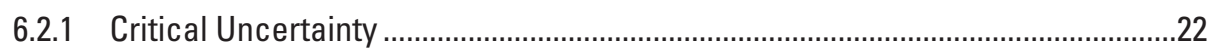

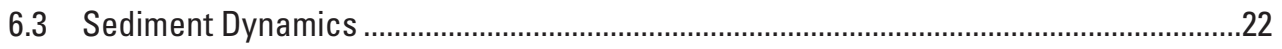

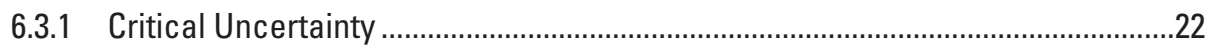

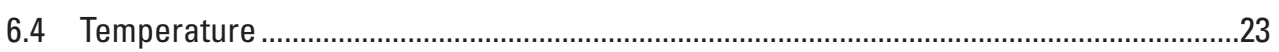

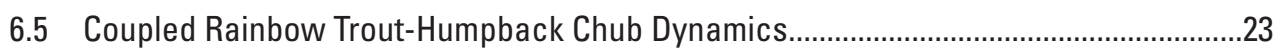

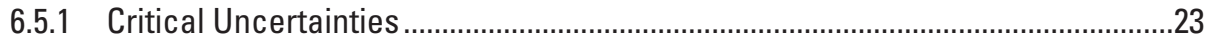

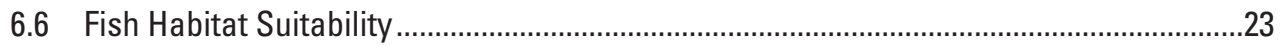

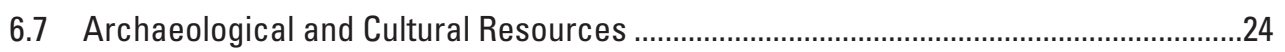

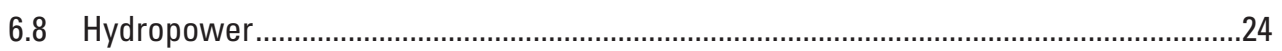

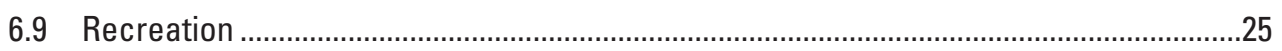

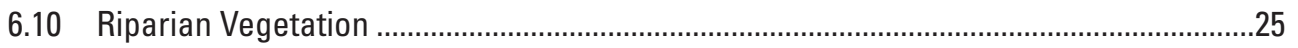

7 Consequence Analysis Results...........................................................................................25

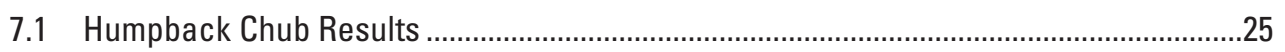

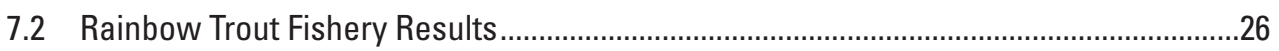

7.3 Archeological and Cultural Resources Results ...........................................................

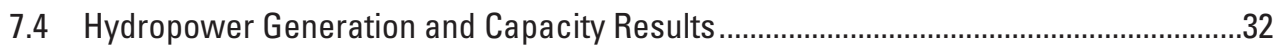

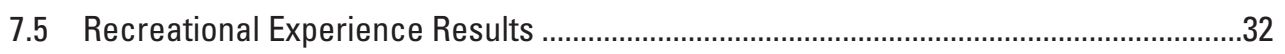

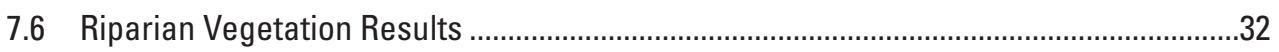

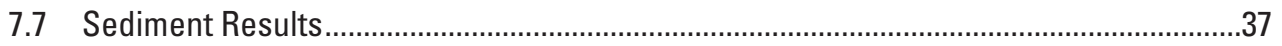

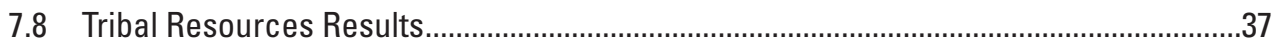

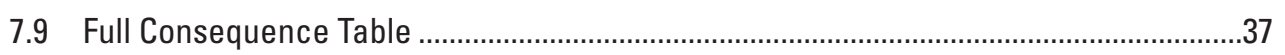

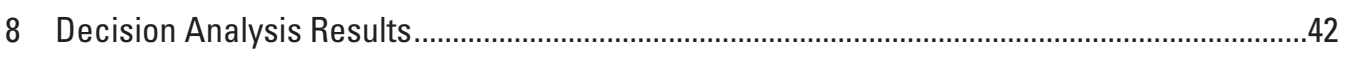

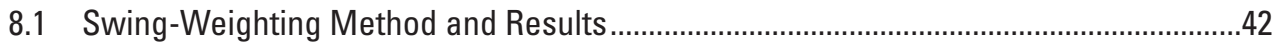

8.2 Multicriteria Decision Analysis ..............................................................................42

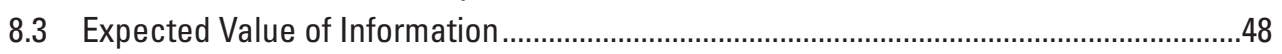

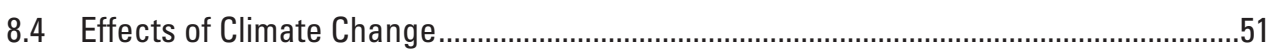




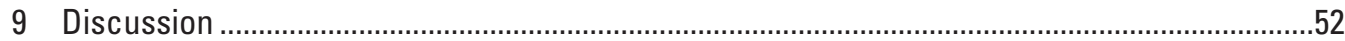

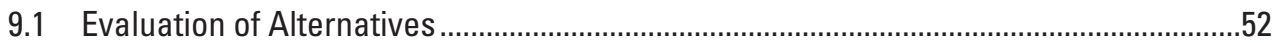

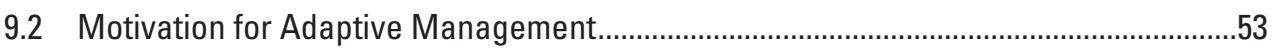

9.3 Decision Analysis and the National Environmental Policy Act ......................................54

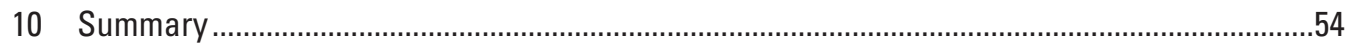

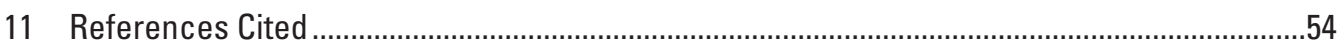

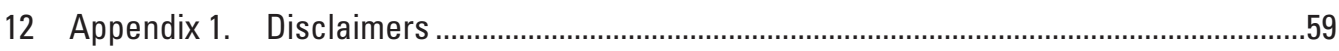

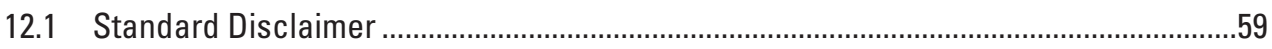

12.2 Arizona Department of Water Resources Disclaimer .................................................59

12.3 Arizona Game and Fish Department Disclaimer ............................................................60

12.4 Salt River Project Explanatory Letter .........................................................................60

12.5 Utah Associated Municipal Power Systems Explanatory Letter .................................61

12.6 Colorado River Energy Distributors Association Submittal Letter ..............................61

\section{Figures}

1. Map showing the Colorado River ecosystem below Glen Canyon Dam, depicting the Glen Canyon Dam Adaptive Management Program project area ...............................3

2. Diagram showing model flow for the analysis of the Long-Term Experimental and Management Plan long-term strategies against the performance metrics ....................21

3. Graphs showing uncertainty in the humpback chub population dynamics as represented by four alternative sets of parameters.

4. Box plots showing minimum number of adult humpback chub (performance metric 1) forecast for 19 long-term strategies with equal weighting of traces................26

5. Box plots showing temperature suitability index for humpback chub at river mile 157 and 213 (performance metric 2) forecast for 19 long-term strategies with equal weighting of traces..

6. Box plots showing rainbow trout catch rate (performance metric 3 ) forecast for 19 long-term strategies with equal weighting of traces.

7. Box plots showing rainbow trout emigration rate from Glen Canyon (performance metric 4) forecast for 19 long-term strategies with equal weighting of traces.

8. Box plots showing abundance of high-quality rainbow trout (performance metric 5) forecast for 19 long-term strategies with equal weighting of traces...

9. Box plots showing wind transport of sediment index (performance metric 6) forecast for 19 long-term strategies with equal weighting of traces

10. Box plots showing Glen Canyon flow index (performance metric 7) forecast for 19 long-term strategies with equal weighting of traces.

11. Box plots showing cultural resources time-off-river index (performance metric 8) forecast for 19 long-term strategies with equal weighting of traces

12. Box plots showing annualized net present value of hydropower generation (performance metric 9) forecast for 19 long-term strategies with equal weighting of traces.

13. Box plots showing annualized net present value of hydropower capacity (performance metric 10) forecast for 19 long-term strategies with equal weighting of traces . 
14. Box plots showing camping area index (performance metric 11) forecast for 19 long-term strategies with equal weighting of traces...

15. Box plots showing fluctuation index (performance metric 12) forecast for 19 long-term strategies with equal weighting of traces.

16. Box plots showing Glen Canyon rafting use metric (performance metric 13) forecast for 19 long-term strategies with equal weighting of traces.

17. Box plots showing riparian vegetation index (performance metric 14) forecast for 19 long-term strategies with equal weighting of traces

18. Box plots showing sand load index (performance metric 15) forecast for 19 long-term strategies with equal weighting of traces

19. Box plots showing marsh vegetation ratio (ratio of average marsh cover over 20-year period to current marsh cover, performance metric 16) forecast for 19 long-term strategies with equal weighting of traces

20. Box plots showing frequency of mechanical removal (performance metric 17) forecast for 19 long-term strategies with equal weighting of traces

21. Box plots showing frequency of trout management flows (performance metric 18) forecast for 19 long-term strategies with equal weighting of traces

22. Graphs showing principal components analysis of the weights on the performance metrics across stakeholder agencies.

23. Box plots showing joint-lead agency weighted performance across 18 metrics forecast for 19 long-term strategies using equal weighting of hydrological traces .......46

24. Box plots showing joint-lead agency weighted performance across 18 metrics, sorted by mean performance, forecast for 19 long-term strategies using equal weighting of hydrological traces

25. Box plots showing weighted performance across 18 metrics, for four stakeholder agencies, sorted in descending order of mean performance.

26. Box plots showing mean annual inflow to Lake Powell during the 20 -year period of the Long-Term Experimental and Management Plan for 21 historical hydrological traces and 112 climate-change-influenced hydrological traces.

27. Box plots showing joint-lead agency weighted performance across 18 metrics forecast for 19 long-term strategies using the climate-change weighting of hydrological traces. 


\section{Tables}

1. Summary of the 18 performance metrics used in the decision analysis ........................10

2. Operational characteristics of Long-Term Experimental and Management Plan

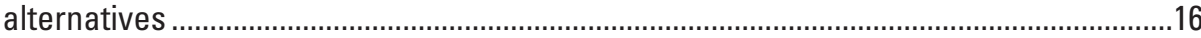

3. Triggered and experimental elements of the Long-Term Experimental and Management Plan long-term strategies

4. Effect of critical uncertainty on minimum adult humpback chub population size

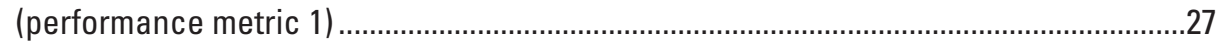

5. Effect of hydrological trace on minimum adult humpback chub population size (performance metric 1) ...................................................................................................28

6. Expected value of information, by performance metric, for resolving critical

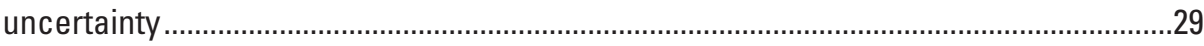

7. Full consequence table showing the mean value of each performance metric for

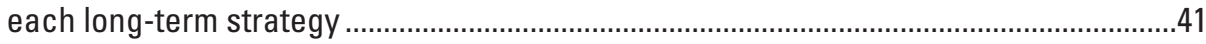

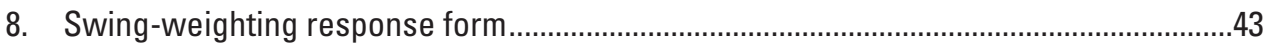

9. Agencies participating in the swing-weighting exercise ...............................................44

10. Weighted performance for 19 long-term strategies using the weights on the performance metrics expressed by 14 participating agencies

11. Expected value of perfect information for resolving various uncertainties, as a function of the agency-specific weights

\section{Conversion Factors}

[Inch/Pound to International System of Units]

\begin{tabular}{lcl}
\hline & Multiply & \multicolumn{1}{c}{ By obtain } \\
\hline inch (in.) & Length & \\
inch (in.) & 2.54 & centimeter $(\mathrm{cm})$ \\
foot (ft) & 25.4 & millimeter $(\mathrm{mm})$ \\
mile (mi) & 0.3048 & meter $(\mathrm{m})$ \\
\hline & 1.609 & kilometer $(\mathrm{km})$ \\
\hline acre & Area & \\
acre & 4,047 & square meter $\left(\mathrm{m}^{2}\right)$ \\
\hline & 0.4047 & hectare $($ ha $)$ \\
\hline acre-foot (acre-ft) & Volume & \\
acre-foot (acrea-ft) & 1,233 & cubic meter $\left(\mathrm{m}^{3}\right)$ \\
\hline & 0.001233 & cubic hectometer $\left(\mathrm{hm}^{3}\right)$ \\
\hline cubic foot per second $\left(\mathrm{ft}^{3} / \mathrm{s}\right)$ & Flow rate & cubic meter per second $\left(\mathrm{m}^{3} / \mathrm{s}\right)$ \\
\hline
\end{tabular}

Vertical coordinate information is referenced to the North American Vertical Datum of 1988 (NAVD 88).

Horizontal coordinate information is referenced to the North American Datum of 1983 (NAD 83).

Altitude, as used in this report, refers to distance above the vertical datum. 


\section{Abbreviations}

\begin{tabular}{|c|c|}
\hline ADWR & Arizona Department of Water Resources \\
\hline AGFD & Arizona Game and Fish Department \\
\hline AMWG & Adaptive Management Working Group \\
\hline Argonne & Argonne National Laboratory \\
\hline Aurora & AURORAxmp \\
\hline AZGFD & Arizona Game and Fish Department \\
\hline $\mathrm{BIA}$ & Bureau of Indian Affairs \\
\hline CMIP3 & Coupled Model Intercomparison Project Phase 3 \\
\hline CREDA & Colorado River Energy Distributors Association \\
\hline CRSP & Colorado River Storage Project \\
\hline CRSS & Colorado River Simulation System \\
\hline DEIS & Draft Environmental Impact Statement \\
\hline DFC & desired future condition \\
\hline DOI & U.S. Department of the Interior \\
\hline DT & Decision-Theoretic school of adaptive management \\
\hline EIS & Environmental Impact Statement \\
\hline ESA & Endangered Species Act of 1973 \\
\hline EVPI & expected value of perfect information \\
\hline EVXI & expected value of partial information \\
\hline FWS & U.S. Fish and Wildlife Service \\
\hline GCDAMP & Glen Canyon Dam Adaptive Management Program \\
\hline GCMRC & Grand Canyon Monitoring and Research Center \\
\hline GCPA & Grand Canyon Protection Act of 1992 \\
\hline GCRG & Grand Canyon River Guides \\
\hline GTMax-Lite & Generation and Transmission Maximization model, spreadsheet version \\
\hline $\mathrm{HBC}$ & humpback chub (Gila cypha) \\
\hline HFE & high-flow experiment \\
\hline IFFF & International Federation of Fly Fishers \\
\hline LTEMP & Long-Term Experimental and Management Plan \\
\hline MCDA & multicriteria decision analysis \\
\hline MLFF & Modified Low Fluctuating Flow \\
\hline NEPA & National Environmental Policy Act \\
\hline NPCA & National Parks Conservation Association \\
\hline NPS & National Park Service \\
\hline
\end{tabular}




$\begin{array}{ll}\text { NPV } & \text { net present value } \\ \text { O\&M } & \text { operating and maintenance } \\ \text { RBT } & \text { rainbow trout (Onchorhynchus mykiss) } \\ \text { RE } & \text { Resilience-Experimentalist school of adaptive management } \\ \text { Reclamation } & \text { Bureau of Reclamation } \\ \text { RM } & \text { river mile } \\ \text { ROD } & \text { Record of Decision } \\ \text { SDA } & \text { structured decision analysis } \\ \text { SDM } & \text { structured decision making } \\ \text { SLI } & \text { sand load index } \\ \text { SMART } & \text { Simple Multi-attribute Rating Technique } \\ \text { SME } & \text { subject-matter expert } \\ \text { SRP } & \text { Salt River Project } \\ \text { TMF } & \text { trout management flow } \\ \text { UAMPS } & \text { Utah Associated Municipal Power Systems } \\ \text { WAPA } & \text { Western Area Power Administration } \\ \text { WTSI } & \text { wind transport of sediment index }\end{array}$





\title{
Decision Analysis to Support Development of the Glen Canyon Dam Long-Term Experimental and Management Plan
}

\author{
By Michael C. Runge, ${ }^{1}$ Kirk E. LaGory, ${ }^{2}$ Kendra Russell, ${ }^{3}$ Janet R. Balsom, ${ }^{4}$ R. Alan Butler, ${ }^{3}$ Lewis G. Coggins, \\ Jr., ${ }^{5}$ Katrina A. Grantz, ${ }^{3}$ John Hayse, ${ }^{2}$ Ihor Hlohowskyj, ${ }^{2}$ Josh Korman, ${ }^{6}$ James E. May, ${ }^{2}$ Daniel J. O'Rourke, ${ }^{2}$ \\ Leslie A. Poch, ${ }^{2}$ James R. Prairie, ${ }^{3}$ Jack C. VanKuiken, ${ }^{2}$ Robert A. Van Lonkhuyzen, ${ }^{2}$ David R. Varyu, ${ }^{3}$ Bruce T. \\ Verhaaren, ${ }^{2}$ Thomas D. Veselka, ${ }^{2}$ Nicholas T. Williams, ${ }^{3}$ Kelsey K. Wuthrich, ${ }^{2}$ Charles B. Yackulic, ${ }^{1}$ Robert P. \\ Billerbeck, ${ }^{4}$ and Glen W. Knowles ${ }^{3}$
}

\section{Abstract}

The U.S. Geological Survey, in cooperation with the Bureau of Reclamation, National Park Service, and Argonne National Laboratory, completed a decision analysis to use in the evaluation of alternatives in the Environmental Impact Statement concerning the long-term management of water releases from Glen Canyon Dam and associated management activities. Two primary decision analysis methods, multicriteria decision analysis and the expected value of information, were used to evaluate the alternative strategies against the resource goals and to evaluate the influence of uncertainty.

A total of 18 performance metrics associated with 8 out of 12 resource goals (fundamental objectives) were developed by the Bureau of Reclamation and National Park Service in partnership with subject-matter teams composed of Federal, State, tribal, and private experts. A total of 19 long-term strategies associated with 7 alternatives were developed by the Bureau of Reclamation, National Park Service, Argonne National Laboratory, U.S. Geological Survey, and Cooperating Agencies. The 19 long-term strategies were evaluated against the 18 performance metrics using a series of coupled simulation models, taking into account the effects of several important sources of uncertainty. A total of 27 Federal, State, tribal, and nongovernmental agencies were invited by the Assistant Secretary of Interior to participate in a swing-weighting exercise to understand the range of perspectives about how

\footnotetext{
${ }^{1}$ U.S. Geological Survey

${ }^{2}$ Argonne National Laboratory

${ }^{3}$ Bureau of Reclamation

${ }^{4}$ National Park Service

${ }^{5}$ National Oceanic and Atmospheric Administration

${ }^{6}$ Ecometric Research, Inc.
}

to place relative value on the resource goals and performance metrics; 14 of the 27 chose to participate. The results of the swing-weighting exercise were combined with the evaluation of the alternatives to complete a multicriteria decision analysis. The effects of uncertainty on the ranking of long-term strategies were evaluated through calculation of the value of information.

The alternatives and their long-term strategies differed across performance metrics, producing unavoidable tradeoffs; thus, there was no long-term strategy that was dominated by another across all performance metrics. When the performance of each alternative was weighted across performance metrics, three alternatives (B, D, and G) were top-ranked depending on the set of weights proposed: Alternative B was favored by those stakeholders that placed a high value on hydropower; Alternative $\mathrm{G}$ was favored by those stakeholders that placed a high value on the restoration of natural processes, like beachbuilding and natural vegetation; and Alternative D was favored by the remaining stakeholders. Surprisingly, these rankings were not sensitive to the critical uncertainties that were evaluated; that is, the choice of a preferred long-term strategy was sensitive to the value-based judgment about how to place relative weight on the resource goals but was not sensitive to the uncertainties in the system dynamics that were evaluated in this analysis. The one area of uncertainty that did slightly affect the ranking of alternatives was the long-term pattern of hydrological input; because of this sensitivity, some attention to the possible effects of climate change is warranted.

The results of the decision analysis are meant to serve as only one of many sources of information that can be used to evaluate the alternatives proposed in the Environmental Impact Statement. These results only focus on those resource goals for which quantitative performance metrics could be formulated and evaluated; there are other important aspects of the resource goals that also need to be considered. Not all the stakeholders who were invited to participate in the decision 
analysis chose to do so; thus, the Bureau of Reclamation, National Park Service, and U.S. Department of Interior may want to consider other input.

\section{Introduction}

The Glen Canyon Dam is on the Colorado River in Arizona, United States, within the boundaries of Glen Canyon National Recreation Area and upstream from Grand Canyon National Park (fig. 1) and is managed by the Bureau of Reclamation (hereinafter referred to as "Reclamation"). The Glen Canyon Dam Adaptive Management Program (GCDAMP) was established in 1997 to provide research and monitoring of downstream resources to Reclamation and the U.S. Department of the Interior (DOI). The GCDAMP project area stretches along the Colorado River from the forebay of Glen Canyon Dam to the westernmost boundary of Grand Canyon National Park. Locations along the Colorado River are indexed by river miles (RM) with a reference point at Lees Ferry (RM 0). The Glen Canyon Dam is at RM -15.5 (15.5 mi upstream from Lees Ferry). Other important locations that are referenced in this report include the following: Paria River (RM 1.0), Little Colorado River (RM 61.4), and Bright Angel Creek (RM 87.8) (fig. 1). The reach from Glen Canyon Dam to Lees Ferry is known as Glen Canyon, the reach from Lees Ferry to the Little Colorado River is known as Marble Canyon, and Grand Canyon proper begins at the Little Colorado River.

In October 1996, the Secretary of the Interior signed a Record of Decision (ROD) documenting the selection of operating criteria for Glen Canyon Dam (Bureau of Reclamation, 1996) as analyzed in the 1995 Final Environmental Impact Statement (Bureau of Reclamation, 1995). The preferred alternative, known as Modified Low Fluctuating Flow (MLFF), has governed the operation of Glen Canyon Dam for the last 19 years (1996 to present) with important modifications described in "Final Environmental Impact Statement-Colorado River interim guidelines for lower basin shortages and the coordinated operations for Lake Powell and Lake Mead" (Bureau of Reclamation, 2007), "Environmental Assessment-Development and implementation of a protocol for high-flow experimental releases from Glen Canyon Dam" (Bureau of Reclamation, 2011a), "Environmental Assessment-Non-native fish control downstream from Glen Canyon Dam" (Bureau of Reclamation, 2011b), and many other regulatory documents. The Bureau of Reclamation (1996) also established the GCDAMP and Grand Canyon Monitoring and Research Center (GCMRC), which has led extensive monitoring and research aimed to improve the management of the Colorado River and its environs below Glen Canyon Dam.

In July 2011, the Secretary of the Interior announced the intent to develop a Long-Term Experimental and Management Plan (LTEMP) and Environmental Impact Statement (EIS) for Glen Canyon Dam as the first comprehensive review of dam operations in 15 years and as an opportunity to integrate the considerable scientific information collected since the GCDAMP began in 1996. The Bureau of Reclamation and National Park Service (NPS) are serving as joint-lead agencies for the EIS. The following agencies are participating as Cooperating Agencies in development of the EIS: Arizona Game and Fish Department (AGFD), Bureau of Indian Affairs (BIA), Colorado River Board of California, Colorado River Commission of Nevada, the Havasupai Tribe, the Hopi Tribe, the Hualapai Tribe, the Kaibab Band of Paiute Indians, the Navajo Nation, the Pueblo of Zuni, Salt River Project (SRP), U.S. Fish and Wildlife Service (FWS), Upper Colorado River Commission, Utah Associated Municipal Power Systems (UAMPS), and Western Area Power Administration (WAPA).

The purpose of the LTEMP is to provide a comprehensive framework for adaptively managing Glen Canyon Dam over the next 20 years consistent with the Grand Canyon Protection Act of 1992 (GCPA) and other provisions of federal law (Bureau of Reclamation and National Park Service 2015); thus, the preferred alternative ultimately selected for the LTEMP will govern the management of water releases at Glen Canyon Dam for the next 20 years, specifying conditiondependent seasonal, weekly, and daily patterns of release, as well as nonflow actions, including vegetation management and the potential for mechanical removal of nonnative fish. The goals for the LTEMP are to meet the requirements of the GCPA; and to minimize, consistent with the law, adverse effects on the downstream natural, recreational, and cultural resources in Glen Canyon National Recreation Area and Grand Canyon National Park, including resources of importance to American Indian Tribes, while ensuring water delivery and maintaining or increasing hydroelectric capacity and generation. The need for the LTEMP arises from scientific information developed since the 1996 record of decision (Bureau of Reclamation, 1996), the use of which will better inform DOI decisions on dam operations and other management and experimental actions so that the Secretary of the Interior may continue to meet statutory obligations to protect resources downstream from Glen Canyon Dam for future generations, conserve species listed under the Endangered Species Act of 1973 (ESA), avoid or mitigate effects on National Register eligible properties, and protect tribal interests, while meeting water delivery obligations and providing hydropower generation. The list of resources of concern in the analysis of alternatives includes the following: tribal resources and interests, sediment deposition and retention, riparian vegetation, humpback chub (HBC) (Gila cypha) and other native fish, historic properties, recreation, the rainbow trout fishery in Glen Canyon, water delivery, and hydropower. There is uncertainty about how management actions in this system affect the resources of concern, which complicates the analysis of alternatives. There is an acknowledged need for adaptive management (Walters, 1986), perhaps even for experimental actions chosen to accelerate learning for the benefit of selecting future management actions. The decision problem, therefore, can be characterized as one of multiple objective tradeoffs in the face 


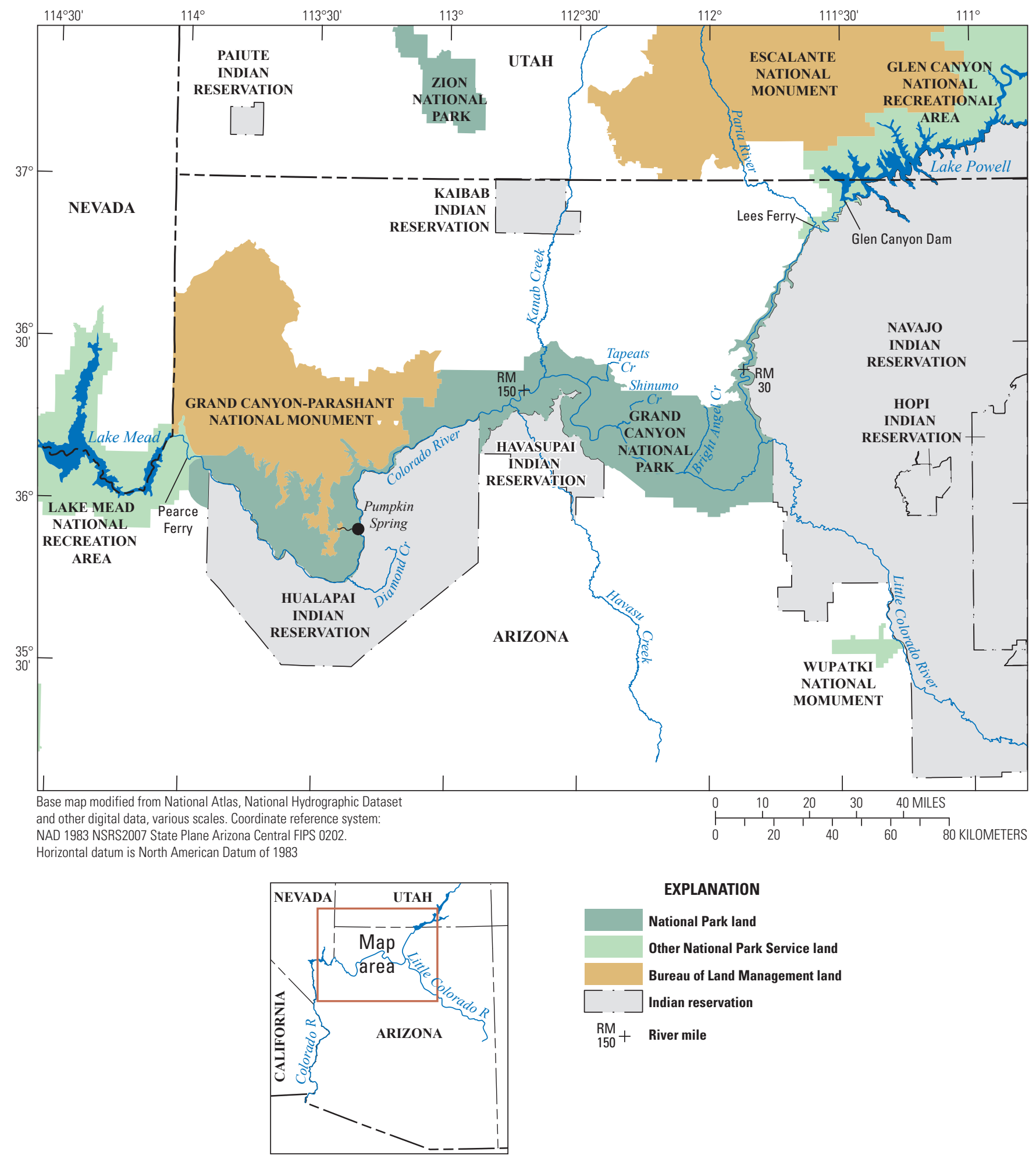

Figure 1. The Colorado River ecosystem below Glen Canyon Dam, depicting the Glen Canyon Dam Adaptive Management Program project area. 
Decision Analysis to Support Development of the Glen Canyon Dam Long-Term Experimental and Management Plan

of uncertainty, where the management actions themselves are condition-dependent, information-dependent, and complex; and where there is the opportunity to reduce uncertainty early on to improve later actions through adaptive implementation.

In July 2012, the Assistant Secretary of the Interior for Water and Science, Reclamation, and NPS embraced the idea of using structured and formal decision analysis as one of several tools to evaluate alternatives in this EIS. Formal decision analysis was seen as a way to address multiple objectives, engage stakeholders, and evaluate the degree to which uncertainty is an impediment to the selection of management actions.

The purpose of this report is to document the formal decision analysis completed by the U.S. Geological Survey, in cooperation with the Bureau of Reclamation, National Park Service, and Argonne National Laboratory, as one component of the evaluation of alternatives for the LTEMP EIS. This report is a stand-alone document and an appendix to the Draft EIS (Bureau of Reclamation and National Park Service, 2015); it is also anticipated to be an appendix to the Final EIS. The emphasis in this report is on the decision analysis; the reader is referred to the Draft EIS (DEIS) and its appendixes for many other details, including the following: the legal, ecological, and cultural context of the LTEMP; an indepth description of the alternatives; the details of the quantitative models used to evaluate the alternatives; and a comprehensive comparison of the alternatives and their effects on resources of concern, including qualitative assessments that were not included in the decision analysis.

\section{Decision Analysis}

The DOI is including formal decision analysis tools to accompany more traditional qualitative tools to evaluate alternatives in the Glen Canyon Dam LTEMP EIS. The LTEMP EIS concerns the management of a very complex system with many, possibly competing, resources of interest and considerable uncertainty about the relations between management strategies and the responses of resources of interest to management strategies; furthermore, there are multiple stakeholder viewpoints to consider, and the DOI wants to use a structured process as one of the tools for better evaluating and understanding stakeholder viewpoints. This section provides an overview of decision analysis and describes the quantitative methods the DOI used to analyze the alternatives.

\subsection{Structured Decision Making}

"Structured decision making" (SDM) is a term of art, used by a community of practitioners in the United States, Canada, and Australia, to refer to the application of a broad array of decision analysis tools to natural resource management (Gregory and others, 2012). The analytical tools used in any application will depend on the specific needs of that decision setting, so SDM can look quite different from case to case. The set of analytical tools that might be used include the following: multicriteria decision analysis (MCDA), decision trees, expert elicitation, objectives hierarchies, value of information, stakeholder involvement, predictive modeling, utility theory, dynamic optimization, portfolio analysis, and many others. The common features in any application of decision analysis are (1) an attention to value-focused thinking (Keeney, 1996), recognizing that any decision is an attempt to achieve something of value to the decision maker; and (2) decomposing the decision problem into basic elements (objectives, alternatives, consequences, and tradeoffs) (Runge, 2011). The goal of SDM is to provide a transparent process for articulating objectives, developing alternatives, and evaluating those alternatives against the objectives. Note, however, that SDM does not substitute for a decision maker, and the application of the SDM process does not make a decision; rather, SDM only serves to aid the decision maker in understanding and organizing the complexities of the problem. The DOI prefers to use the term "structured decision analysis" or simply "decision analysis" for the LTEMP EIS process because the Secretary of the Interior retains the responsibility and authority to make a decision. In the context of the LTEMP EIS, two key decision analysis tools are used to evaluate the alternatives: MCDA and the expected value of perfect information (EVPI).

\subsection{Multicriteria Decision Analysis}

Many objectives associated with management of Glen Canyon Dam are important to stakeholders, including tribal cultural and spiritual values, endangered species, hydropower generation, sediment conservation, and recreation. It is possible that some of these objectives compete; if so, no single strategy will be best at achieving all the objectives. One of the difficulties the decision maker faces, then, is the value judgment regarding how to weight this host of objectives based on the many statutes governing Glen Canyon Dam operation and resource protection. Multicriteria decision analysis is a formal decision analysis tool designed to help evaluate the competing objectives and explore how to weight them within the context of the statutes (Figueira and others, 2005), and has been applied to a wide variety of natural resource management problems (Herath and Prato, 2006). Considerable literature advocates the use of MCDA in National Environmental Policy Act (NEPA) processes (Gregory and others, 1992; Kulkarni and others, 1993; Prato, 1999; Sheehy and Vik, 2002; Kiker and others, 2005; Linkov and others, 2006a, 2006b, 2006c; Stich and Holland, 2011; Marcot and others, 2012). Although not common, a few examples of NEPA documents explicitly incorporate MCDA methods (National Oceanic and Atmospheric Administration, 1995a, 1995b; Kimbrough and others, 2008; Nobrega and others, 2009; Bureau of Reclamation, 2011b; Runge and others, 2011a). Notably, the value of using MCDA for evaluation of management alternatives for Glen Canyon Dam has been argued by Flug and others (2000). 
One of the key advantages of MCDA in the context of the LTEMP EIS is that it provides a structured and transparent method for receiving detailed stakeholder input about the resource goals, ways to evaluate performance of the alternatives against the resource goals, and the value of resource goals relative to each other. Stakeholders have legitimate differences in viewpoint about the relative importance of the objectives affected by the LTEMP alternatives, differences that stem from policy judgments rather than scientific judgments. Multicriteria decision analysis provides a way for stakeholders to articulate those judgments. By clearly understanding those different viewpoints, Reclamation and NPS (hereinafter referred to as the "joint-lead agencies") were better able to analyze and compare the alternatives and ultimately advise the Secretary of the Interior regarding her choice of a preferred alternative. In selecting a preferred alternative, the Secretary of the Interior needed to consider the appropriate suite of laws, regulations, agency guidance, and policies; the language in the purpose and need statement; stakeholder input; and the public input at various points in the process. The MCDA helped organize at least part of that complex input.

\subsubsection{A Full Articulation of Resource Goals}

The first step in a MCDA is a full articulation of the resource goals important to the decision maker, stakeholders, and the public. The set of resource goals should be (1) complete because it should cover the full range of concerns relevant to the decision; (2) concise because it should not contain redundant or irrelevant resource goals; (3) sensitive so that the resource goals are able to distinguish the performance of the alternatives under consideration; (4) understandable so that the resource goals directly communicate what matters; and, if possible, (5) independent so that the resource goals describe unique aspects of the problem (Gregory and others, 2012). The completeness of the set of resource goals is often very important because it provides objectivity and transparency to otherwise invisible values (Turner and others, 2008).

In an MCDA, the focus of the resource goals should be should be on objectives that are fundamental (called "fundamental objectives") to the decision maker, stakeholders, and public. Fundamental objectives, as distinguished from means objectives, are objectives that are important in their own right - they are the desired outcomes of the decision, not because they lead to something else of importance but because of their inherent value. Means objectives are pursued as a pathway to fundamental objectives but are not themselves of inherent value to the decision maker; for example, a high juvenile survival rate of $\mathrm{HBC}$ is important as a means to achieving a sustainable population of HBC in the Colorado River below Glen Canyon Dam, but juvenile survival is not itself the objective that the decision maker fundamentally cares about. Achieving population sustainability with low or moderate juvenile survival rates of $\mathrm{HBC}$, if possible, would be acceptable; thus, the fundamental objective concerns population sustainability.
The joint-lead agencies, in consultation with the tribes and Cooperating Agencies and with input from public scoping comments, developed a set of resource goals, which represent the fundamental objectives to be pursued in the LTEMP EIS. Some of these resource goals are closely aligned with the desired future conditions (DFCs) developed by the Adaptive Management Working Group (AMWG); and are grounded in the laws, regulations, and policies relevant to the joint-lead agencies. In a few instances, the resource goals differ from the DFCs to more clearly identify a set of fundamental objectives for the specific context of the LTEMP EIS that meet the characteristics described previously in this section (complete, concise, sensitive, understandable, and independent). In a parallel effort, the joint-lead agencies worked directly with interested tribes to develop resource goals that are specific to tribal perspectives.

\subsubsection{Performance Metrics}

Performance metrics are scales of measurement on which the fundamental objectives (resource goals) can be evaluated. By developing performance metrics that are closely tied to the resource goals, the assessment of alternatives can include a quantitative, rather than solely narrative, analysis. Also, articulation of performance metrics forces considerable clarity about the resource goals; thus, using performance metrics encourages a high degree of transparency in the analysis of alternatives. It is difficult, however, to express all the resource goals in quantitative form. The use of performance metrics, therefore, does not preclude use of narrative analyses to evaluate additional resource goals in a NEPA process.

Ideally, performance metrics should directly reflect the resource goals, but this is often very difficult to achieve because the resource goals can be subtle, nuanced, complex, and difficult to quantify. There are also cases where a desired performance metric can be articulated, but the scientific tools do not exist to predict the performance of alternatives on that scale; thus, development of performance metrics is a very important science-policy interface. For the management agency, the desire is to have performance metrics that closely track the corresponding resource goals, but for the scientists, the desire is to have performance metrics that can be predicted with high confidence. When the difference between these desires is large, the question is how far the quantitative assessment can stretch toward the desired performance metric while maintaining a robust scientific foundation. There is, of course, a tendency to want to use proxy metrics that can be reliably predicted (for example, temperature as a proxy for $\mathrm{HBC}$ recruitment), but this only shifts a difficult burden to the decision maker who has to then make invisible judgments about how closely the proxy aligns with the underlying resource goal. The performance metrics developed for this decision analysis span the gamut from direct, natural measures of resource goals to distant proxies, depending on the science available to support their assessment. An effort has been made 
Decision Analysis to Support Development of the Glen Canyon Dam Long-Term Experimental and Management Plan

to transparently articulate the relation between each performance metric used and the resource goal it represents.

The joint-lead agencies in conjunction with subject-matter expert (SME) teams from all relevant disciplines developed performance metrics corresponding to the resource goals that were used as the scales on which alternatives were quantitatively evaluated. During the course of development, the jointlead agencies sought feedback on draft performance metrics from the Cooperating Agencies, tribes, and other stakeholders.

\subsubsection{Transparent and Quantitative Evaluation of Alternatives}

As part of the effects analysis for the LTEMP EIS, and as a supplement to the traditional narrative analysis, Argonne National Laboratory (hereinafter referred to as "Argonne") and collaborators completed quantitative analyses of the alternatives against the performance metrics. These quantitative analyses are an exercise in forecasting - predicting the relative performance of the alternatives against the resource goals using the best available science. In some cases, existing models were available for this task; in other cases, new predictive models were developed; and in still other cases, formal methods of expert elicitation (Martin and others, 2012) were needed. But, in all cases, the methods for assessing the alternatives provide transparency to the evaluation.

The ecological, economic, and social systems being evaluated in the LTEMP EIS are complex, and even though the systems are some of the best studied systems in the world, they are nevertheless incompletely understood; thus, the models used to predict performance of the alternatives were necessarily simplifications of the real world and had to account for uncertainty. Specific details about how uncertainty was handled in the decision analysis are described in section 3.3, "Uncertainty, Value of Information, and Adaptive Management."

A traditional, narrative evaluation of alternatives has to make all the same assumptions as a quantitative evaluation does. The use of a quantitative approach raises the degree of transparency about these assumptions and allows better inspection by interested parties. Also, quantitative analysis of the alternatives provides the raw material for later steps in a decision analysis.

\subsubsection{Tradeoff Analysis}

The outcome of the assessment phase can be viewed as a "consequence table" - a summary of how each alternative is expected to perform against each resource goal (as expressed by the corresponding performance metric). That assessment phase is a scientific endeavor - an evaluation of the current knowledge of the system to forecast how the system will respond to any proposed alternative. The consequence table provides a visual way to compare the alternatives and is an important analytical and communication step. Selection of a preferred alternative involves a policy choice based on sound science, which requires a values judgment about how to comply with the laws applicable to the proposed action while achieving a multitude of fundamental objectives, particularly if there are tradeoffs among the objectives. Some fundamental objectives, because of legal and policy considerations, may take precedence over other objectives; the remaining objectives need to be balanced appropriately. The joint-lead agencies, in evaluating the alternatives and providing a recommendation to the Secretary of the Interior, wanted to understand how Cooperating Agencies and other stakeholders would individually value the range of resource goals. This structured input was not the only consideration; in the NEPA process, decisions are also informed by the legal and policy framework, including relevant laws, regulations, agency policies and guidance, court cases, consultation with tribes, and public comment at various points in the process.

Multicriteria decision analysis provides tools for eliciting and investigating the values judgments associated with balancing tradeoffs. There are a variety of MCDA methods; we used the Simple Multi-Attribute Rating Technique (SMART) (Edwards, 1971; Goodwin and Wright, 2004) with swing weighting (Winterfeldt and Edwards, 1986). Stakeholders were asked to individually complete a swing-weighting exercise to express how they valued the resource goals relative to one another, while accounting for the range in performance across alternatives. The weights derived were combined with the consequence table to rank the alternatives from the viewpoint of each participating stakeholder. These individual viewpoints were provided as input to the joint-lead agencies and are documented in this report.

\subsection{Uncertainty, Value of Information, and Adaptive Management}

The second major set of tools from decision analysis that were used in the development and assessment of alternatives for the LTEMP EIS concern how to articulate, evaluate, and address uncertainty in an adaptive design. The primary analytical tool that informed this process is the expected value of information (Raiffa and Schlaifer, 1961; Howard, 1966). In a decision analysis context, the value of information is the best method for sensitivity analysis (Felli and Hazen, 1998). Runge and others (2011b) describe how the value of information can be used to design an adaptive management program that focuses on finding the best management strategy (rather than reducing the most uncertainty).

\subsubsection{Adaptive Management Versus Experimental Management}

Several different schools of adaptive management, which differ in their emphasis on various decision analysis tools and approach to experimental design, exist (McFadden and others, 2011). All the schools trace their lineage back to Walters 
(1986), but their current approaches can look very different. In the Resilience-Experimentalist (RE) school of adaptive management, emphasis is placed on experimental design focused on policy choices (management alternatives) as the elements of uncertainty. To some extent, the RE school is most focused on "unknown unknowns"- uncertainty that cannot be anticipated in advance - and, therefore, advocates robust experimental designs composed of management alternatives to provide accelerated learning about the system dynamics in response to management. This accelerated learning might not be formally linked to subsequent long-term management planning because of a sense that there is too much hubris in making long-term plans when so much surprise is expected. The RE school perhaps draws more inspiration from Walters and Holling (1990) than from the seminal text (Walters, 1986). Examples of adaptive management that are often associated with the RE school include management in the Columbia River Basin, water management in the Everglades, and past management in the GCDAMP (McFadden and others, 2011).

In the Decision-Theoretic (DT) school of adaptive management, the emphasis is placed on a priori articulation of uncertainty through alternative hypotheses about system response to management and derivation of optimal strategies that solve the "dual-control problem" of achieving long-term management objectives by balancing the benefits and costs of learning in the short term. The DT school is most focused on known unknowns - uncertainty that can be explicitly articulated - and, therefore, advocates adaptive design that seeks resolution of this uncertainty but only to the degree that such resolution will improve future management. Learning is explicitly linked to future management decisions by associating particular courses of action with the degree of evidence in support of the alternative hypotheses; in this way, long-term management is articulated as part of the adaptive program, so the natural transition from experimentation to implementation is specified up front. The tenets of the DT school are arguably a more direct expression of Walters (1986) than other schools of adaptive management. The example most commonly associated with the DT school is the adaptive harvest management of mallards in North America (Johnson and others, 1997).

It seemed appropriate that the 1995 Glen Canyon Dam Final EIS and the GCDAMP embraced an RE school approach to adaptive management. At the time, there was very significant uncertainty about the dynamics of the Colorado River system below Glen Canyon Dam, so an approach that emphasized learning about unknown unknowns made sense. Several policy experiments have been completed, and a great deal has been invested in research; together these have greatly advanced the state of knowledge. It would have been difficult in 1995 to anticipate all the discoveries and specify clearly how and when management of Glen Canyon Dam would move from an experimental phase to a long-term implementation phase. The current question for the joint-lead agencies is if the last two decades of research and experimentation have generated enough knowledge to allow the articulation of uncertainty as known unknowns and pursue a DT school approach to adaptive management. The joint-lead agencies believe this is the case, and approached the development of the LTEMP EIS with this philosophy in mind.

\subsubsection{Articulating Uncertainty as Competing Hypotheses}

For many, if not all, of the resource goals, the performance of the alternatives is uncertain. Some of that uncertainty can be captured simply by including estimates of variance around the forecasts, but some uncertainty is pervasive enough that it could change the ranking of the alternatives relative to a particular resource goal and, thus, could impede the identification of a preferred alternative. For these critical uncertainties, the SME teams characterized the uncertainty in the predictive models as a set of competing hypotheses. The focus of the uncertainty was on the mechanisms or parameters in the models, not on a holistic statement of uncertainty about whether a particular management intervention will work or not; thus, for example, rather than state the uncertainty as whether or not a particular management alternative will build and sustain beaches, the uncertainty was expressed as competing hypotheses about the long-term rate of sediment input from the Paria River. Likewise, whether trout management flows (TMFs) work or not was expressed as competing hypotheses about the rate of recruitment of juvenile rainbow trout when TMFs are used.

Development of competing hypotheses to capture critical uncertainty is challenging. It requires very deliberative thought about the limits of knowledge and the nature of uncertainty that would affect the ranking of management alternatives. To do so with a small number of discrete hypotheses requires a simplification of the full degree of uncertainty. But careful thought along these lines allows a transparent and explicit statement of the uncertainty that is the focus of experimental and adaptive design. In a NEPA context, such explicit articulation of critical uncertainty allows full disclosure of the motivation for experimental design and explanation of how subsequent management will respond to newfound knowledge.

\subsubsection{Deconstructing Complex Alternatives}

Several of the alternatives under consideration in the DEIS (especially Alternatives C, D, and E; see explanations of each in the "Alternatives" sections 5.4, 5.5, and 5.6) include, either explicitly or implicitly, complex experimental or adaptive designs (see, for example, figs. 2-13 and 2-14 in Bureau of Reclamation and National Park Service, 2015). These strategies prescribe different management interventions depending on state and information conditions. It is particularly important to distinguish state-dependent triggers from informationdependent triggers. State-dependent triggers are conditions of the state of the system that would lead to implementation of a different management action, primarily in recognition that the Colorado River is a stochastic ecosystem, and it is important 
Decision Analysis to Support Development of the Glen Canyon Dam Long-Term Experimental and Management Plan

to be able to respond to natural variation. Most obviously, all the alternatives contain state-dependent triggers under the Bureau of Reclamation (2007) guidelines that specify, among other parameters, the annual volume for water release from Glen Canyon Dam. Other state-dependent triggers are designed to guard against chance reductions in HBC or other resources of concern. State-dependent triggers are in contrast to information-dependent triggers, which are indications that the state of knowledge has changed substantially and a new approach to management is warranted; for example, Alternatives $\mathrm{C}$ and $\mathrm{E}$ propose experimental implementation of TMFs, and it is at least implicit in both that if those TMFs are ineffective in reducing downstream migration of rainbow trout from Lees Ferry, they would be discontinued. This is an information-dependent trigger. To the extent possible, informationdependent triggers should be explicit in that they specify the weight of evidence that would be needed on one hypothesis or another to induce a change in management strategy.

A complex experimental or adaptive strategy can be viewed as a portfolio of simpler strategies combined and implemented in a manner to reduce critical uncertainty, with the ultimate intention to implement one of the simpler strategies as the operational standard in the long term. The information-dependent triggers govern the switch between these simpler strategies. To evaluate such a complex design, the first step is to understand what the simpler strategies are; thus, the complex strategies were deconstructed into simpler long-term strategies, each of which might have state-dependent triggers but not information-dependent triggers. In other words, an experimental or adaptive strategy can be viewed as a set of simpler, operational strategies arrayed against a set of competing hypotheses. Resolution of the competing hypotheses would lead to identification of a long-term strategy, but of course, in the short term, an experimental design is needed to achieve that resolution. The first step in development of such a complex strategy is the articulation of the simpler component strategies and the attendant competing hypotheses; the development of the experimental design is a later step.

\subsubsection{Value of Information}

The essence of the DT school of adaptive management is a focus on uncertainty that is an impediment to the decision maker; that is, resolution of the uncertainty could affect the choice of the long-term management strategy. To evaluate the importance of a source of uncertainty, we used a technique known as the value of information (Raiffa and Schlaifer, 1961; Howard, 1966; Runge and others, 2011b), which was also advocated by Walters (1986) as the motivation for adaptive management. The idea behind the value of information is to compare the expected performance if a decision has to be made in the face of uncertainty with the expected performance if uncertainty can be resolved before committing to a decision. This contrast, known as the EVPI, sets an upper bound on the value of experimental or adaptive management measured on the scale of the management objective(s). To make a decision in the face of uncertainty, a decision maker chooses to implement an action that achieves the highest expected performance against the uncertainties, but that decision carries the risk of being wrong (because some other action could have performed better); the value of information measures how important it is to eliminate that risk. There are two related methods: (1) the expected value of partial information (EVXI) allows calculation of the value of reducing some component of uncertainty, while remaining uncertain about the rest; and (2) the expected value of sample information takes into account the noise in the monitoring.

To calculate the value of information, uncertainty must be explicitly articulated (as competing hypotheses with evidentiary weights or as a probability distribution on a set of parameters). With a small set of competing hypotheses, the calculations involve several steps: (1) forecasting the performance of each long-term strategy under each hypothesis, (2) calculating a weighted performance across hypotheses to identify an optimal decision in the face of uncertainty, (3) calculating the expected performance if uncertainty could be fully resolved before the management alternative was chosen, and then (4) comparing the expected values in steps 2 and 3 .

In a single-objective setting, the EVPI is measured on the scale of that objective; thus, it could be expressed, for example, as the expected increase in the probability of persistence of HBC if uncertainty could be resolved before committing to a long-term management strategy. In a multiple-objective setting, EVPI is calculated on the composite utility scale (in which the full array of objectives is weighted); thus, an evaluation of the importance of uncertainty cannot be calculated without first completing a MCDA to understand the value weights on the resource goals. The sequence of assessment matters; the LTEMP EIS process was crafted to accommodate this series of steps. First, the long-term strategies (the elements of the full alternatives broken down into their constituent parts) were analyzed against the array of performance metrics under all the competing hypotheses. Second, using the expected value across hypotheses, MCDA (with input from stakeholders) was used to generate a preliminary weighting of fundamental objectives. Third, with those weights, the individual competing hypotheses were investigated, and the expected value of information (perfect and partial) was calculated.

\subsubsection{Experimental and Adaptive Design}

The motivation for the EVPI analysis was to provide guidance useful for developing an experimental or adaptive design for implementing management actions, taking into account their value as long-term strategies and the value of reducing uncertainty. This report only describes the results from the decision analysis, with a brief discussion of the implications of the results for experimental design (section 9.2, "Motivation for Adaptive Management"); the development of the experimental design is described in the DEIS. 


\section{Resource Goals and Performance Metrics}

In February 2010, the Assistant Secretary of the Interior asked an ad hoc group of the AMWG to develop a set of DFCs, which were outcomes of fundamental importance that were "achievable through the operation of Glen Canyon Dam, subject to the Law of the River and consistent with the Grand Canyon Protection Act" (Castle, 2010, p. 2) During the next 2 years, this ad hoc group worked with the AMWG and DOI to develop the set of DFCs, which were adopted by the AMWG and recommended to the Secretary of the Interior in February 2012. The set of DFCs formed the basis for the development of the resource goals for the LTEMP EIS. The resource goals express the fundamental objectives for the LTEMP EIS and are described in the nine subsections that follow (4.1 through 4.9).

Associated with the resource goals, the joint-lead agencies developed metrics to evaluate the relative performance of the LTEMP alternatives. These scientifically based performance metrics were developed in a series of workshops among SMEs working on the LTEMP EIS and were revised to incorporate feedback from Cooperating Agencies and other stakeholders. The performance metrics are intended to be objective measures of the performance of alternatives relative to goals for each affected resource being evaluated in the LTEMP EIS. Note that these performance metrics are not the full impacts analysis for the LTEMP EIS. Other sources of quantitative and qualitative information, in addition to the performance metrics, were used to assess the overall and relative performance of alternatives and their constituent elements for the LTEMP EIS. A summary of the performance metrics used in the decision analysis is given in table 1 .

\subsection{Aquatic Ecology}

The resource goals associated with aquatic ecology focused on the persistence of HBC and other native fish, the quality of the rainbow trout (RBT) (Oncorhynchus mykiss) fishery, and absence or containment of nonnative aquatic species.

\subsubsection{Humpback Chub}

Resource Goal.-Meet HBC recovery goals including maintaining a self-sustaining population, spawning habitat, and aggregations in the natural range of the $\mathrm{HBC}$ in the Colorado River and its tributaries below the Glen Canyon Dam.

Performance Metric 1.-Expected minimum number of adult (greater than or equal to $[\geq] 200$ millimeters [mm]) HBC in the Little Colorado River population during the LTEMP planning period (20 years).

Performance Metric 2.-Average temperature suitability index (scale 0-1) for HBC at RM 157 (Havasu Creek) and
RM 213 (Pumpkin Spring) (fig. 1). The potential for a selfsustaining aggregation of $\mathrm{HBC}$ at each of these locations was based on a temperature suitability model that considered how well water temperatures met requirements for important $\mathrm{HBC}$ life-history stages (spawning, egg incubation, and growth) using triangular probability functions based on the reported ranges of suitable temperatures for each life-history stage (Valdez and Speas, 2007). The composite temperature suitability index was the geometric mean of the suitability indices for each of the life-history stages.

\subsubsection{Other Native Fish}

Resource Goal.-Maintain self-sustaining native fish species populations and their habitats in their natural ranges on the Colorado River and its tributaries.

In the analysis for the EIS, temperature suitability indexes for other native fish, similar to the one for HBC, were developed. They did not, however, show much differentiation among alternatives, and they did not differ much from each other and from the HBC temperature suitability metric. These metrics were not, subsequently, used in the decision analysis; the $\mathrm{HBC}$ temperature suitability metric was assumed to stand in for other native fish as well.

\subsubsection{Rainbow Trout Fishery}

Resource Goal.-Achieve a healthy high-quality recreational RBT fishery in the Glen Canyon National Recreation Area and reduce or eliminate downstream RBT migration consistent with NPS fish management and ESA compliance.

Performance Metric 3.-Rainbow trout catch rate in Glen Canyon National Recreation Area (age 2+ fish per angler-hour).

Performance Metric 4.-Rainbow trout emigration rate (number of age-0 RBT moving into Marble Canyon from Glen Canyon per year).

Performance Metric 5.-Abundance of high-quality RBT (greater than [>] 16 inches total length) in the Glen Canyon reach.

\subsubsection{Nonnative Aquatic Species}

Resource Goal.-Minimize or reduce the presence and expansion of aquatic nonnative invasive species.

In the analysis for the EIS, temperature suitability metrics for nonnative warm-water and cold-water fish and aquatic parasites, similar to the one for HBC, were developed. They did not, however, provide much differentiation among the alternatives. These metrics are reported in the EIS but were not used in the decision analysis. 
Table 1. Summary of the 18 performance metrics used in the decision analysis.

[The range for each performance metric captures the amount of variability in the metric because of the effects of the different alternatives, the hydrological and sediment traces, and structural and parametric uncertainty. The range shown was used in the swing-weighting elicitation. HBC, humpback chub; RBT, rainbow trout; \#, number; >, greater than]

\begin{tabular}{|c|c|c|c|c|c|}
\hline Number & Resource goal & Performance metric & Units & $\begin{array}{c}\text { Desired } \\
\text { direction }\end{array}$ & Range \\
\hline 1 & \multirow{2}{*}{ Humpback chub } & Minimum number of adult HBC & $\#$ adults & Increase & $3,000-8,500$ \\
\hline 2 & & $\mathrm{HBC}$ temperature suitability & Index $(0-1)$ & Increase & $0.0-0.2$ \\
\hline 3 & \multirow{3}{*}{ RBT fishery } & $\mathrm{RBT}$ catch rate & Fish/angler-hour & Increase & $1.0-5.0$ \\
\hline 4 & & RBT emigration rate & Trout/year & Decrease & $15,000-125,000$ \\
\hline 5 & & Abundance of high-quality RBT & $\#$ fish $>16$ inches & Increase & $400-1,200$ \\
\hline 6 & \multirow{3}{*}{$\begin{array}{l}\text { Archaeological and } \\
\text { cultural resources }\end{array}$} & Wind transport of sediment index & Index $(0-1)$ & Increase & $0.0-0.5$ \\
\hline 7 & & Glen Canyon flow index & Days/year & Decrease & $0-75$ \\
\hline 8 & & Time-off-river index & Index $(0-1)$ & Increase & $0.60-0.95$ \\
\hline 9 & \multirow{2}{*}{ Hydropower and energy } & Hydropower generation & Million $\$ /$ year & Increase & $120-200$ \\
\hline 10 & & Hydropower capacity & Million \$/year & Increase & $10-50$ \\
\hline 11 & \multirow{3}{*}{ Recreation } & Camping area index & Index $(0-1)$ & Increase & $0.0-0.5$ \\
\hline 12 & & Fluctuation index & Index $(0-1)$ & Increase & $0.0-1.0$ \\
\hline 13 & & Rafting use index & Visitor-days/year & Decrease & $0-1,300$ \\
\hline 14 & Riparian vegetation & Riparian vegetation index & Sum of ratios & Increase & $2.0-6.0$ \\
\hline 15 & Sediment & Sand load index & Proportion $(0-1)$ & Increase & $0.0-0.6$ \\
\hline 16 & \multirow{3}{*}{ Tribal resources } & Marsh vegetation ratio & Ratio & Increase & $0.0-1.5$ \\
\hline 17 & & Mechanical removal & Years (out of 20) & Decrease & $0-5$ \\
\hline 18 & & Trout management flows & Years (out of 20) & Decrease & $0-20$ \\
\hline
\end{tabular}

\subsection{Archaeological and Cultural Resources}

Resource Goal.-Maintain the integrity of potentially affected National Register of Historic Places eligible or listed historic properties in place, where possible, with preservation methods used on a site-specific basis.

Performance Metric 6.-Wind transport of sediment index (WTSI). This WTSI metric captures the availability of fine sediment for movement by wind. The potential settlement of such sediment over historic properties may provide protection from erosion. The WTSI is the product of the sand load index (SLI; see section 4.7, "Sediment"), which is a proxy for the availability of sediment, and a flow factor, which is higher when low flows happen during the windy season. The WTSI can range between 0 and 1 , with higher values indicating more opportunity for transport of sediment.

Performance Metric 7.-Glen Canyon flow index (number of days per year that the maximum daily flow is greater than 23,200 cubic feet per second $\left[\mathrm{ft}^{3} / \mathrm{s}\right]$ ). There are a number of archaeological sites within the Glen Canyon National Recreation Area that could be negatively affected by high flows. Ninemile Terrace is considered representative of other archaeological sites on terraces within the Glen Canyon National Recreation Area; the toe of its slope is at an elevation that corresponds to flows from Glen Canyon Dam of 23,200 fts.
Performance Metric 8.-Time-off-river index. This metric reflects the availability of discretionary time off river for rafting parties, which allows for greater visitation of archaeological sites. From the standpoint of protection of archaeological and cultural sites, such discretionary time is not desirable. The time-off-river index is calculated from the mean daily flow levels in the river: daily flows less than $10,000 \mathrm{ft}^{3} / \mathrm{s}$ receive a score of 1 (because rafting progress is slow and there is little discretionary time); daily flows greater than $31,500 \mathrm{ft}^{3} / \mathrm{s}$ receive a score of 0 (because rafting progress is fast, allowing the most discretionary time); and daily flows between 10,000 and 31,500 $\mathrm{ft}^{3} / \mathrm{s}$ receive a score based on linear interpolation. The daily scores are averaged within seasons: summer (May-August), winter (November-February), and spring and fall (March-April and September-October, respectively). An annual value is calculated using a weighted average across seasons, with higher weight $(0.54)$ given to summer than to spring and fall $(0.31)$ or winter $(0.15)$. The final metric ranges between 0 and 1 , with higher values indicating better potential to protect archaeological resources. 


\subsection{Hydropower and Energy}

Resource Goal.-Maintain or increase Glen Canyon Dam electric energy generation, load following capability, and ramp rate capability; and minimize emissions and costs to the greatest extent practicable, consistent with improvement and long-term sustainability of downstream resources.

Performance Metric 9. - Value of hydropower generation (million dollars per year). The value of hydropower energy production over a 20 -year trace is discounted at 3.375 percent per year. The total net present value of energy production is divided by 20 to provide an annualized measure.

Performance Metric 10.- Value of hydropower capacity (million dollars per year). The WAPA enters into longterm firm contracts that obligate them to deliver firm electric service to their customers. For the purpose of the LTEMP EIS, the value of these contracts is estimated by first calculating the amount of power (megawatt [MW]) that can be contracted, then multiplying by the replacement cost for that capacity (dollars per MW-year). The capacity itself is calculated by finding the 90-percent exceedance value (10th percentile) for the daily maximum generation in August (August is the month with the highest demand) during a 20-year trace. The replacement cost used was $\$ 50,100 / \mathrm{MW}$-year based on a natural gas combustion turbine.

Additional metrics associated with hydropower generation, including the retail rate effects on residential and nonresidential consumers, are examined in the LTEMP EIS but were not available in time to be included as part of the decision analysis.

\subsection{Natural Processes}

Resource Goal.-Restore, to the extent practicable, ecological patterns and processes within their range of natural variability, including the natural abundance, diversity, and genetic and ecological integrity of the plant and animal species native to those ecosystems.

A quantitative performance metric to capture this resource goal was not developed because of its multifaceted complexity. In the EIS, the alternatives are compared qualitatively against this resource goal, but it was not used in the decision analysis.

\subsection{Recreational Experience}

Resource Goal.-Maintain and improve the quality of recreational experiences for the users of the Colorado River ecosystem. Recreation includes, but is not limited to, flatwater and whitewater boating, river corridor camping, and angling in Glen Canyon.

Performance Metric 11.-Camping area index. This metric captures the availability of medium (16-25 people) and large ( $>25$ people) campsites on beaches along the Colorado River. The camping area index is the product of the SLI (see section 4.7, "Sediment"), which measures the availability of sediment for beach forming, and a flow factor, which reflects exposure of the beaches. The flow factor is calculated from the maximum daily flows. A score of 1 is given to flows less than $8,000 \mathrm{ft}^{3} / \mathrm{s}$ (because the lower flow means a lower elevation of the water and hence more beach exposure); a score of 0 is given to flows greater than $31,500 \mathrm{ft}^{3} / \mathrm{s}$; and an intermediate score is determined by linear interpolation for flows between 8,000 and $31,500 \mathrm{ft}^{3} / \mathrm{s}$. The flow factor is averaged over days within each season, and then over seasons, with higher weight given to the summer season (0.54) than the spring and fall $(0.31)$ or winter $(0.15)$ seasons. The camping area index can range between 0 and 1, with higher values indicating greater availability of medium and large campsites.

Performance Metric 12.-Fluctuation index. This index measures the fraction of time that the daily fluctuations in flow are within a tolerable range; tolerable is defined based on the study by Bishop and others (1987). As the mean daily flow increases, greater fluctuations are tolerable. For mean daily flow in the range from 5,000 to $8,999 \mathrm{ft}^{3} / \mathrm{s}$, the daily fluctuation index is 1 if the daily fluctuation is less than $3,400 \mathrm{ft}^{3} / \mathrm{s}$; for daily flow in the range from 9,000 to $15,999 \mathrm{ft}^{3} / \mathrm{s}$, the fluctuation index is 1 if the daily fluctuation is less than $4,800 \mathrm{ft}^{3} / \mathrm{s}$; for daily flow in the range from 16,000 to $31,999 \mathrm{ft}^{3} / \mathrm{s}$, the fluctuation index is 1 if the daily fluctuation is less than $7,200 \mathrm{ft}^{3} / \mathrm{s}$; and for daily flow greater than $32,000 \mathrm{ft}^{3} / \mathrm{s}$, the fluctuation index is 1 if the daily fluctuation is less than $9,800 \mathrm{ft}^{3} / \mathrm{s}$. In all cases, the daily fluctuation index is 0 if the daily fluctuation is greater than $10,000 \mathrm{ft}^{3} / \mathrm{s}$. For fluctuation index values between 1 and 0 , the index is determined by linear interpolation between the tolerable threshold and $10,000 \mathrm{ft}^{3} / \mathrm{s}$. The daily values for the fluctuation index are averaged within seasons, then averaged across seasons with higher weight $(0.54)$ given to summer months than to spring and fall (0.31) or winter months (0.15). The fluctuation index can range between 0 and 1, with higher values indicating a better visitor experience as influenced by fluctuation in water levels.

Performance Metric 13.-Glen Canyon rafting use metric (average boat seats lost per year because of high-flow experiments [HFEs]). During HFEs and for 2 days before and after, Glen Canyon day-rafting operators cannot take recreational passengers. This metric calculates the average number of boat seats lost per year.

Several other metrics reflecting the recreational experience were analyzed in the LTEMP EIS. In some cases, these did not help to discriminate among the alternatives, and in other cases, these metrics were highly correlated with other metrics. For these reasons, the metrics were not included in the decision analysis and are not described here.

\subsection{Riparian Vegetation}

Resource Goal.-Maintain native vegetation and wildlife habitat, in various stages of maturity, such that they are 
diverse, healthy, productive, self-sustaining, and ecologically appropriate.

Performance Metric 14.-Riparian vegetation index. This index summarizes predicted changes during the 20-year LTEMP period in the relative cover of native vegetation community types and the relative diversity of community types, as described by a seven-state state-and-transition model (Ralston and others, 2014). The index is calculated as the sum of four component ratios: the ratio of final to initial native vegetation cover, the ratio of final to initial vegetation state diversity, the ratio of final to initial native to nonnative dominant vegetation state, and the ratio of initial to final cover of arrowweed. An index value of 4.0 indicates an unchanged vegetation condition; values greater than 4.0 indicate improved vegetation conditions; values less than 4.0 indicate degraded vegetation conditions.

\subsection{Sediment}

Resource Goal.-Increase and retain fine sediment volume, area, and distribution in the Glen, Marble, and Grand Canyon reaches above the elevation of the average base flow for ecological, cultural, and recreational purposes.

Performance Metric 15.-The SLI (the cumulative sand load transported by high flows [greater than $31,500 \mathrm{ft}^{3} / \mathrm{s}$ ] divided by the cumulative sand load transported in total). The range of this metric is $0-1$, with higher values reflecting the potential for larger sandbars because more of the sediment is transported at higher river volumes and hence higher elevations. A number of other metrics that summarize the transportation and deposition of sediment were analyzed in the LTEMP EIS. They were all fairly highly correlated; only the SLI was used in the decision analysis.

\subsection{Tribal Resources}

Resource Goal.-Maintain the diverse values and resources of traditionally associated tribes along the Colorado River corridor through Glen, Marble, and Grand Canyons.

In discussions with tribal representatives during the course of the development of the LTEMP EIS, a large number of important resource goals were identified. A concerted effort was made to understand these goals as clearly as possible, but it was challenging to express some of them in terms amenable to measurement. Although all these goals are important aspects of the importance to the tribes of the Grand Canyon, the Colorado River, and their management, not all of them will be affected by the alternatives being considered in the LTEMP EIS. All of these resource goals are discussed and evaluated in the LTEMP EIS. The full set of goals is described in this section, but only those for which performance metrics were identified are included in the decision analysis.

\subsubsection{Health of the Ecosystem}

The ecosystem in Glen, Marble, and Grand Canyons is more than the sum of its parts and, in the view of the tribes, should be healthy as a whole. Historically, in the GCDAMP, the overall health of the ecosystem has been examined by evaluating the status of each part, but this reductionist approach might possibly miss some important aspects. There are a variety of indicators of ecosystem health that could be considered including, but not limited to, the following: the health of the river and its ability to sustain life; the color of the water; the absence of contaminants, pollutants, and disease in the water; the potability of the water; the quality of the water that reaches Lake Mead; and the viability and health of wildlife and plants in Glen, Marble, and Grand Canyons. It is important to understand that, for many tribes, the Colorado River is a sentient being and the spiritual center of the ecosystem because it has the capability of giving and taking life and is prone to anger if mistreated. The health of the ecosystem depends on the health of the Colorado River.

Because of the holistic nature of this resource goal, it was difficult to find a single performance metric that summarized it. A narrative analysis of this resource goal is found in the LTEMP EIS, but it was not included in the decision analysis.

\subsubsection{Sites of Cultural Importance}

There are specific sites within Glen, Marble, and Grand Canyons that are important for cultural reasons; and for preservation of tribal, religious society, kiva group, and clan history (for example, shrines, sacred sites, ancient burial sites, springs, plant collection areas, mineral collection areas, offering places, and other elements). These sites can be threatened by erosion, loss of sediment inputs, and intrusive human use (especially nontribal, outside visitors). Flow and nonflow actions (for example, education, permitting, research and monitoring, and interpretation) may affect these sites.

Performance Metric 16.-Marsh vegetation ratio (ratio of frequency of wetland states during the course of 20 years to frequency of wetland states if the initial abundance remained unchanged). Wetlands are a rare and important habitat type along the Colorado River; within Glen, Marble, and Grand Canyons, there are currently approximately 4.6 acres of such habitat. Maintenance and increase of marsh vegetation is important from a tribal perspective. The metric is calculated by looking at the marsh and shrub wetland states in the riparian state-and-transition model (Ralston and others, 2014) during the course of a 20 -year projection and comparing that to the current abundance. The metric is a ratio; thus, a value of 1.0 indicates an unchanged abundance of marsh (on average), a value greater than 1.0 indicates an average increase, and a value less than 1.0 indicates an average decrease.

A number of aspects of this resource goal are also reflected in other performance metrics described in previous sections. The WTSI (performance metric 6) focuses on the availability of fine sediment for transfer to protect National 
Register eligible or listed sites. Such sites, however, do not represent the full set of places of tribal concern, so other metrics must also be considered. The Glen Canyon flow index (performance metric 7) reflects the protection of some important sites in Glen Canyon. The time-off-river index (performance metric 8) measures the degree to which the discretionary time off river of rafters might affect cultural resources, including those of tribal importance.

In additions to these performance metrics, a number of other considerations are evaluated narratively in the LTEMP EIS, including riparian vegetation diversity, native fish diversity, and access to springs.

\subsubsection{Respect for Life}

To many of the tribes associated with the Colorado River and Glen, Marble, and Grand Canyons, life itself is sacred. Human activities should protect and promote life, not destroy it. There are two aspects to this resource goal: first, minimize the taking of life; and second, encourage the expansion and proliferation of life. These are both complex concepts. The tribes recognize that it is appropriate for humans to take other life in some circumstances, especially when it promotes other life (particularly, our own consumption for survival), but this taking needs to be minimal and respectful because there are spiritual consequences associated with the taking of life. The promotion of life is also important but does not necessarily imply a return to historical or "natural" conditions. The Glen Canyon Dam has encouraged new life in Glen, Marble, and Grand Canyons, so a return to predam conditions is not necessarily implied by this objective. It is worth noting that many of the tribes do not make a strong distinction between native and nonnative species.

Performance Metric 17.-Frequency of mechanical removal, as measured by the average number of years in which trout mechanical removal trips happen. Several of the alternatives considered in the LTEMP EIS include the use of electrofishing and removal of nonnative trout at the confluence of the Colorado River with the Little Colorado River in an effort to reduce the piscivory of juvenile HBC by trout. A number of tribes, especially Hopi and Zuni, have raised concerns about this taking of life. As a coarse measure of the cultural, spiritual, and ethical effects of killing trout, this performance metric allows distinctions among alternatives, favoring those that make an effort to minimize mechanical removal. But the nature of the take, the purpose behind it, the methods of the take, the disposition of the trout taken, and the mind set of those killing the fish all also affect the sacred treatment of living beings.

Performance Metric 18.-Frequency of trout management flows, as measured by the average number of years in which TMFs happen. Several of the alternatives considered in the LTEMP EIS include the potential for use of TMFs. The TMFs, designed to reduce reproduction or survival of juvenile trout, are considered to be killing by some tribes and should be minimized. Alternatives that include TMFs are likely to differ in how often the flows are triggered, so this performance metric helps to distinguish among the alternatives.

\subsubsection{Sacred Integrity of Grand, Marble, and Glen Canyons}

Glen, Marble, and Grand Canyons are sacred to many tribes, and the preservation of their sacred integrity is important. The sanctity of Glen, Marble, and Grand Canyons may be threatened by human activities and behaviors, development, and the presence of artificial structures and activities. An important aspect of the sanctity is the intentionality of visitors: when outsiders enter Glen, Marble, and Grand Canyons (on boat or hiking trips), the respect they show to the canyons and Colorado River can affect the spiritual integrity. There are many consequences of the disturbance of this sanctity, including, but not limited to, the following: a reduction of the spiritual strength of plants gathered and used by the Navajo for medicinal and cultural purposes; an inability to retire Navajo sacred objects into the Colorado River when they have become too old for continued use; weakening of the sacred role the canyons play as a final resting place for Hopi; and an overall disruption of the state of mind and spirit of Zuni religious leaders and of their experience of being within a very sacred place that embodies the Zuni emergence, migrations, and communion with the spirits of Zuni ancestors.

This resource goal, although of profound importance to the tribes, is not thought to differ measurably across the alternatives under consideration in the LTEMP EIS because it is not driven by flow operations from Glen Canyon Dam or currently envisioned attendant activities. This goal is evaluated in the narrative EIS analysis but not in the formal decision analysis.

\subsubsection{Stewardship}

According to their traditions, several of the tribes understand that they have been given a sacred stewardship responsibility for the preservation and harmony of the world; for example, the Hopi have a covenant with the caretaker of this world, Masaw, to be stewards of the earth; other Tribes have similar stewardship ethics grounded in spiritual traditions. To maintain these stewardship responsibilities, the tribes need to be an active part of stewardship of the Glen, Marble, and Grand Canyons. This stewardship includes the following: ceremonial activities, whether performed in the canyons or in the villages; participation in management of the canyons, including water management, through traditional practices and western management activities; and education to maintain cultural knowledge and connection with the canyons. The tribes note that the Federal government also has stewardship responsibilities that arise out of Federal legislation; because Federal involvement has sometimes taken stewardship responsibility from the tribes, it is critical that the Federal government be accountable for its stewardship. At times, some tribes believe 
the presence of the Federal government has made it more difficult for them to carry out their stewardship responsibilities. Successful development of joint stewardship among the tribes and Federal government will require continued building of mutual respect and trust between those entities.

Tribal stewardship opportunities are not tied to individual alternatives being considered in the LTEMP EIS but could be crafted to apply to any of the alternatives; thus, this resource goal, although of critical importance to the tribes individually and to the ongoing relationship between the tribes and Federal government, may not help distinguish among the alternatives. This goal is evaluated in the narrative EIS analysis but not in the formal decision analysis.

\subsubsection{Tribal Connections to the Canyons}

The spiritual, historical, and cultural connections that tribes have to Glen, Marble, and Grand Canyons require the protection of sacred sites and the integrity of the canyons as a whole, but protection alone is not enough. The tribes also need opportunities for access, education, and stewardship to keep their connections vibrant. Access can be undermined by physical barriers and by the effects of human activity that decrease the power of those sites and the experience when at them (for example, lack of privacy, disturbance of the soundscape, and viewshed).

Like the sacred integrity and stewardship resource goals, this resource goal is not thought to differ across the alternatives. The flow operations of Glen Canyon Dam are not likely to affect tribal access, education, spiritual ceremonies, or other connections to Glen, Marble, and Grand Canyons. This resource goal may be more appropriately addressed through government-to-government consultation in other forums. This goal is evaluated in the narrative EIS analysis but not in the formal decision analysis.

\subsubsection{Economic Opportunity}

The Glen, Marble, and Grand Canyons, Colorado River, and Glen Canyon Dam are sources of economic benefit for the tribes in the area. The canyons provide tourism and other opportunities that enhance the economic well-being of tribes. (As an important note, tourism can also undermine the wellbeing of tribes in aspects other than economic; see the other tribal resource goals.) The Glen Canyon Dam provides affordable electricity for tribal needs and for development projects.

The hydroelectric performance metrics (especially hydroelectric generation, performance metric 9) may reflect one aspect of economic opportunity in that provision of affordable hydroelectricity is a component of economic development. Other economic effects are evaluated in the narrative EIS but were not included in the formal decision analysis.

\subsubsection{Tribal Water Rights and Supply}

Tribes in the area depend on the Colorado River for many of their water needs; so the preservation of established, traditional, and desired water rights, now and into the future, is important to them. There are a number of claims to water rights that have been asserted by the tribes but for which there are not yet quantified rights through decree or negotiated settlement; some Tribes have indicated that these claims to water rights are as important as established water rights.

Based on its purpose and need, the LTEMP EIS was not intended to include any alternative that violated agreed-upon water rights. The effect of the Lake Powell water elevation on Navajo access to water was examined and was not determined to differ across alternatives.

\subsubsection{Process Objectives}

The tribes also expressed several important process objectives - objectives that govern how the LTEMP decision is made, rather than what decision is made. The first of these is the genuine incorporation of tribal input to the LTEMP process as a reflection of Federal trust responsibilities. The second is the importance of incorporating learning to improve management with time; in this spirit, an experimental approach that can result in adaptive management is favored.

Because these were process objectives, they were not evaluated in the formal decision analysis, which focused on objectives that could help discern among the alternatives.

\subsection{Water Delivery}

Resource Goal.-Ensure that water delivery continues in a manner that is fully consistent with and subject to the Colorado River Compact, Upper Colorado River Basin Compact, Water Treaty of 1944 with Mexico, decree of the Supreme Court in Arizona v. California, and provisions of the Colorado River Storage Project Act of 1956 and the Colorado River Basin Project Act of 1968 that govern allocation, appropriation, development, and exportation of the waters of the Colorado River Basin; and consistent with applicable determinations of annual water release volumes from Glen Canyon Dam made pursuant to the Long-Range Operating Criteria for Colorado River Basin Reservoirs, which are currently implemented through the 2007 interim guidelines (Bureau of Reclamation, 2007).

The scope and need of the LTEMP EIS was designed to preserve existing agreements concerning water delivery; thus, none of the alternatives considered were meant to differ with regard to aspects of water delivery. A number of water delivery metrics were evaluated to make certain that this part of the purpose and need was upheld. None of the alternatives were determined to differ with regard to these metrics; thus, they were not included in the decision analysis. 


\section{Alternatives}

Seven alternatives were considered in the LTEMP EIS. Each of these alternatives is a complex combination of flow and nonflow actions, often with condition-dependent and information-dependent triggers for various components. Four of the alternatives (B, C, D, and E) also contain variants (called long-term strategies) to represent different combinations of actions that would be taken once critical uncertainties were resolved. In total, 19 long-term strategies were evaluated. A brief summary of these alternatives is given here to provide context for the decision analysis with an emphasis on those elements that differ across alternatives. A full description of these alternatives, with the rationale for each, is given in chapter 2 of the LTEMP EIS.

\subsection{Action Elements}

The alternatives are composed of flow actions, which govern how water flow through Glen Canyon Dam is to be managed on hourly, daily, and monthly scales, as well as nonflow actions, which govern other activities meant to complement the flow actions to achieve the resource goals.

\subsubsection{Monthly Release Pattern and Other Base Operations}

The seven alternatives differ in the operational characteristics that govern flow through Glen Canyon Dam (table 2). All alternatives follow the 2007 interim guidelines (Bureau of Reclamation, 2007), which specifies the annual volume of water to be passed through Glen Canyon Dam. The alternatives differ in how they apportion the annual volume to monthly volumes, ranging from patterns that match releases under the previous EIS to patterns that match monthly demand for electricity to patterns that approximate the unregulated flow in the Colorado River. The minimum flow at any time differs across alternatives, with a range from 5,000 to $8,000 \mathrm{ft}^{3} / \mathrm{s}$. The maximum flow for base operations is the same for all alternatives $\left(25,000 \mathrm{ft}^{3} / \mathrm{s}\right)$. The daily range specifies the limit to how much variation there can be between the minimum and maximum flow on a given day and ranges between 0 and $12,000 \mathrm{ft}^{3} / \mathrm{s}$ across alternatives. The ramp rates limit how quickly the flow can change; for all alternatives the ramp rate for increasing flow is 4,000 cubic feet per second per hour $\left(\mathrm{ft}^{3} / \mathrm{s}-\mathrm{h}\right)$; the ramp rate for decreasing flow is lower, ranging from 1,500 to $4,000 \mathrm{ft}^{3} / \mathrm{s}-\mathrm{h}$.

\subsubsection{High-Flow Experiments}

Since 1996, there have been a number of experimental high-flow releases of water through Glen Canyon Dam, designed to mimic natural high flows and deposit sediment at higher elevations, in an effort to rebuild sandbars and restore other ecosystem processes in Glen, Marble, and Grand Canyons. High-flow releases exceed the operational maximum daily flow and can be as high as $45,000 \mathrm{ft}^{3} / \mathrm{s}$ depending on the number of generation units available. The Bureau of Reclamation (2011a) established a protocol for determining when HFE releases were warranted and how they should be implemented. To date, the HFEs that have been implemented under the 2011 HFE protocol have happened in the fall, although the HFE protocol allows them to happen in the spring after 2015. The LTEMP EIS alternatives differ in if, when, and how they allow fall HFEs and spring HFEs (table 3). In addition, some of the alternatives allow proactive spring HFEs; these are HFE releases designed to protect sand supply in years when the annual guidelines call for high annual volumes ( $>10$ million acre-feet). Most of the HFEs are limited to a maximum duration of 96 hours, but some of the alternatives allow extendedduration HFEs if adequate sediment supply is available (table 3).

\subsubsection{Trout Management Flows}

High flows, whether through high annual volumes or HFEs, have been determined to increase RBT production in the Glen Canyon reach. Because of the concern about the effect of RBT on HBC, methods have been sought to manage RBT populations. One proposed method is TMFs. These are patterns of high-water release (for example, 20,000 ft $3 / \mathrm{s}$ ) for 2-7 days to encourage young-of-the-year trout to move to higher elevation shallow-water habitats followed by a rapid drop to a low flow (for example, 5,000 to $8,000 \mathrm{ft}^{3} / \mathrm{s}$ ) during the day to strand young trout and expose them to sunlight and heat. The intention is to reduce RBT production and, hence, reduce emigration of trout from Glen to Marble Canyon, lowering the risk to HBC farther downstream. The TMFs have not previously been implemented at Glen Canyon Dam. They are considered an experimental element in several of the alternatives (table 3).

\subsubsection{Other Flow Manipulations}

A variety of other flow manipulations are built into the alternatives. Low summer flows are designed to produce warmer conditions for juvenile HBC growth in the Colorado River at the confluence with the Little Colorado River by reducing flows from July through September. These flows would be implemented experimentally in those alternatives that allow them (table 3).

Sustained low flows for benthic invertebrate production ("bug flows") are an experimental action considered under Alternative D for restoring mayflies, stoneflies, and caddisflies to Glen and Marble Canyons. If implemented, steady minimum flows would be provided every weekend from May through August, to ensure that eggs laid during weekends would not be subject to drying because of lower water levels during egg development. Demand for electricity is lower on 


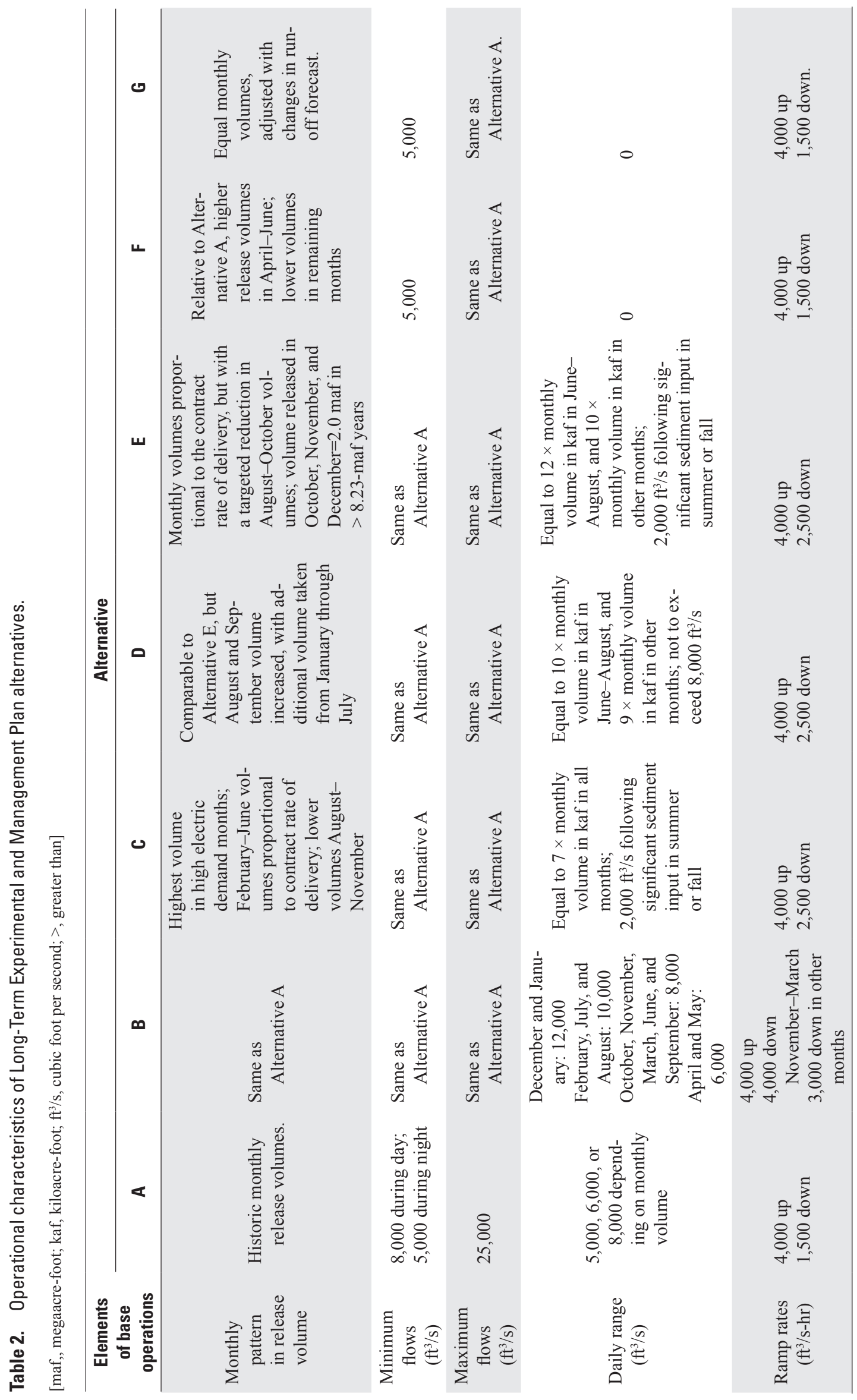


Table 3. Triggered and experimental elements of the Long-Term Experimental and Management Plan long-term strategies.

[A filled circle (•) indicates the element in question is implemented fully in the long-term strategy; an open circle (०) indicates the element in question is implemented in some partial degree; and -- indicates that element is not part of that long-term strategy. HFE, high-flow experiment]

\begin{tabular}{|c|c|c|c|c|c|c|c|c|c|c|c|c|c|c|c|c|c|c|c|}
\hline \multirow{3}{*}{ Element } & \multicolumn{19}{|c|}{ Alternative } \\
\hline & \multirow{2}{*}{$\begin{array}{l}\mathbf{A} \\
\mathbf{A}\end{array}$} & \multicolumn{2}{|c|}{ B } & \multicolumn{4}{|c|}{ C } & \multicolumn{4}{|c|}{ D } & \multicolumn{6}{|c|}{$\mathbf{E}$} & \multirow{2}{*}{$\begin{array}{l}F \\
F\end{array}$} & \multirow{2}{*}{$\begin{array}{l}\text { G } \\
\text { G }\end{array}$} \\
\hline & & B1 & B2 & C1 & C2 & C3 & C4 & D1 & D2 & D3 & D4 & E1 & E2 & E3 & E4 & E5 & E6 & & \\
\hline Spring HFEs & 0 & 0 & 0 & $\bullet$ & $\bullet$ & -- & -- & 0 & 0 & 0 & 0 & 0 & 0 & -- & -- & -- & -- & $\bullet$ & - \\
\hline Proactive spring HFEs & -- & -- & -- & $\bullet$ & $\bullet$ & -- & -- & $\bullet$ & $\bullet$ & $\bullet$ & $\bullet$ & -- & -- & -- & -- & -- & -- & -- & $\bullet$ \\
\hline Low summer flows & -- & -- & -- & -- & $\bullet$ & -- & -- & 0 & 0 & 0 & -- & -- & $\bullet$ & -- & -- & $\bullet$ & -- & -- & - \\
\hline Bug flows & -- & -- & -- & -- & -- & -- & -- & -- & $\bullet$ & -- & - & -- & -- & -- & -- & -- & -- & -- & - \\
\hline Hydropower improvement flows & -- & -- & $\bullet$ & -- & -- & -- & -- & -- & -- & -- & -- & -- & -- & -- & -- & -- & -- & -- & - \\
\hline Steady flows before HFEs & -- & -- & -- & $\bullet$ & $\bullet$ & -- & $\bullet$ & $\bullet$ & $\bullet$ & $\bullet$ & $\bullet$ & $\bullet$ & $\bullet$ & -- & $\bullet$ & -- & -- & $\bullet$ & - \\
\hline
\end{tabular}

weekends, so timing the benthic invertebrate production flows during the weekends minimizes the effect on the value of hydropower generation.

Hydropower improvement flows are an experimental action considered under Alternative B to increase hydropower generation during high-demand months (December-February and June-August) in years when the annual volume is less than or equal to $(\leq) 8.23$ million acre-feet. These flows work largely by allowing a greater daily range and higher ramp rates.

Some of the alternatives use steady flows before an HFE to conserve sediment for the high-flow release, after an HFE to reduce erosion of newly built sandbars, or both (table 3). These steady flows stop the load-following patterns of hourly releases and are sometimes called "load-following curtailment."

\subsubsection{Nonflow Actions}

Under a 2011 assessment (Bureau of Reclamation, 2011b), experimental methods of controlling trout populations were evaluated and implemented. These methods include mechanical removal of brown trout (Salmo trutta) and RBT at the Little Colorado River through electrofishing, selective removal, and beneficial use of the fish removed. Many of the LTEMP EIS alternatives allow for continued use of mechanical removal with specific requirements for when such removal would be triggered (table 3 ).

Under all alternatives except Alternative A (no-action alternative), the NPS would implement experimental vegetation restoration to modify the cover and distribution of plant communities along the Colorado River. This restoration would include removal of nonnative species, prevention of new introductions, planting of native species, management of vegetation at campsites, and removal of windrows that block wind transport of sediment.

\subsubsection{Long-Term Strategies}

Four of the seven alternatives (Alternatives B, C, D, and E) were conceived as experimental and adaptive strategies, with elements that would be deployed experimentally to allow resolution of uncertainty and subsequent adaptation of the strategy in response to the information acquired; thus, within each of these alternatives are a number of implicit long-term strategies that might result after resolution of uncertainty. Not all of those possible long-term strategies were analyzed, but a representative set from each alternative was articulated and analyzed to capture the possible range of environmental effects and evaluate the importance of resolving the underlying uncertainty; thus, for example, under Alternative $C$, whether or not to implement fall HFEs, spring HFEs, TMFs, low summer flows, or mechanical removal will depend on the efficacy of those actions in achieving their intended purpose, the strengths of undesirable side effects of those actions, and the underlying effect of RBT on HBC. The long-term strategies $\mathrm{C} 1, \mathrm{C} 2, \mathrm{C} 3$, and $\mathrm{C} 4$ represent a range of possible solutions once such uncertainty is resolved; if, for instance, spring HFEs have a beneficial effect on sediment deposition and only a small effect on RBT production, TMFs are ineffective, but low summer flows benefit HBC, then long-term strategy C2 might be the best version of Alternative $\mathrm{C}$ to use. All of the 19 long-term strategies (table 3) were evaluated against the critical uncertainties described in sections 6.2.1, 6.3.1, and 6.5.1. 


\subsection{Alternative A (No Action)}

Alternative A, the no-action alternative, represents continued operation of Glen Canyon Dam under the existing guidelines in Bureau of Reclamation (1996), interim guidelines in Bureau of Reclamation (2007), and the two 2011 EAs (Bureau of Reclamation, 2011a, 2011b), as well as other applicable guidance. This alternative has a base operation pattern that was called MLFF in Bureau of Reclamation (1996). Both of the 2011 EAs expire after 2020, so the elements specified in them (HFEs and mechanical removal) would cease at that point (Bureau of Reclamation 2011a, 2011b). Beyond the actions discussed in Bureau of Reclamation (2011a, 2011b), there are limited experimental options that can be tested under this alternative.

\subsection{Alternative B}

Alternative B was designed to increase the value of hydropower generation while limiting negative effects to other resources. This alternative was submitted by the Colorado River Energy Distributors Association (CREDA), a member of AMWG. The base operations are designed to generate more valuable power than Alternative A by increasing the daily range and ramp rates to allow power generation to more closely follow power demand. This alternative limits the implementation of HFEs to one every other year because HFEs release water without generating power and require water volumes to be shifted from months when the value of power is potentially higher to other months. To moderate some of the negative effects of this water-release pattern on other resources, Alternative B includes mechanical removal, evaluation of TMFs, and experimental implementation of vegetation restoration.

\subsubsection{Alternative Long-Term Strategies}

Alternative B includes two long-term strategies, one with its base operations (B1) and one that includes hydropower improvement flows (B2), maximum power plant capacity flows implemented as many as four times during the LTEMP period, in years when the annual volume is $\leq 8.23$ million acre-feet (table 3). Such years, because of their lower volume of release, typically require the most purchases by WAPA to meet contractual demand, so the higher flows could mitigate costly purchases in high-demand months. Whether B1 or B2 is a better long-term strategy, when the effects across all resource goals are taken into account, depends on the strength of negative effects of greater power generation on other resources. Specific hypotheses for these negative effects, which are uncertain, were not explicitly articulated when Alternative $\mathrm{B}$ was submitted. The long-term strategies B1 and B2 were evaluated, however, against the set of uncertainties developed in the context of other alternatives.

\subsection{Alternative C}

Alternative $\mathrm{C}$ was developed by the joint-lead agencies to maintain or improve multiple resources, with some priority placed on HBC, sediment, and hydropower. Called the "condition-dependent adaptive strategy" in interim public documents during the preparation of the EIS (Bureau of Reclamation and National Park Service, 2014), Alternative C has informationdependent and condition-dependent triggers, seeks to test critical hypotheses, and contains explicit instructions for how new insights will affect subsequent implementation of action elements.

Compared to many of the other alternatives, the base operations for Alternative $\mathrm{C}$ shift monthly volumes from the monsoon months (August through November) to highdemands months (December, January, and July) to reduce sediment transport during the monsoonal high-sediment-input period and limit effects on the value of power generation. The reduced volume in late summer is also intended to provide warmer river temperatures for the benefit of $\mathrm{HBC}$ and other native fish.

Alternative $\mathrm{C}$ includes a number of condition-dependent (triggered) elements; among them are fall HFEs, spring HFEs, proactive spring HFEs, extended duration HFEs, TMFs, low summer flows, load-following curtailment, and mechanical removal of trout. The specific details of the triggers for these events are found in chapter 2 of the EIS. Most of these elements are experimental, and so there are informationdependent triggers as well; that is, monitoring and evaluation of all these elements would be completed, and elements would be dropped or retained depending on if the evidence supported their retention.

\subsubsection{Alternative Long-Term Strategies}

Four long-term strategies (C1, C2, C3, and C4) were developed to capture the range of possible outcomes from adaptive implementation of Alternative $\mathrm{C}$ (table 3 ). The motivation for the creation of these long-term strategies was the recognition that there are critical uncertainties that impede identification of the best long-term strategy. The key questions concerned the following: the magnitude of increase in RBT production in the Glen Canyon reach caused by fall HFEs, the relative effects of temperature and trout density on survival and growth of juvenile $\mathrm{HBC}$ at the Little Colorado River, and the effectiveness of TMFs in reducing RBT production. The relevance of these uncertainties arises because of the possible tradeoffs among the objectives of supporting the HBC population, maintaining a strong rainbow trout fishery, increasing sediment deposition and sandbar building, and affirming tribal values concerning the respect for life (especially aquatic life). Each of the action elements under consideration (HFEs, TMFs, low summer flows, and mechanical removal) is meant to increase achievement of one or more of those objectives, but the question is if the benefits to one objective come at the expense of others. Alternative $\mathrm{C}$ was designed under the 
assumption that the best mix of action elements (the best long-term strategy) depends on resolution of the critical uncertainties.

Long-term strategy $\mathrm{C} 1$ allows use of all the triggered elements from Alternative $\mathrm{C}$ except for low summer flows and mechanical removals; such a strategy has been hypothesized to be warranted, for instance, if the effect of spring HFEs on trout production was weak, TMFs were effective, and low summer flows were not effective. Long-term strategy C2 is similar to $\mathrm{C} 1$ except that it calls for low summer flows but not TMFs. Long-term strategy C3 does not allow HFEs and might be called for if HFEs are determined to cause a very strong increase in trout recruitment and other actions are ineffective at mitigating the effect of trout on HBC. Long-term strategy C4 allows fall HFEs but not spring HFEs and manages the effect of trout on HBC through mechanical removal.

Whether or not the resolution of the critical uncertainties actually matters to the ranking of the long-term strategies is one of the central questions in section 8.3, "Expected Value of Information."

\subsection{Alternative D}

Alternative D was developed by the joint-lead agencies after a full analysis of the other six LTEMP alternatives had been completed. The initial analysis suggested that there were strong characteristics of Alternatives $\mathrm{C}$ and $\mathrm{E}$ that contributed to achievement of resource goals and motivated creative thinking about how to achieve more of those benefits in a single alternative. Alternative D adopts characteristics of Alternatives $\mathrm{C}$ and $\mathrm{E}$.

The base operations for Alternative D are in many respects a compromise between those of Alternatives $\mathrm{C}$ and $\mathrm{E}$ (table 2). The monthly pattern of release is most similar to that of Alternative E, with an increase in the August and September volumes (and a corresponding decrease in the January through June volumes). The daily range for flows is about midway between the ranges from Alternatives $\mathrm{C}$ and $\mathrm{E}$.

The experimental and adaptive options for Alternative D include all the elements considered in the any of the alternatives, except for hydropower improvement flows (table 3 ). The experimental implementation calls for early testing of TMFs in the first 2-5 years without having to meet the conditiondependent triggers and delayed consideration of spring HFEs until the third year of implementation.

\subsubsection{Alternative Long-Term Strategies}

Four long-term strategies (D1, D2, D3, and D4) were developed to capture the range of possible outcomes from adaptive implementation of Alternative D (table 3). The longterm strategies in this set look more similar than in the sets for Alternatives $\mathrm{C}$ and $\mathrm{E}$ because they were created after an initial analysis of the other six alternatives and, thus, reflect insights from that analysis. For instance, long-term strategies D1 through D4 are all similar with regard to implementation of HFEs because the initial analysis suggested that the benefits of HFEs outweighed the costs, even in the face of the uncertainties tested. There remain, however, other long-term strategies implicit in Alternative D; for example, if spring, proactive, or extended HFEs are determined to have very strong negative effects on resources of importance that cannot be mitigated by other actions, they could be removed from long-term implementation. The four long-term strategies for Alternative D, however, are thought to capture the most important differences that might arise in long-term implementation.

Long-term strategy D4 might be considered the base strategy under Alternative D because all action elements except low summer flows and bug flows are in operation (table 3). Long-term strategy D1 adds low summer flows. Long-term strategy D2 adds implementation of bug flows and would be supported if early experimental tests of bug flows determined they had the intended effects in restoring important native benthic invertebrate communities without having adverse effects on other resources. Under this long-term strategy, low summer flows would only be implemented in the second 10 years. Long-term strategy D3 is similar to D1 but removes TMFs.

The motivations for the different long-term strategies in Alternative D are the same critical uncertainties that motivate the long-term strategies in Alternative $\mathrm{C}$, with a specific focus on the effectiveness of TMFs, the influence of temperature on juvenile HBC growth and survival, and the effect of bug flows on other resources.

\subsection{Alternative E}

Alternative E was developed by representatives of the seven states in the Colorado River Basin to provide for recovery of $\mathrm{HBC}$ while protecting other important resources, including sediment, the RBT fishery at Lees Ferry, aquatic food base, and hydropower resources. Called the "resourcetargeted condition-dependent" strategy in interim public documents during the preparation of the EIS (Bureau of Reclamation and National Park Service, 2014), Alternative E has information-dependent and condition-dependent triggers, seeks to test critical hypotheses, and contains explicit instructions for how new insights will affect subsequent implementation of action elements.

The base operations for Alternative E seek greater value of hydropower production than Alternatives C and D (table 2). The monthly volumes largely follow hydropower demand and are proportional to the contract rate of delivery but with a reduction in August through October volumes to conserve sediment during the monsoon period. The daily range is large compared to the other alternatives. The ramp rates are the same as in Alternative C and D.

Alternative E includes a number of condition-dependent (triggered) elements; among them are fall HFEs, spring HFEs, TMFs, low summer flows, load-following curtailment 
(before but not after HFEs), and mechanical removal of trout (table 3). Implementation of spring HFEs is delayed until the second 10 years to allow testing of TMFs in the early years (with long-term implementation of spring HFEs conditional on TMFs being an effective tool). An important experimental element of Alternative $\mathrm{E}$ is early testing of the response of RBT populations to TMFs and fall HFEs in a $2 \times 2$ factorial design, replicated two to three times (in hopes of experiencing both cold and warm water temperatures). The specific details of the triggers for these events are found in chapter 2 of the EIS. Most of these elements are experimental, and so there are information-dependent triggers as well; that is, monitoring and evaluation of all these elements would be completed, and elements would be dropped or retained depending on if the evidence supported their retention.

\subsubsection{Alternative Long-Term Strategies}

Six long-term strategies (E1, E2, E3, E4, E5, and E6) were developed to capture the range of possible outcomes from adaptive implementation of Alternative $\mathrm{E}$ (table 3 ). The motivation for the creation of these long-term strategies was the recognition that there are critical uncertainties that impede identification of the best long-term strategy. The key questions concerned the following: the magnitude of increase in RBT production in the Glen Canyon reach caused by fall HFEs, the relative effects of temperature and trout density on survival and growth of juvenile HBC at the Little Colorado River, the effectiveness of TMFs in reducing RBT production, and the effect of high flows on sediment retention.

Long-term strategy E1 uses spring and fall HFEs when triggered, along with TMFs to manage the trout populations; this long-term strategy would be favored, for example, if HFEs are determined to be beneficial to sediment conservation and TMFs are effective in controlling trout populations. Longterm strategy E2 also uses spring and fall HFEs but uses low summer flows instead of TMFs; this strategy might be favored if temperature is a more important factor in HBC survival than trout predation and TMFs are ineffective. Long-term strategy E3 does not allow HFEs, TMFs, or low summer flows and uses mechanical removal to manage trout density at the Little Colorado River when needed; such a strategy might be favored if HFEs greatly increase production of trout, TMFs are ineffective in managing trout populations, HBC are strongly affected by trout predation, and low summer flows do not provide enough advantage to $\mathrm{HBC}$ to warrant use. Long-term strategy E4 allows fall HFEs but not spring HFEs and relies on mechanical removal to manage trout at the Little Colorado River. Long-term strategy E5 is like E3 in not allowing HFEs but uses low summer flows rather than mechanical removal to support HBC population growth. Long-term strategy E6 also does not use HFEs and uses TMFs when needed to manage trout. As with Alternatives $\mathrm{C}$ and D, these long-term strategies are not meant to be a comprehensive set of the possible permutations of Alternative $\mathrm{E}$ that might arise from adaptive implementation but, rather, are meant to represent a broad range of possible outcomes, effectively bracketing the strategies that might arise.

As with Alternative $\mathrm{C}$ and $\mathrm{D}$, whether or not the resolution of the critical uncertainties actually matters to the ranking of the long-term strategies is one of the central questions in section 8.3, "Expected Value of Information."

\subsection{Alternative F}

Alternative $\mathrm{F}$ was designed to follow a more natural pattern of flows, limiting sediment transport and providing warmer temperatures in the summer months. The base operations provide higher release volumes in April-June (to mimic spring runoff), including a May 1 high-flow spike of 45,000 $\mathrm{ft}^{3} / \mathrm{s}$ (essentially an untriggered HFE) and lower volumes the remainder of the year. The daily flows are steady with no daily fluctuations (no hydropeaking). The only modification to base operations would be sediment-triggered HFEs (fall and spring). In keeping with the desire to have this alternative better match predam conditions than the other alternatives, it does not use TMFs or mechanical removal.

\subsection{Alternative G}

Alternative $\mathrm{G}$ was designed to maximize the conservation of sediment by providing year-round steady flows. The base operations provide equal monthly volumes and steady daily flows. In practice, the monthly volumes would have to be adjusted as the forecasts for annual volume change through the year, but the intent is to keep flows quite steady. This alternative does allow all forms of HFEs to be used to maximize sandbar building and sediment conservation.

\section{Quantitative Methods}

The 19 long-term strategies were evaluated against the 18 performance metrics and 5 sources of uncertainty: the hydrology during the 20-year LTEMP period of performance, the sediment inputs during the 20-year LTEMP period of performance, the relative effects of temperature and trout predation on juvenile HBC survival and growth, the effectiveness of trout management flows, and the effect of fall HFEs on trout recruitment. A total of 10 modeling teams built a linked set of analyses to simulate the performance of the long-term strategies; the performance metrics were calculated from the simulation outputs. This section describes the methods used to complete these analyses.

\subsection{Modeling Overview}

The basis of the analysis of the alternatives was a large, linked set of simulation models that were meant to represent the Colorado River ecosystem below Glen Canyon Dam (fig. 2). 


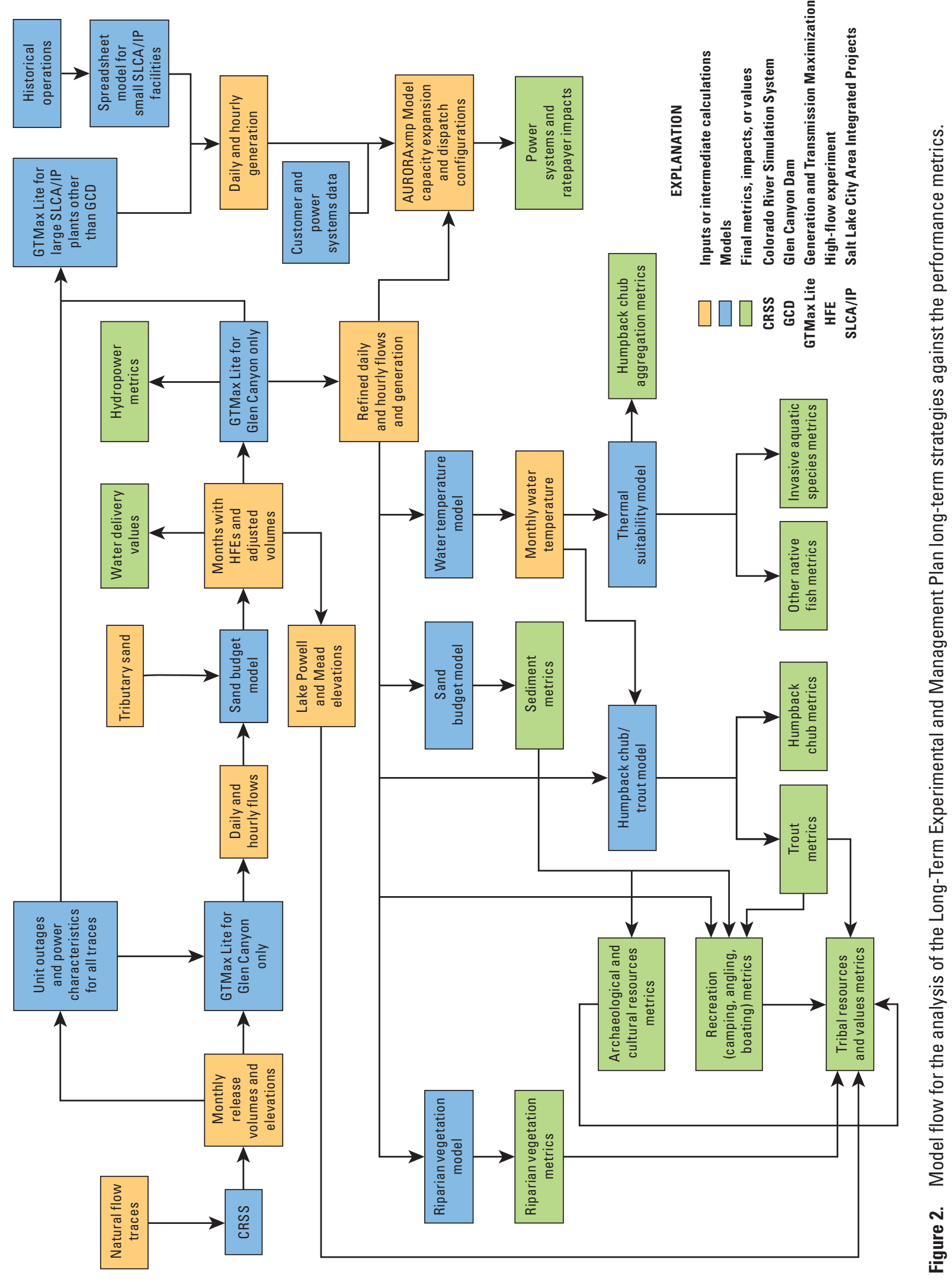


Each long-term strategy encoded a set of rules that governed annual, monthly, daily, and hourly flow through the dam, as well as mechanical removal of nonnative fish from the Colorado River at its confluence with the Little Colorado River and vegetation treatments along the river corridor. The long-term strategy, coupled with 21 hydrological traces and 3 sediment traces (to represent environmental variation), determined the flows through the Glen Canyon Dam. The daily and hourly flows then were sent to models for vegetation, sediment, and temperature. The temperature and flow outputs then informed models for RBT, HBC, and other aquatic organisms. The outputs of all these models were collected and used to calculate performance metrics under all the resource goals. The details of all these modeling methods are provided in the technical appendixes to the LTEMP EIS; a synopsis is provided here.

\subsection{Hydrology}

The hydrological modeling requires three sets of input: a time series of hydrological flow into Lake Powell, a time series of sediment input into the Colorado River from the Paria River and the Little Colorado River, and the operational rules determined by a long-term strategy. The output of the hydrological modeling is the monthly, daily, and hourly flows through Glen Canyon Dam for the 20-year LTEMP period of performance. This requires three modeling systems. First, the Colorado River Simulation System (CRSS), built with the commercial software package RiverWare ${ }^{\mathrm{TM}}$ (Zagona and others, 2001), generates monthly volumes and lake elevations taking into account the operations of the 12 primary reservoirs on the Colorado River. Second, the Generation and Transmission Maximization model (GTMax-Lite) generates daily and hourly flows taking into account patterns of demand and supply of electric power in the Colorado River Storage Project (CRSP) region. Third, a sand budget model tracks sediment in Glen, Marble, and Grand Canyons; and is used to indicate when sediment conditions warrant high-flow experiments (if the long-term strategy in question allows them). After the HFEs are identified, a second pass through GTMax-Lite is required to refine the daily and hourly flows. Note that the effect of TMFs on hydrology were not modelled because this would have required a full coupling of the hydrology and fish models (with feedback from the fish models to the hydrology models), which was a computing task that was beyond the resources available.

\subsubsection{Critical Uncertainty}

To model uncertainty in future inflow, the indexed sequential method (Ouarda and others, 1997) was used to resample the historical record of natural flow in the Colorado River system during the 105-year period from 1906 through 2010. Every fifth trace was selected from this series to produce 21 hydrological traces; every long-term strategy was evaluated against all 21 hydrological traces.
To investigate the possible effects of climate change on the performance of the long-term strategies, CRSS was run with 112 natural flow traces developed from downscaled general circulation model projected hydrological traces (Bureau of Reclamation, 2012). These climate scenarios were based on 16 general circulation models from the Coupled Model Intercomparison Project Phase 3 (CMIP3) using three forcing scenarios (A2, high; A1b, medium; and B1, low) (Maurer and others, 2007). The LTEMP models were not run with the 112 hydrological traces; rather, the 112 hydrological traces from the climate-change scenarios were used to place weights on the 21 index sequential historical traces. The model results are compared using historical (equal) and climate-change weights on the 21 hydrological traces.

\subsection{Sediment Dynamics}

A sand budget model (Russell and Huang, 2010; Wright and others, 2010) was used to track sand storage and transport from Lees Ferry (RM 0) to Bright Angel Creek (RM 87) (fig. 1). The sand budget model takes as input hourly hydrographs at the reach boundaries (RM 30, RM 61, and RM 87) developed based on release schedules from Glen Canyon Dam and hourly sand delivery from the Paria and Little Colorado Rivers. The model tracks sand storage and movement through three reaches (Upper Marble Canyon, RM 0 to 30; Lower Marble Canyon, RM 30 to 61; and Eastern Grand Canyon, RM 61 to 87) using empirically-based rating curves formulated on a particle-size-specific basis. The outputs of the model include hourly time series of the sand transported at the downstream border of each reach, and the sand budget for each reach. From these outputs a variety of performance metrics, including the SLI (performance metric 15), can be calculated.

\subsubsection{Critical Uncertainty}

Sediment input to the Colorado River between Lees Ferry and Bright Angel Creek comes primarily from the Paria River and the Little Colorado River (fig. 1). Variation in sediment input is driven by spatial and temporal variation in precipitation. To capture uncertainty about the time series of future sediment input, three 20 -year traces of sediment input were created from historical records using an index sequential method. For Paria River input, 49 reconstructed historical traces were available (index years 1964-2012). For Little Colorado River input, 18 reconstructed historical traces were available (index years 1995-2012). The cumulative 20-year sediment delivery for each trace was calculated; and the traces corresponding to the 10th, 50th, and 90th quantiles of cumulative sediment delivery were selected to represent the range of possible uncertainty. The traces from corresponding quantiles for the Paria River and Little Colorado River delivery were coupled in the simulations. Weights were placed on the three sediment traces so that the weighted mean and standard deviation of the 20-year Paria River sediment delivery for the three 
traces matched the mean and standard deviation for the full set of index sequential Paria River traces.

\subsection{Temperature}

The average monthly water temperatures along the river corridor from Glen Canyon Dam to Lake Mead were forecast using the monthly flow and air temperatures forecasts. The release temperature from Glen Canyon Dam was simulated with the CE-QUAL-W2 model (Cole and Wells, 2006). This served as an input to a river temperature model that calculated the gains and losses of heat as the water moved downstream (Wright and others, 2009). For the purposes of the decision analysis, water temperature was an intermediate variable used as input to the fish models but not used directly as a performance metric.

\subsection{Coupled Rainbow Trout-Humpback Chub Dynamics}

A coupled RBT-HBC model was used to simulate the population dynamics of RBT in the Glen Canyon reach, movement of RBT from Lees Ferry to the Little Colorado River confluence, and the population dynamics of HBC in the Little Colorado River reach. The RBT population dynamics were simulated with an age-structured population model that accounted for the effects of water flow on recruitment, survival, growth, and downstream emigration (Korman and others, 2012). The RBT performance metrics are calculated from this model. The RBT catch rate (performance metric 3 ) was calculated from the age-specific abundances, age-specific vulnerabilities, and a catchability coefficient. The abundance of RBT greater than 16 inches (considered high-quality RBT; performance metric 5) was calculated from the age-specific abundances and size-at-age characteristics. The annual emigrants (performance metric 4) were computed as a fraction of the recruitment.

The RBT movement model predicts the monthly abundance of RBT in each 1-mile segment of the Colorado River from RM 0 to RM 150 taking into account movement rates, natural mortality, and implementation of mechanical removal. Movement and survival were density independent and were not affected by flow or temperature.

A size- and location-structured population model was used to predict the adult population size of $\mathrm{HBC}$ at monthly intervals (Yackulic and others, 2014). The HBC population size in two locations, the Colorado River and the Little Colorado River (a tributary of the Colorado River), was accounted for in the model. Survival of juvenile HBC in the Colorado River depended on the abundance of RBT in the Little Colorado River reach of the Colorado River; their growth depended on RBT abundance and temperature. Growth rates in other size classes in the Colorado River depended on water temperature. From this model, the minimum number of adult HBC during each 20-year trace was calculated, and the expected minimum value (performance metric 1) was calculated by taking the mean across traces.

\subsubsection{Critical Uncertainties}

A number of critical uncertainties concerned parameters in the RBT and HBC models. Each of these uncertainties was expressed as alternative sets of model parameters. All longterm strategies, with all sediment and hydrology traces, were run separately against the combinations of model parameters. The alternative sets of model parameters were assigned weights to represent their empirical support, and weighted averages of the performance metrics were calculated across them.

Uncertainty about the effect of fall HFEs on recruitment of RBT in the Glen Canyon reach was expressed as two hypotheses: one that there is no effect on recruitment, and another that proposed recruitment would increase at the same rate as seen with spring HFEs (Korman and others, 2011) but for only 1 year instead of 2 years. An expert panel consisting of four fish biologists who were familiar with RBT dynamics in the Colorado River was convened in March 2014. A modified Delphi process with four-point elicitation (Speirs-Bridge and others, 2010) was used to estimate the likelihood of the two hypotheses; the resulting individual estimates were aggregated by simple averaging.

Uncertainty about the effect of TMFs in reducing RBT recruitment in the Glen Canyon reach was expressed as two hypotheses by the expert panel: TMFs reduce recruitment by 10 percent, and TMFs reduce recruitment by 50 percent. The two levels of effectiveness were chosen to represent equally plausible extremes.

The final area of uncertainty concerned the effects of RBT abundance and temperature on the growth and survival of juvenile HBC in the Little Colorado River reach of the main stem Colorado River. Four hypotheses were generated (fig. $3 A$ and $3 B$ ): a strong effect of temperature on growth and a strong effect of RBT on growth and survival (f1), a weak effect of temperature on growth and a weak effect of RBT on growth and survival (f2), a weak effect of temperature and a strong effect of RBT (g1), and a strong effect of temperature and a weak effect of RBT (g2). The parameter values for the four hypotheses were chosen from the ends of diameters on the 90-percent confidence ellipsoid for the joint parameter likelihood (Yackulic and others, 2014) and, thus, were equally weighted.

\subsection{Fish Habitat Suitability}

Temperature suitability for $\mathrm{HBC}$ and other native and nonnative fish at a number of sites between Lees Ferry (RM 0) and Diamond Creek (RM 225) (fig. 1) was evaluated with species-specific models for the effect of temperature on survival, reproduction, and growth (Valdez and Speas, 2007). The details of all these methods and results are in the LTEMP EIS. 

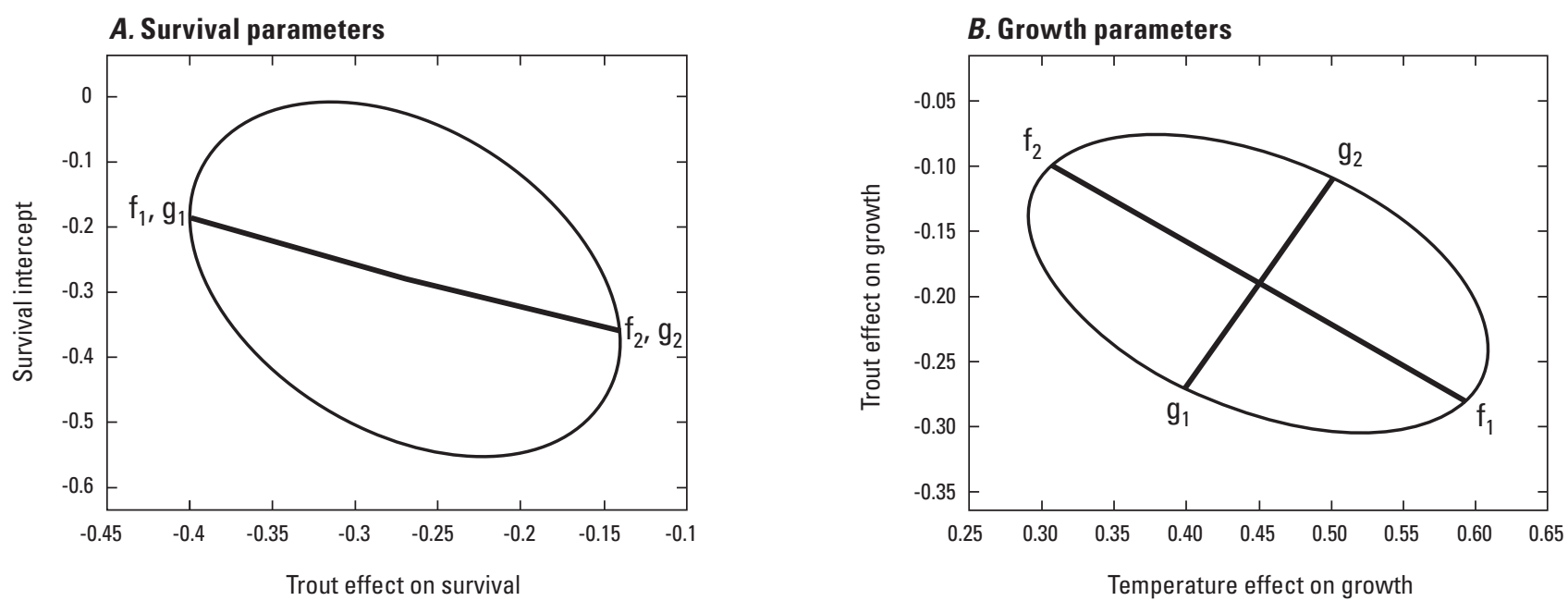

Figure 3. Uncertainty in the humpback chub population dynamics as represented by four alternative sets of parameters. $A$, survival parameters; and, $B$, growth parameters

The only one of those metrics that was retained for the decision analysis was the average temperature suitability for $\mathrm{HBC}$ at Havasu Creek (RM 157) and Pumpkin Spring (RM 213) because most of the other metrics exhibited very little difference across alternatives. Monthly water temperatures in the main stem Colorado River at the various sites under each long-term strategy were used to calculate the suitability for spawning, incubation, and growth during critical periods of the annual cycle. The overall temperature suitability at a site was the product of the suitability for the three component processes during the course of the year and could theoretically vary between 0 and 1 (performance metric 2).

\subsection{Archaeological and Cultural Resources}

The performance metrics associated with archaeological and cultural resources (performance metrics 6-8; table 1) did not require separate models but, rather, were calculated from intermediate sediment and flow variables.

\subsection{Hydropower}

As noted above in the "Hydrology" section (section 6.2), CRSS, the sand budget model, and GTMax-Lite are used in combination to simulate the water release and, therefore, hydropower generation on an hourly basis for each long-term strategy (fig. 2). The GTMax-Lite optimized the economic value of hourly energy produced at Glen Canyon Dam. This model determined an hour-by-hour pattern of generation (in megawatt hours) and water releases (in cubic feet per second) that satisfied the operating constraints imposed by each alternative, such as upramp and downramp rates, maximum change in the release during a rolling 24-hour period, maximum hourly release, and others. Hourly electricity market prices during the 20-year LTEMP period were determined using the
AURORAxmp (Aurora) model to simulate the operation of the Western Interconnection of which Glen Canyon Dam is one of several thousand generating plants. Hourly prices determined by Aurora for 2013 were benchmarked against 2013 day-ahead market prices published by the Intercontinental Exchange. Prices forecast by Aurora for 2013 were compared against historical Intercontinental Exchange prices, and future electricity prices were adjusted accordingly.

For a given long-term strategy, the value of hydropower generation (performance metric 9) was calculated by combining the forecasts of the hourly generation profile and electricity market price. The net present value (NPV) of this 20-year time series was calculated assuming a 3.375 percent discount rate, and then divided by 20 to present the results on an annualized scale.

Hydropower capacity from Glen Canyon Dam is also marketed in the form of long-term firm contracts to provide power up to a given level. Energy demand is highest in August, so to calculate the marketable capacity (in megawatts), the peak daily generation was tabulated for each day in August across the 20 years of a trace (for each long-term strategy). From these 620 daily values (20 years x 31 days in August), the 90-percent exceedance value (10th quantile) was calculated, representing the marketable capacity for that trace. In 90 percent of August days (and much more often in other months), WAPA can be confident of being able to deliver that amount of power without having to purchase it. The net present value of that capacity (performance metric 10) was calculated by multiplying by the levelized cost of capacity plus fixed annual operating and maintenance (O\&M) expenses of a thermal power plant constructed to replace capacity lost at Glen Canyon Dam. The selection of the replacement technology was based on insights obtained from the power systems economic analysis. The Aurora model runs made for this analysis determined that a natural gas combustion turbine would be the type of generating unit most likely constructed 
as a replacement for lost Glen Canyon Dam capacity. The cost to construct that type of unit, spread over its book life, was determined to be $\$ 50,100 / \mathrm{MW}$-year, including capital investment costs, allowance for funds during construction, and fixed O\&M costs. The source of cost data for replacement power plant capacity was U.S. Energy Information Administration (2014). In the analysis in the LTEMP EIS (chapter 4 and appendix K), the daily August generation values for all traces were combined before the exceedance value was calculated; this results in some slight differences in the median values presented but not systematic bias.

\subsection{Recreation}

The performance metrics associated with recreation (performance metrics 11-13; table 1) did not require separate models but, rather, were calculated from intermediate sediment and flow variables.

\subsection{Riparian Vegetation}

The effects of the long-term strategies on riparian vegetation were simulated with a state-and-transition model for Colorado River riparian vegetation downstream from Glen Canyon Dam (Ralston and others, 2014). The model tracks seven vegetation communities (bare sand, marsh, shrub wetland, tamarisk, cottonwood-willow, arrowweed, and mesquite) on channel margins and sandbars in the New High Water Zone and Fluctuation Zone as affected by the depth, timing, and duration of inundation. Six geomorphic submodels are included: lower separation bar, upper separation bar, lower reattachment bar, upper reattachment bar, lower channel margin, and upper channel margin; only four of these are unique (the parameters for the upper separation bar, upper reattachment bar, and upper channel margin are all equal). The model starts in 1 of 25 possible states (the 7 vegetation communities crossed with the 6 geomorphic submodels; not all of the 42 combinations are possible) and then tracks the vegetation state in each subsequent year as affected by the alternative-specific flows. The output is the number of years spent in each vegetation state during the 20-year LTEMP period of performance. These results are summed across the 25 starting states and then compared to the results that would have happened if the starting state was maintained for the 20 -year period. In comparing the native to nonnative states, and in calculating the native diversity, the results are weighted by the current estimated area of each vegetation state.

Four component ratios are calculated as intermediate results: the ratio of cumulative to initial native vegetation cover, the ratio of cumulative to initial vegetation state diversity, the ratio of cumulative to initial native to nonnative dominant vegetation state, and the ratio of initial to cumulative cover of arrowweed. The final value (riparian native states and diversity index; performance metric 14) is the sum of the four component ratios; thus, an index value of 4.0 indicates an unchanged vegetation condition, values greater than 4.0 indicate improved vegetation conditions, and values less than 4.0 indicate degraded vegetation conditions.

\section{Consequence Analysis Results}

In this section, the results for the individual performance metrics are presented. In most cases, these results are reported as means over all sources of uncertainty with boxplots used to show the variance induced by uncertainty. Unless otherwise noted, the historical weighting of hydrological traces was used; the sensitivity of the results to climate change (as captured by weighting of the hydrological traces) is discussed in section 8.4, "Effects of Climate Change."

\subsection{Humpback Chub Results}

Across alternatives, the expected (mean) minimum number of adult HBC during the 20-year LTEMP period of performance differed by about 500 from Alternative A (fig. 4, bottom panel). The variation across hydrological traces within an alternative was greater than the magnitude of variation across alternatives. Many of the long-term strategies were demonstrably better than Alternative A; the biggest exceptions (C2 and $\mathrm{F}$ ) were long-term strategies that increased RBT recruitment (through HFEs) without tools to manage RBT populations (TMFs and mechanical removal). The best-performing long-term strategy (E6) did not allow HFEs of any type and included triggered use of TMFs if needed. The benefit of low summer flows to HBC (compare D1 to D4) is not discernible, likely because of their infrequent use.

The set of 16 scenarios that captured critical uncertainty did not affect the dominance of long-term strategy E6 (table 4); that is, if the only desired outcome is to maximize the HBC metric, the best long-term strategy is E6 regardless of the effect of fall HFEs or TMFs on RBT recruitment or the relative effects of temperature and RBT on juvenile $\mathrm{HBC}$ growth and survival. For the purpose of the HBC objective, therefore, the expected value of information across the critical uncertainties that were articulated is 0 .

Across the uncertainty represented by the hydrological traces, there is a small value of information (table 5). For most hydrological traces, the best long-term strategy for $\mathrm{HBC}$ was E6; but long-term strategies B2, C3, D1, and E5 were also favored in some traces. In the face of uncertainty, the best strategy is E6 with an expected (mean) minimum adult population size of 5,708. If the hydrological trace could be known in advance of choosing an action, the appropriate strategy (B2, C3, D1, E5, or E6) would be chosen; the expected minimum adult population size would be 5,725, which is an increase of 0.30 percent. Of course, the hydrological trace cannot be known in advance of choosing an action because it represents environmental variation during the next 20 years, but the inclusion of these results is helpful in understanding the value 


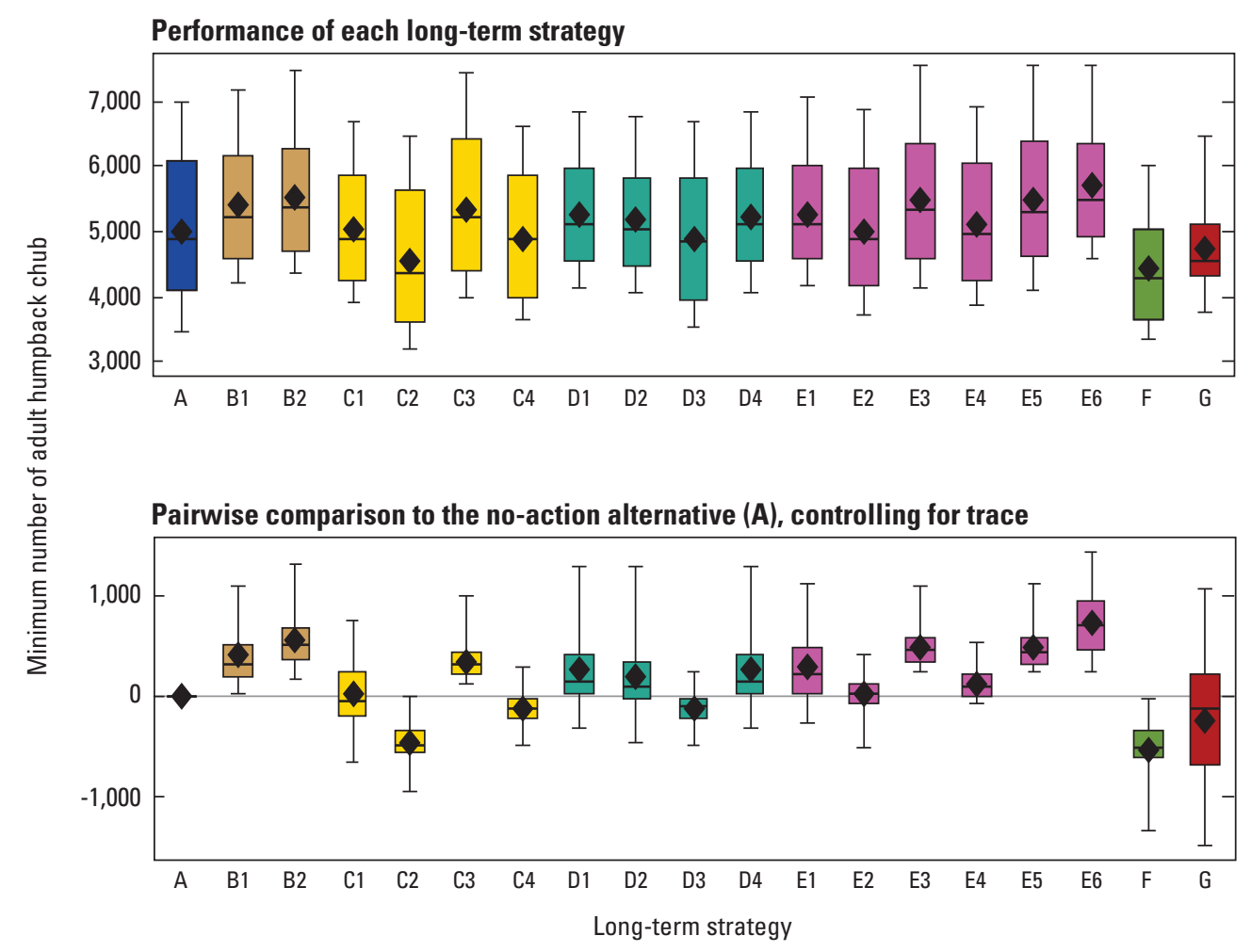

Figure 4. Minimum number of adult humpback chub (performance metric 1) forecast for 19 long-term strategies with equal weighting of traces.

of information for resolvable uncertainty (the 16 scenarios) relative to the value of information for background environmental variation.

The value of information depends on the set of long-term strategies evaluated. The calculations just described assume the decision maker is choosing from the entire set of 19 longterm strategies. In practice, it is more likely that one of the alternatives would be chosen, and the long-term strategy would be chosen from within the set associated with that alternative. The value of information in resolving the critical uncertainties is 0 for all alternatives except Alternative $\mathrm{C}$, which has a value of information of 8.5 adult $\mathrm{HBC}$ (table 6).

Temperature suitability for HBC was forecast at a number of locations in the main stem Colorado River, and in most cases the suitability was low (less than 0.03 on a scale of 0 to 1). At the two locations farthest downstream (Havasu Creek, RM 157; Pumpkin Spring, RM 213; fig. 1), the average suitability was around 0.1 (on a scale of 0 to 1 ). The temperature suitability for HBC was affected more by hydrology than by the long-term strategy; only Alternative F stood out from the other alternatives (fig. 5). Alternative G, with its year-round steady flows, provided the best suitability (mean 0.102 ); its ranking above the other long-term strategies was not affected by any of the critical uncertainties (table 6). There was a small effect of the hydrological trace on the ranking of alternatives based on temperature suitability (EVXI; 0.77 percent; table 6).

\subsection{Rainbow Trout Fishery Results}

The RBT performance metrics differed substantially across long-term strategies (figs. 6-8). The RBT catch rate (performance metric 3 ) and RBT emigration rate (performance metric 4) were highly correlated with one another because both were driven by the RBT population size. Catch rate and emigration rate were highest for those long-term strategies that implemented many HFEs but did not allow TMFs (C2, C4, D3, E2, and F) or that provided steady flows that supported RBT recruitment (G) (figs. 6-7). The abundance of highquality RBT (greater than 16 inches in length, performance metric 5) was negatively correlated with RBT population size; the best long-term strategies were those that restricted or did not allow HFEs (B1, B2, C3, E3, E5, E6) (fig. 8).

Apart from the HBC metric when only the strategies under Alternative $\mathrm{C}$ were considered, the RBT performance metrics were the only ones affected by the critical uncertainties; the fall HFE hypothesis had an EVXI of 0.26 percent, 3.50 percent, and 0.98 percent for the three performance metrics, respectively (table 6). Across all performance metrics and all uncertainties, the strongest effect was the effect of the combined hydrological/sediment trace on the RBT catch rate with an EVXI of 7.53 percent (table 6). The uncertainty about the effectiveness of TMFs did not affect the top ranked longterm strategy for any of the trout or other performance metrics (table 6). 


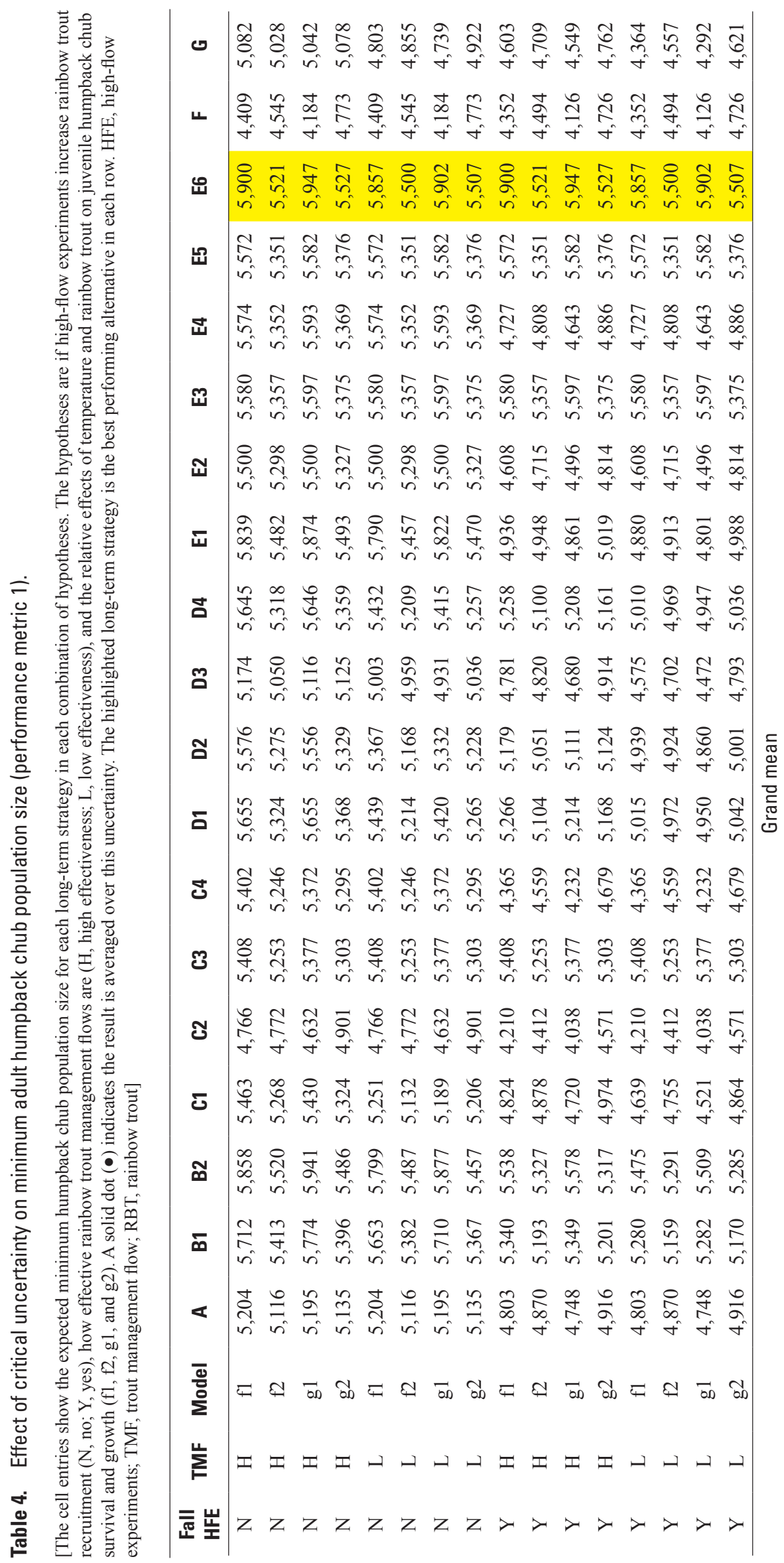

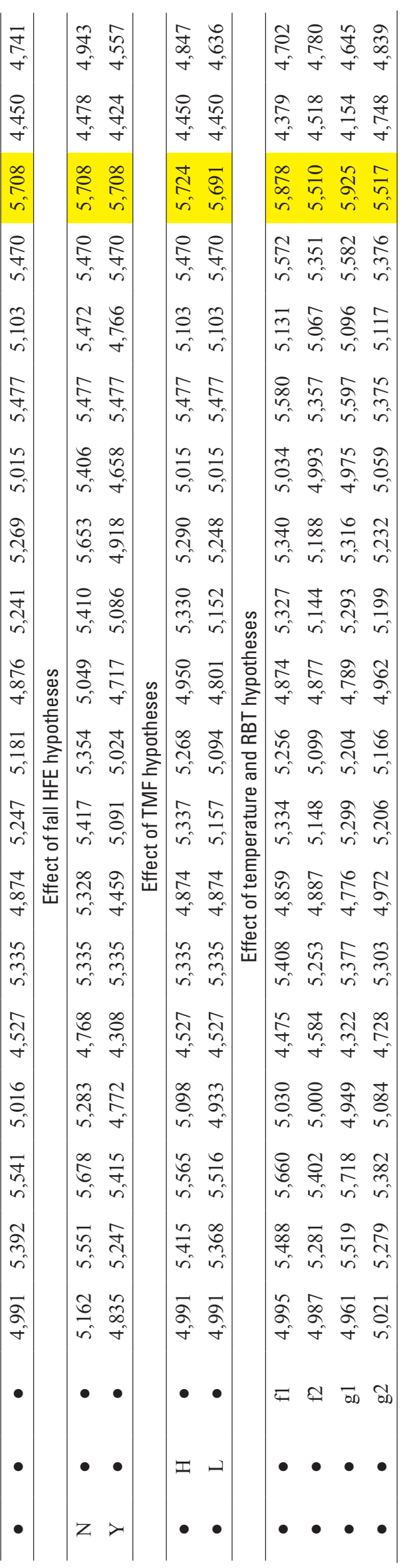




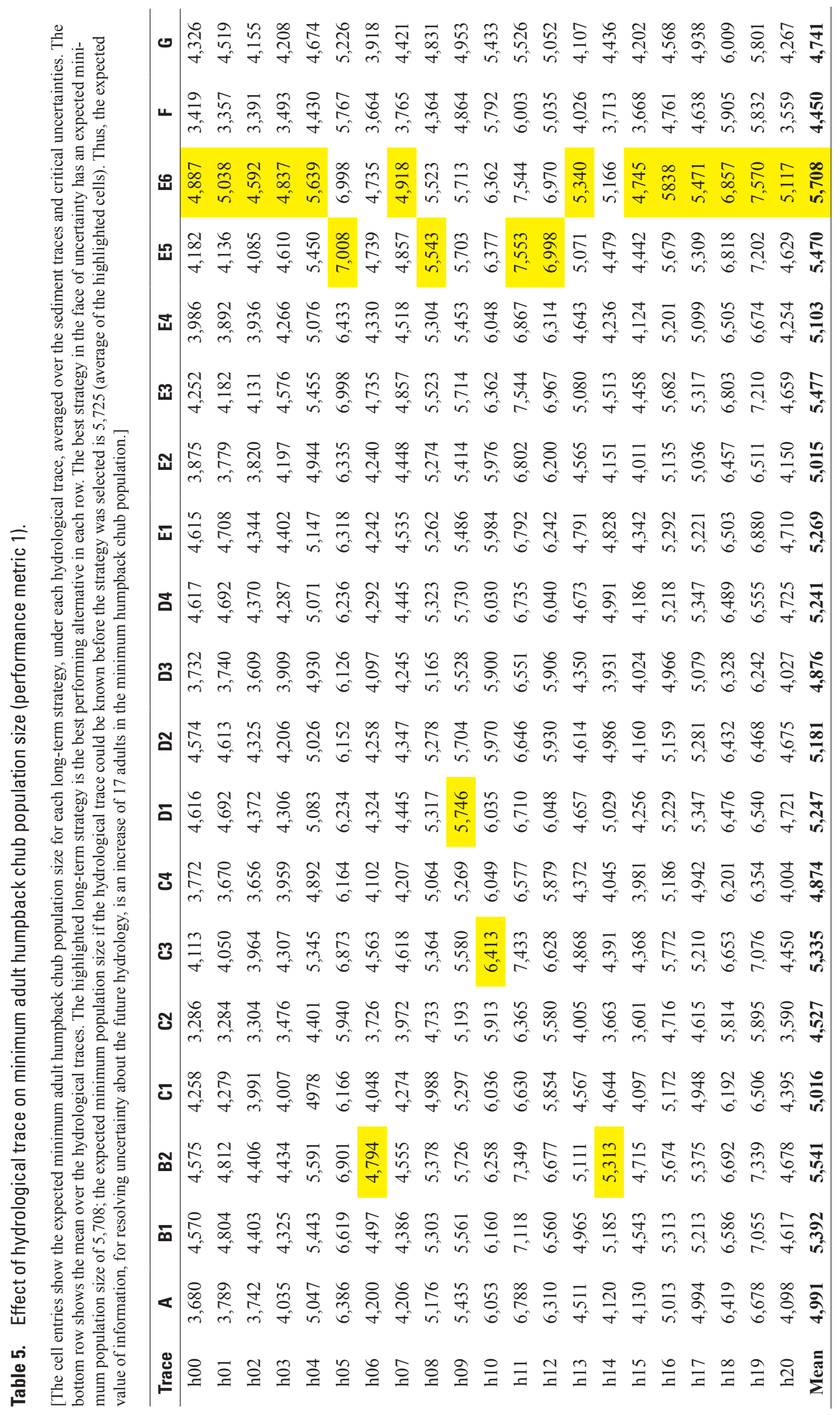




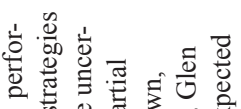

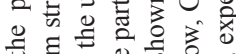

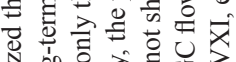
年

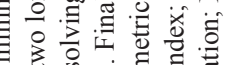

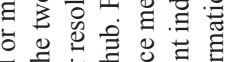

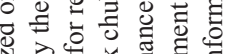

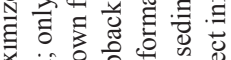
论

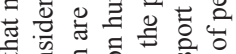

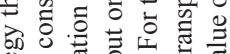

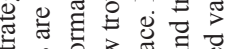
क

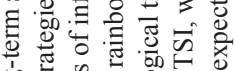

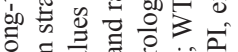

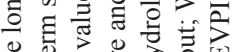

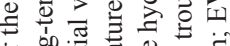

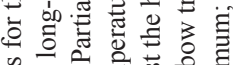
象 帚 $\overline{0}$.

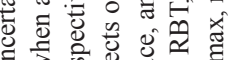

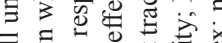

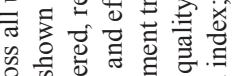

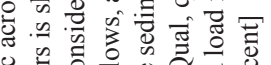

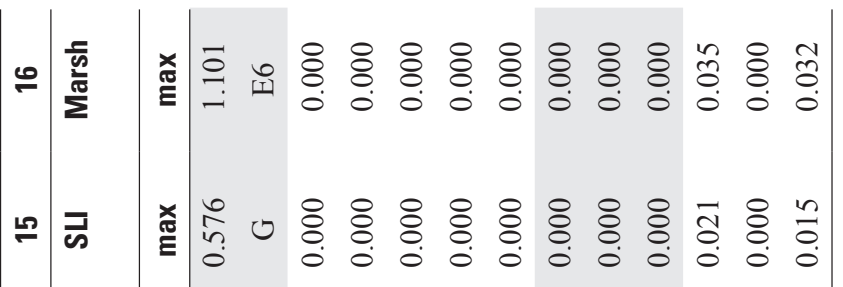
I

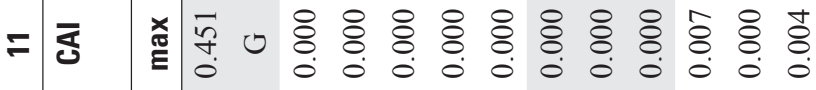

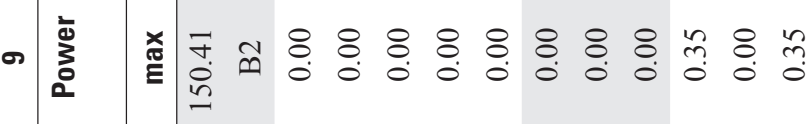

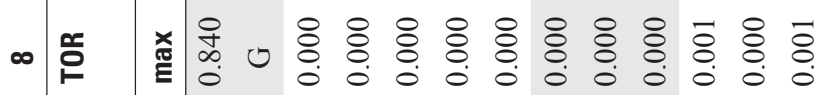
-

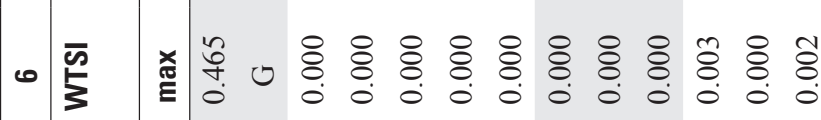
几

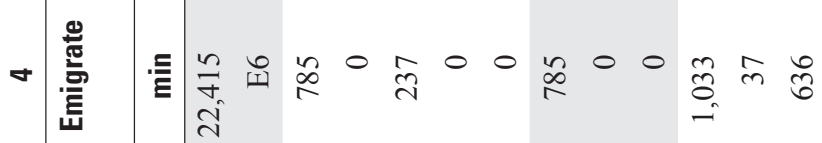
$\begin{array}{lllllllllll}1 & 2 & 2 & 2 & 2 & 2 & 2 & 2 & \text { ते } & 2 & \overline{\mathrm{n}}\end{array} \mid$

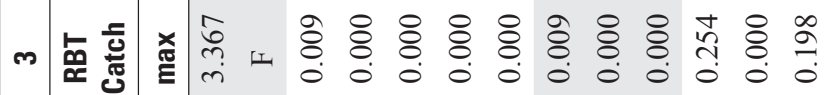

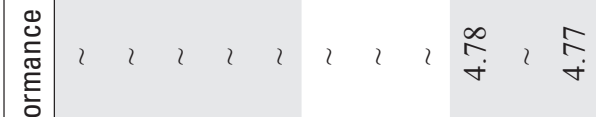

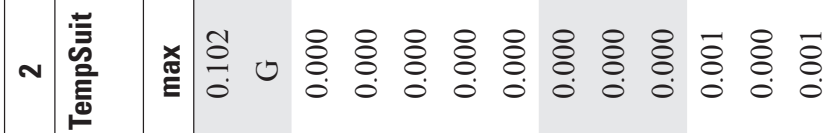

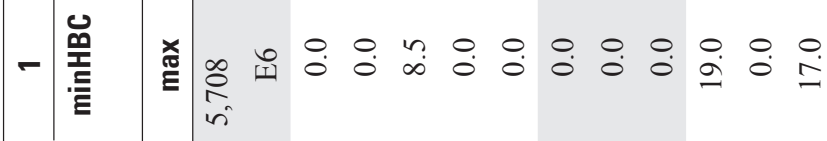
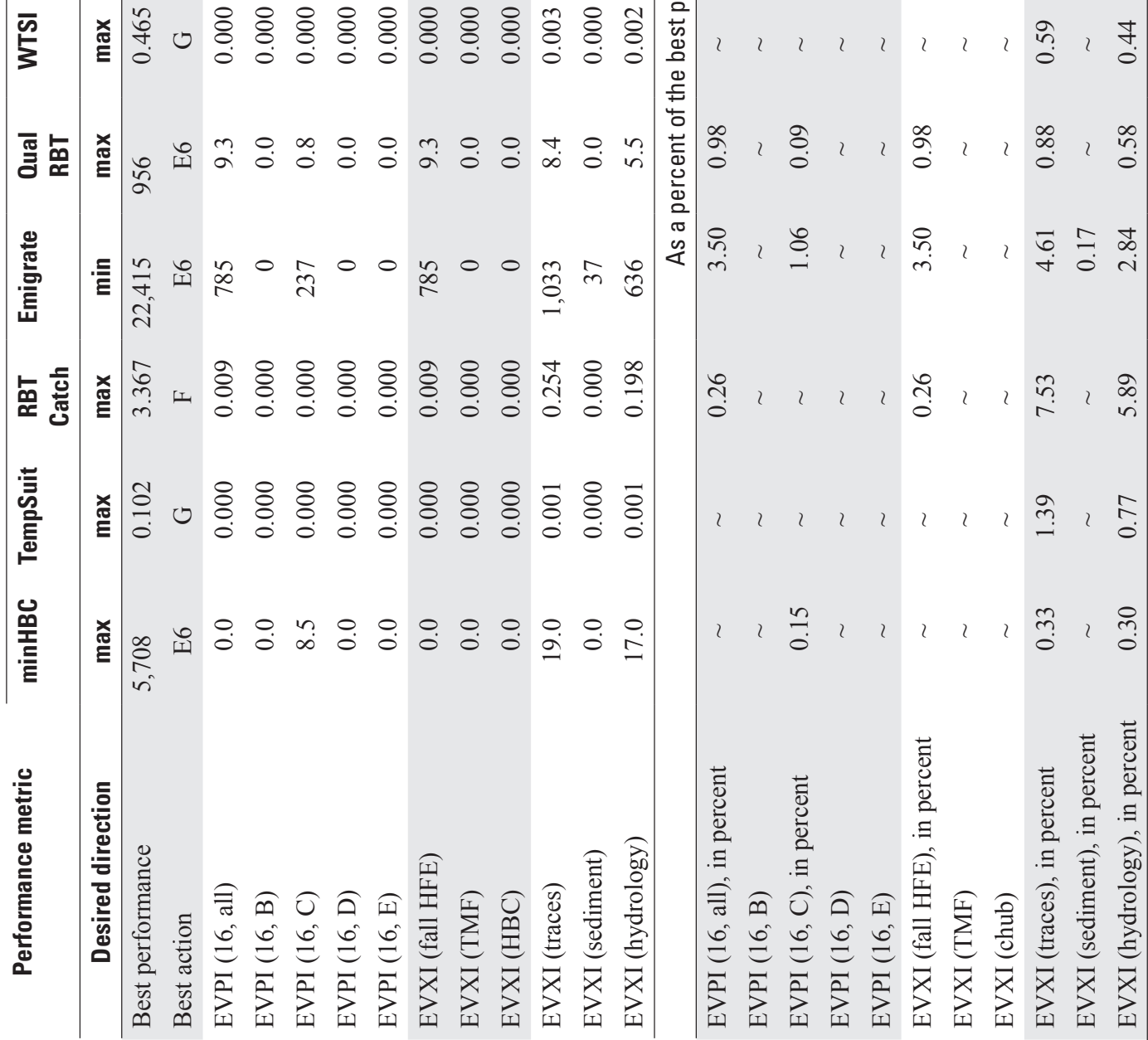

\&

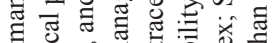

을

2

का

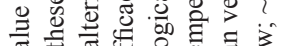

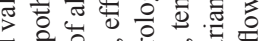

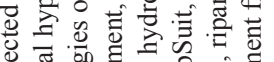

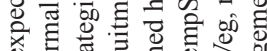

Q

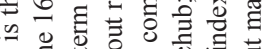

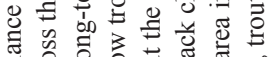

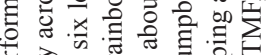

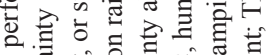

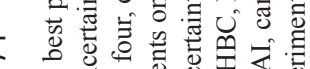

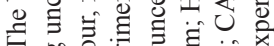

ن.

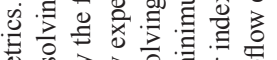

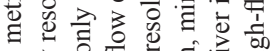

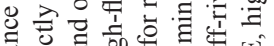

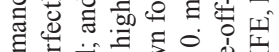

語总击

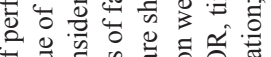

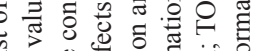

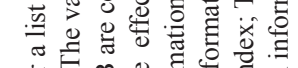

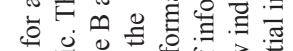

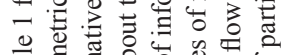

๑

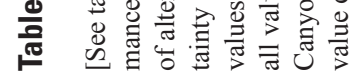




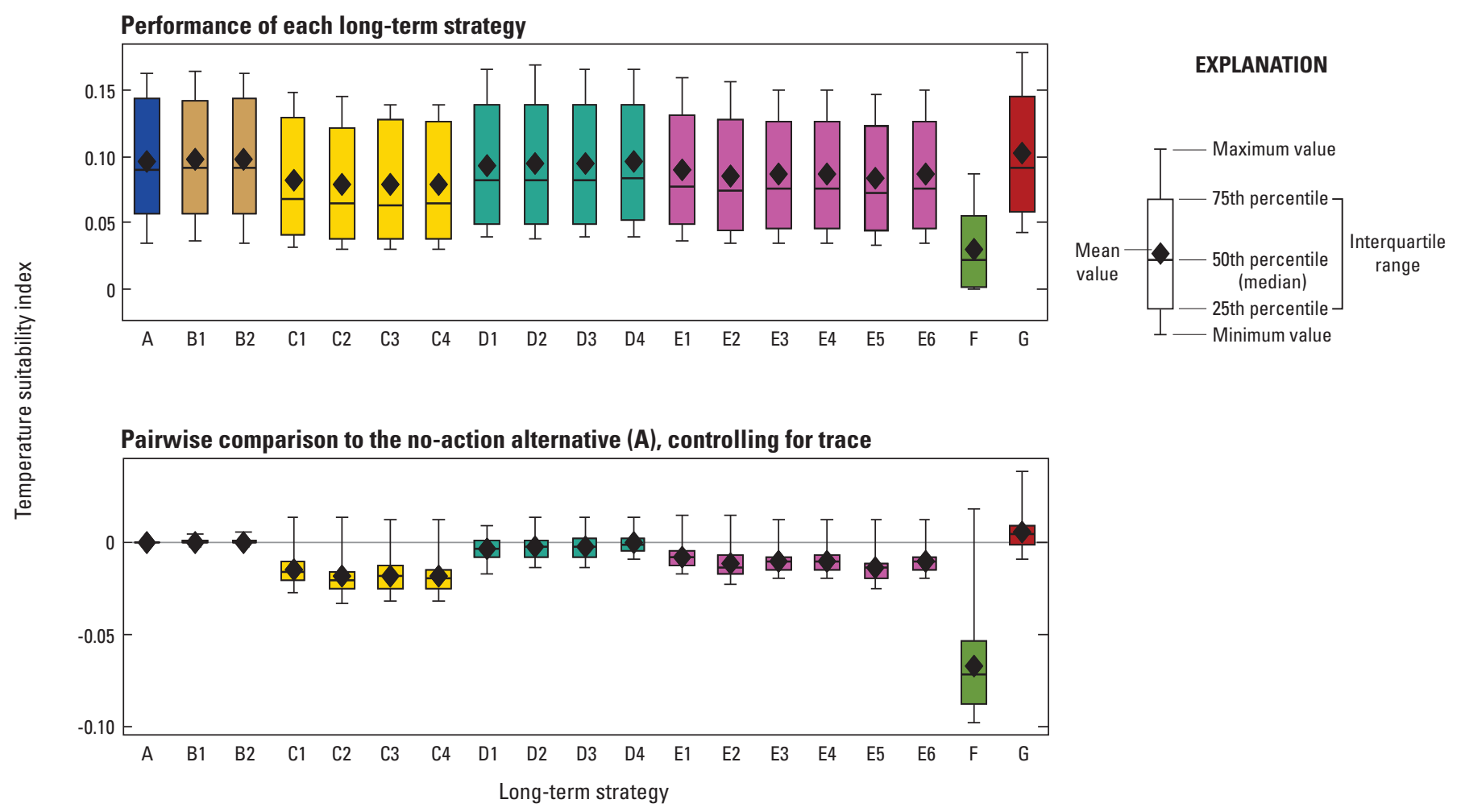

Figure 5. Temperature suitability index for humpback chub at river mile 157 and 213 (performance metric 2) forecast for 19 long-term strategies with equal weighting of traces.

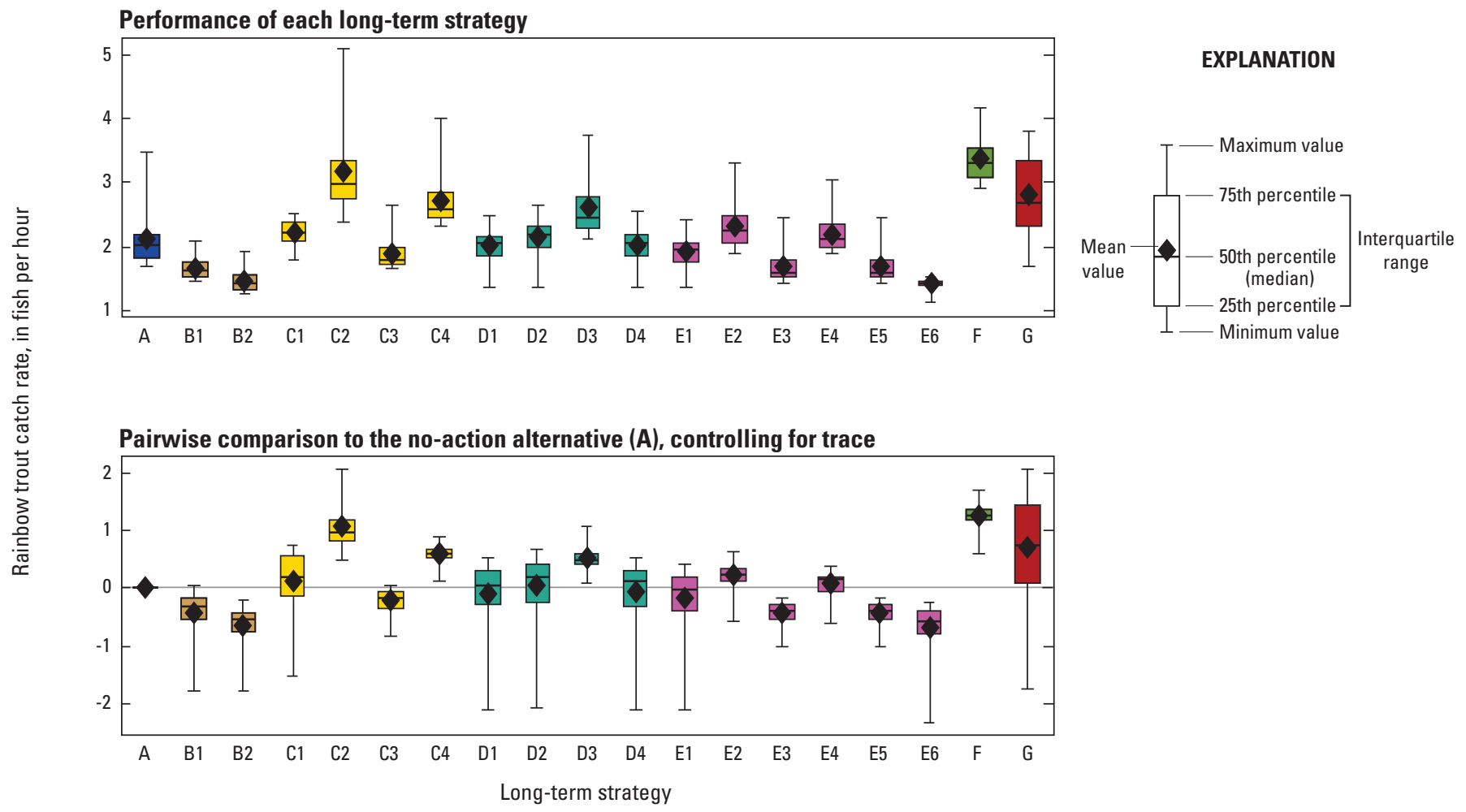

Figure 6. Rainbow trout catch rate (performance metric 3) forecast for 19 long-term strategies with equal weighting of traces. 


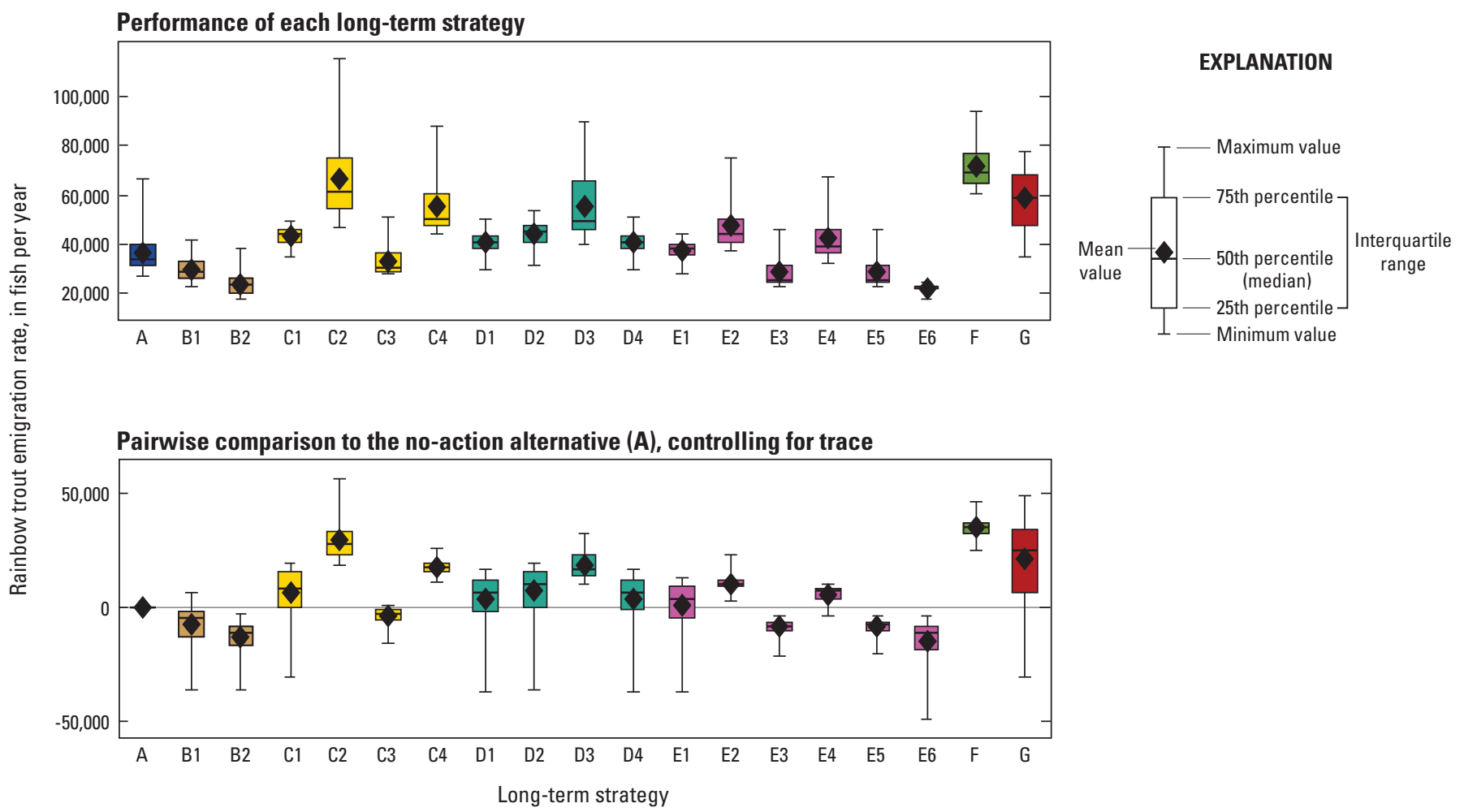

Figure 7. Rainbow trout emigration rate from Glen Canyon (performance metric 4) forecast for 19 long-term strategies with equal weighting of traces.

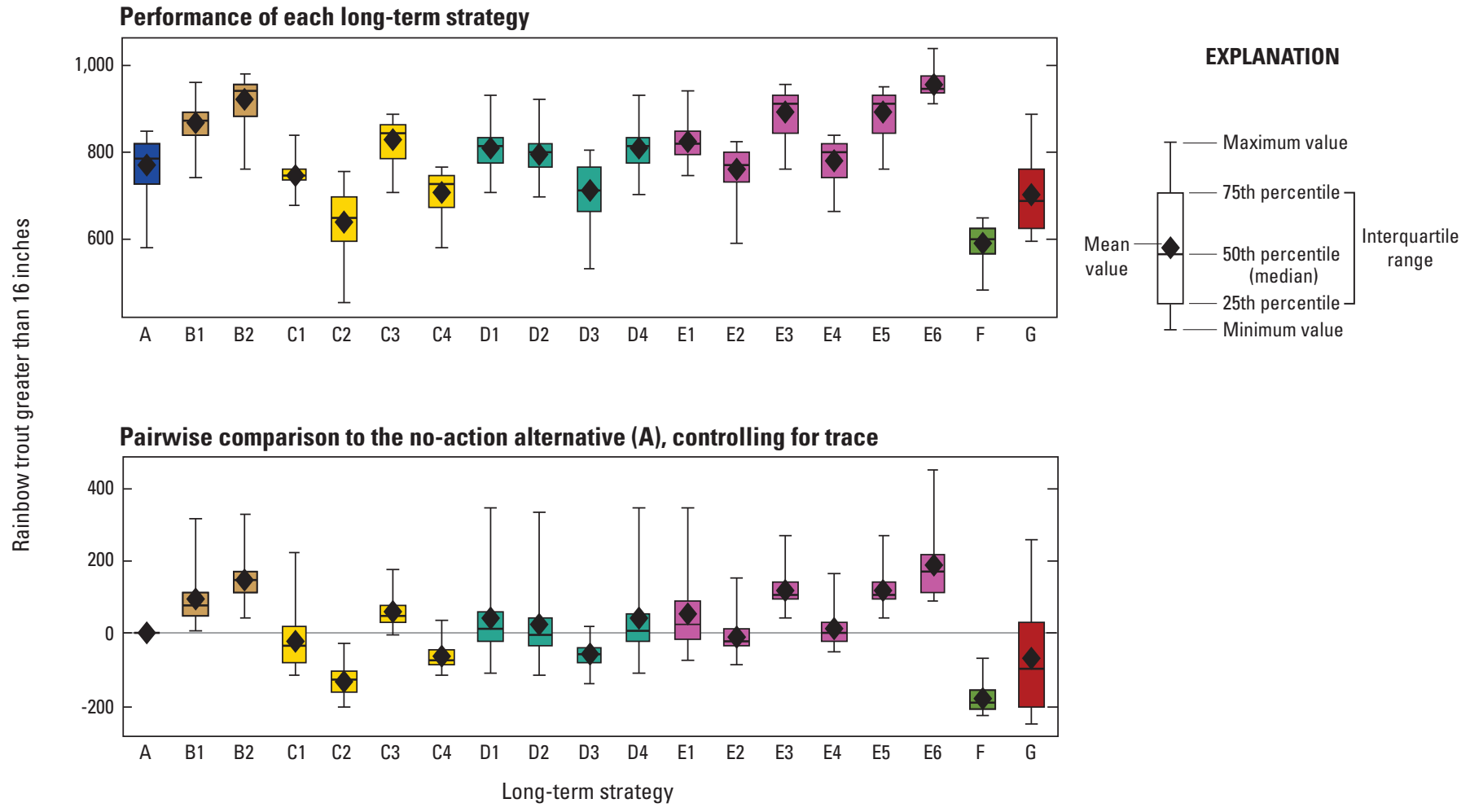

Figure 8. Abundance of high-quality rainbow trout (performance metric 5) forecast for 19 long-term strategies with equal weighting of traces. 


\subsection{Archeological and Cultural Resources Results}

The protection of archeological and cultural resources was reflected in three performance metrics. The WTSI (performance metric 6) was largely driven by the SLI (performance metric 15) and was highest for those long-term strategies that implemented HFEs often (fig. 9). The best-performing alternative for WTSI was Alternative G (mean WTSI, 0.465); this ranking was not affected by any of the critical uncertainties or uncertainty in the sediment input (table 6). For some hydrological traces, long-term strategy $\mathrm{C} 1$ outperformed $\mathrm{G}$, but the value of information related to hydrological uncertainty was small (0.44 percent).

The Glen Canyon flow index (performance metric 7) differed little among alternatives with a mean of around 20 days per year in which the flow exceeded 23,200 ft 3 /s (fig. 10). Only Alternative F differed from the other long-term strategies (mean 36.8 days/year). The long-term strategies that did not allow HFEs (C3, E3, E5, and E6) had the best performance (smallest Glen Canyon flow index). The top ranking long-term strategy was not affected by critical uncertainty or sediment trace (table 6) but did vary depending on the hydrological trace (EVXI, 4.77 percent).

The time-off-river index (performance metric 8) was affected most strongly by the hydrological trace but was also weakly affected by the long-term strategy (fig. 11). Alternatives $\mathrm{B}$ and $\mathrm{C}$ were indistinguishable from Alternative A; Alternatives D, E, and G performed slightly better than Alternative A; and Alternative F performed noticeably worse because high flows during the peak rafting season allow quicker trips and more discretionary time at camping stops. Long-term strategies E1 and G were the best-performing strategies across hydrological and sediment traces, with only a small value of information associated with the trace uncertainty and no value of information associated with the critical uncertainties (table 6).

\subsection{Hydropower Generation and Capacity Results}

The best-performing long-term strategy for hydropower generation (performance metric 9) was B2, a long-term strategy designed to match power generation more closely to demand (fig. 12). For most of the long-term strategies, the annual value of hydropower generation is within \$3 million of the value from Alternative A, except for Alternatives $\mathrm{F}$ and $\mathrm{G}$ for which annual generation is $\$ 6$ million to $\$ 8$ million less than Alternative A (fig. 12). The effect of hydrology on hydropower generation is much greater than the effect of the alternatives, with the average annual power generation over 20 years varying more than $\$ 60$ million across hydrological traces (fig. 12). The dominance of $\mathrm{B} 2$ as the best long-term strategy for hydropower generation, however, is robust to uncertainty in hydrology with a value of information of only $\$ 350,000$ per year (EVXI, 0.23 percent, table 6); for 4 out of 21 hydrological traces, long-term strategy E3 outranked B2.

The value of hydropower capacity (performance metric 10) was more sensitive to the choice of long-term strategy than hydropower generation with long-term strategies differing by nearly $\$ 20$ million per year (fig. 13). Long-term strategy B2 was the best-performing strategy across all uncertainties, including hydrological trace. The long-term strategies in Alternative B outperformed Alternative A; all the remaining long-term strategies had a lower value of hydropower capacity than Alternative A (fig. 13). The value of capacity was somewhat sensitive to hydrological trace (the range of performance within a long-term strategy varied by $\$ 8$ million to $\$ 17$ million per year across hydrological traces), but the identification of the best-performing alternative was not (EVXI, 0).

\subsection{Recreational Experience Results}

The camping area index (performance metric 11), a metric composed from the SLI to represent beach formation and a flow factor to represent beach exposure, was highly correlated with the SLI (performance metric 18). The best-performing long-term strategies (especially $\mathrm{C} 1, \mathrm{~F}$, and $\mathrm{G}$ ) include frequent implementation of HFEs; the worst-performing long-term strategies (for example, C3, E3, E5, and E6) do not permit HFEs (fig. 14). The identification of the top-ranked long-term strategy was affected by the combination of hydrological and sediment trace (EVXI, 1.96 percent) but not by any other uncertainties (table 6).

The fluctuation index (performance metric 12), which reflects the fraction of time the daily flow fluctuations are in a tolerable range for recreation, was highest for Alternatives $\mathrm{F}$ and $\mathrm{G}$ and lowest for Alternative B (fig. 15). Alternative D was comparable to Alternative A. The effect of the long-term strategies within an alternative was small compared to the effect of the base operations within each alternative. The fluctuation index was not strongly affected by any of the uncertainties, including hydrological trace.

The Glen Canyon rafting use metric (performance metric 13), which reflects the visitor-days lost per year because of HFEs, was best for those long-term strategies that did not permit HFEs (for example, C3, E3, E5, and E6) and worst for Alternative F (fig. 16). Under Alternative F, nearly 1,000 boat seats per year in Glen Canyon are expected to be lost because of HFEs. The rafting use metric showed variation as a result of hydrological trace, but the identification of the best-performing long-term strategies was not affected by any of the uncertainties.

\subsection{Riparian Vegetation Results}

The riparian vegetation index (performance metric 14) was the sum of four ratios that represented measures of different aspects of the vegetation community with a score of 4 indicating maintenance of current conditions. 


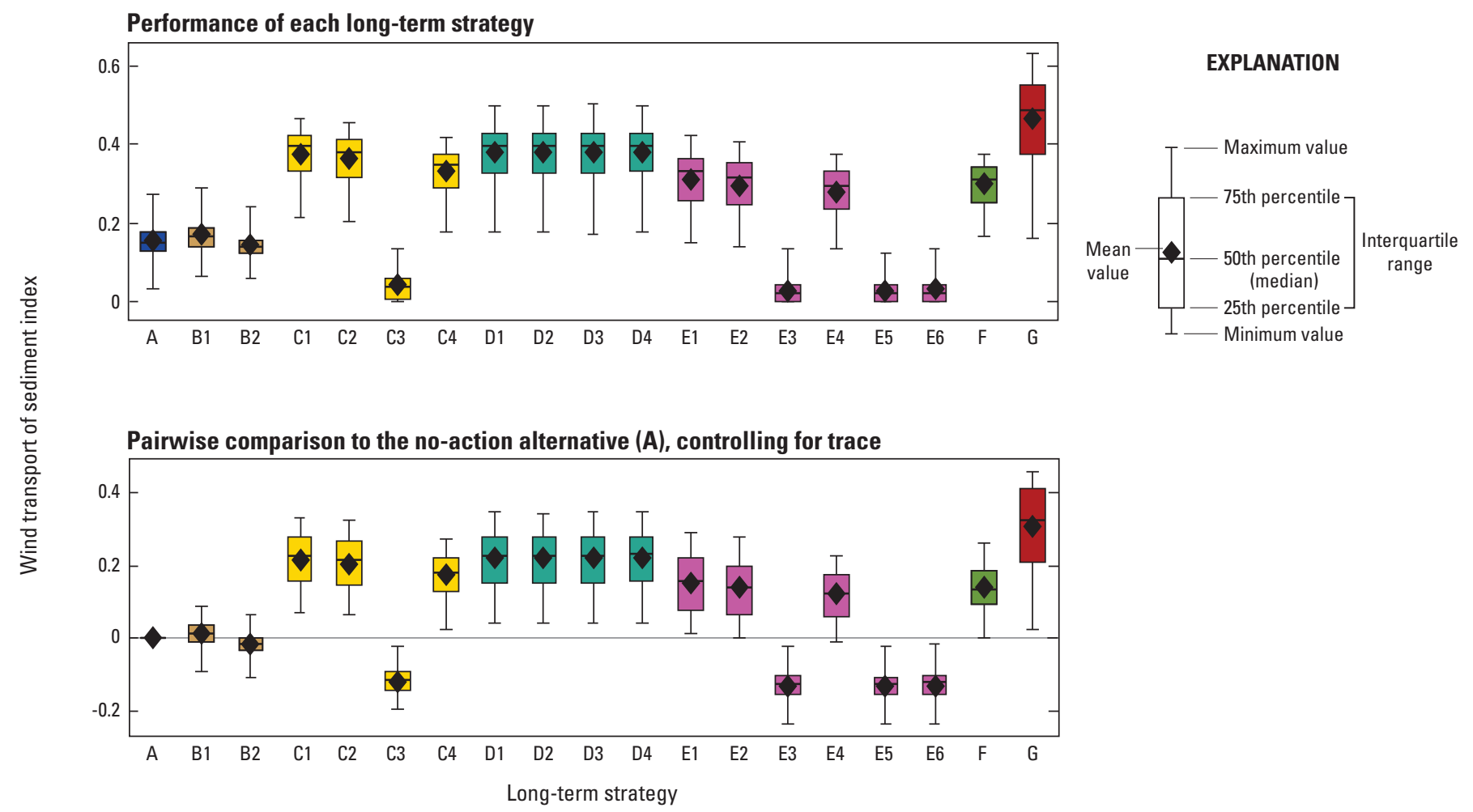

Figure 9. Wind transport of sediment index (performance metric 6) forecast for 19 long-term strategies with equal weighting of traces.

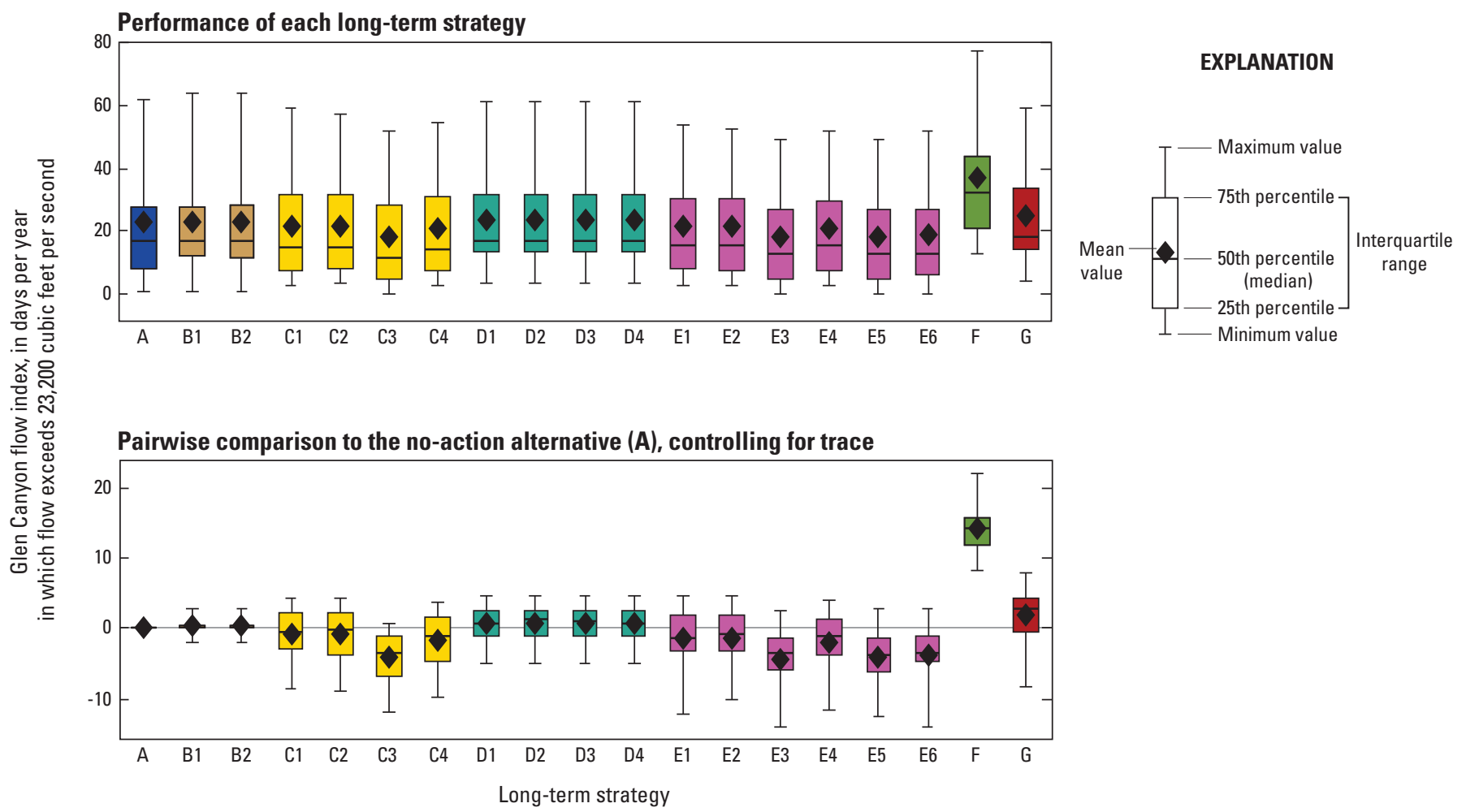

Figure 10. Glen Canyon flow index (performance metric 7) forecast for 19 long-term strategies with equal weighting of traces. 


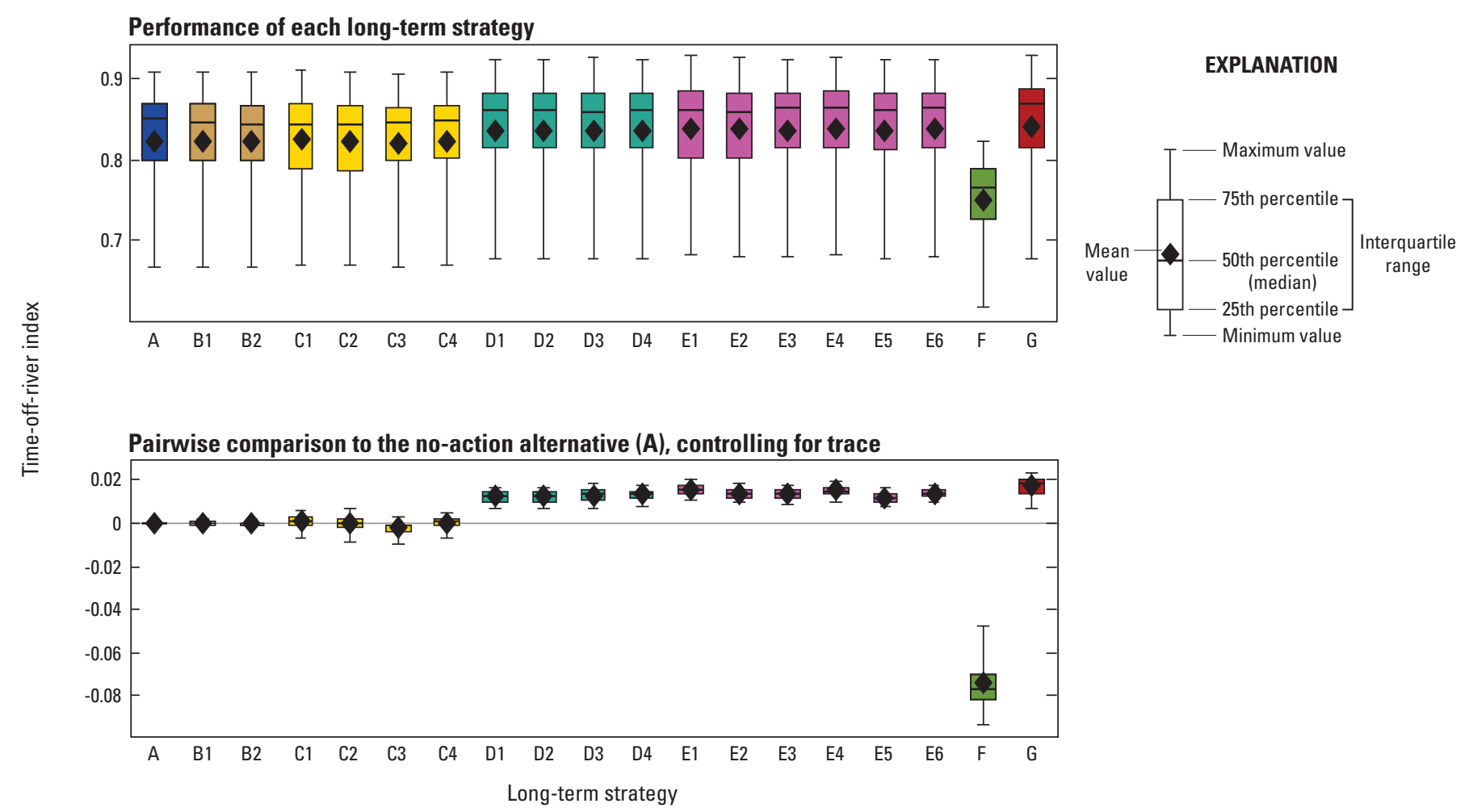

Figure 11. Cultural resources time-off-river index (performance metric 8) forecast for 19 long-term strategies with equal weighting of traces.

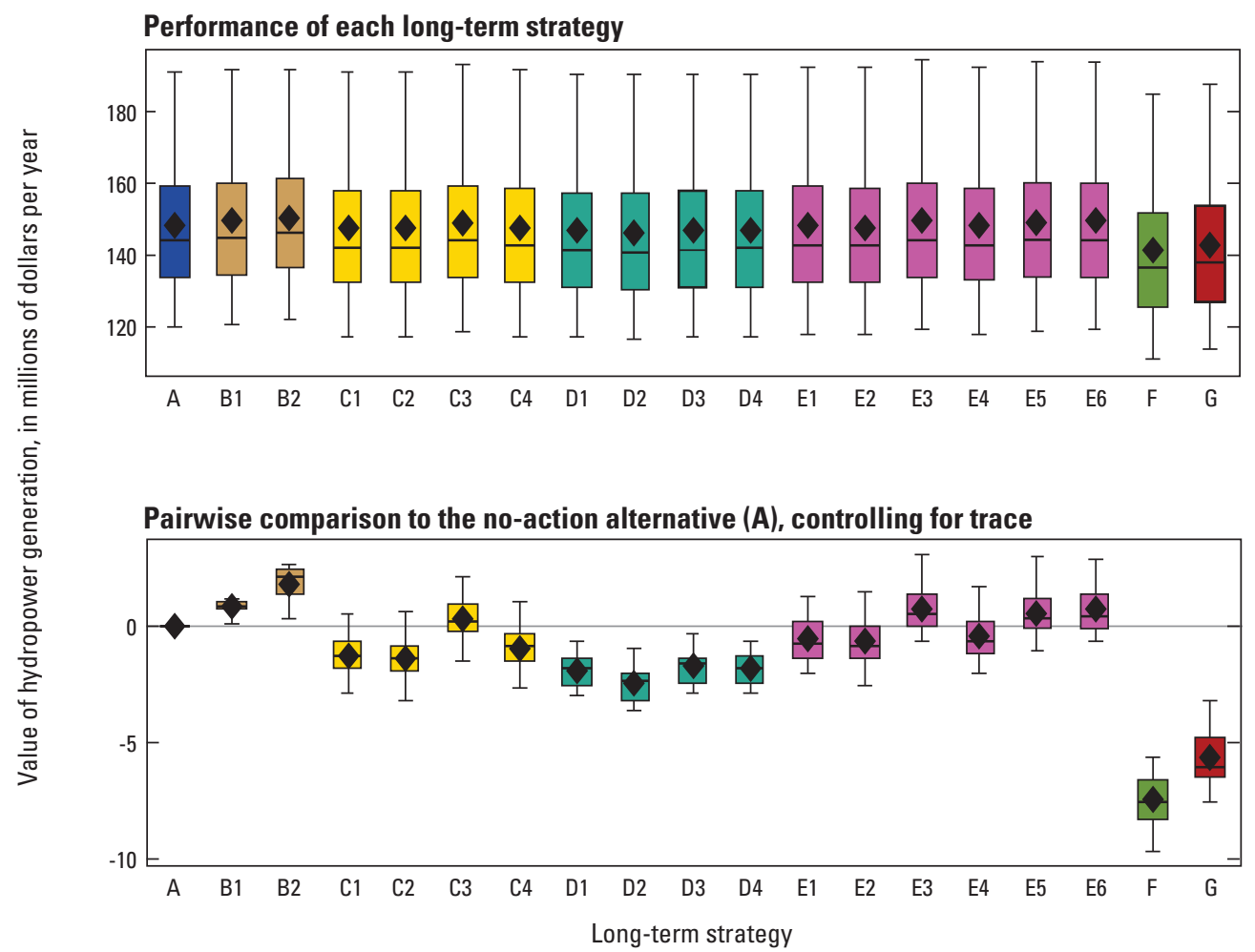

Figure 12. Annualized net present value of hydropower generation (performance metric 9) forecast for 19 long-term strategies with equal weighting of traces. 


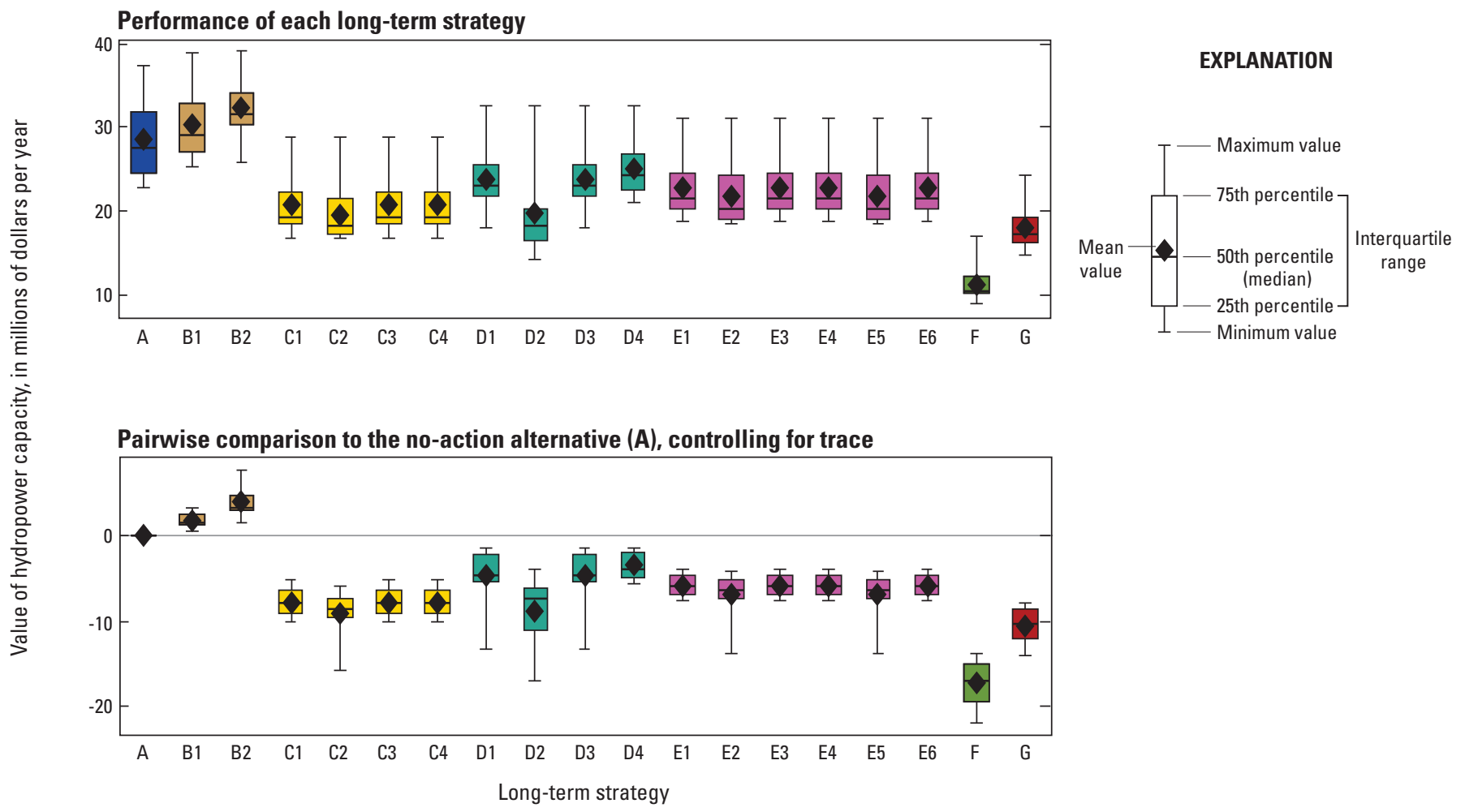

Figure 13. Annualized net present value of hydropower capacity (performance metric 10) forecast for 19 long-term strategies with equal weighting of traces.

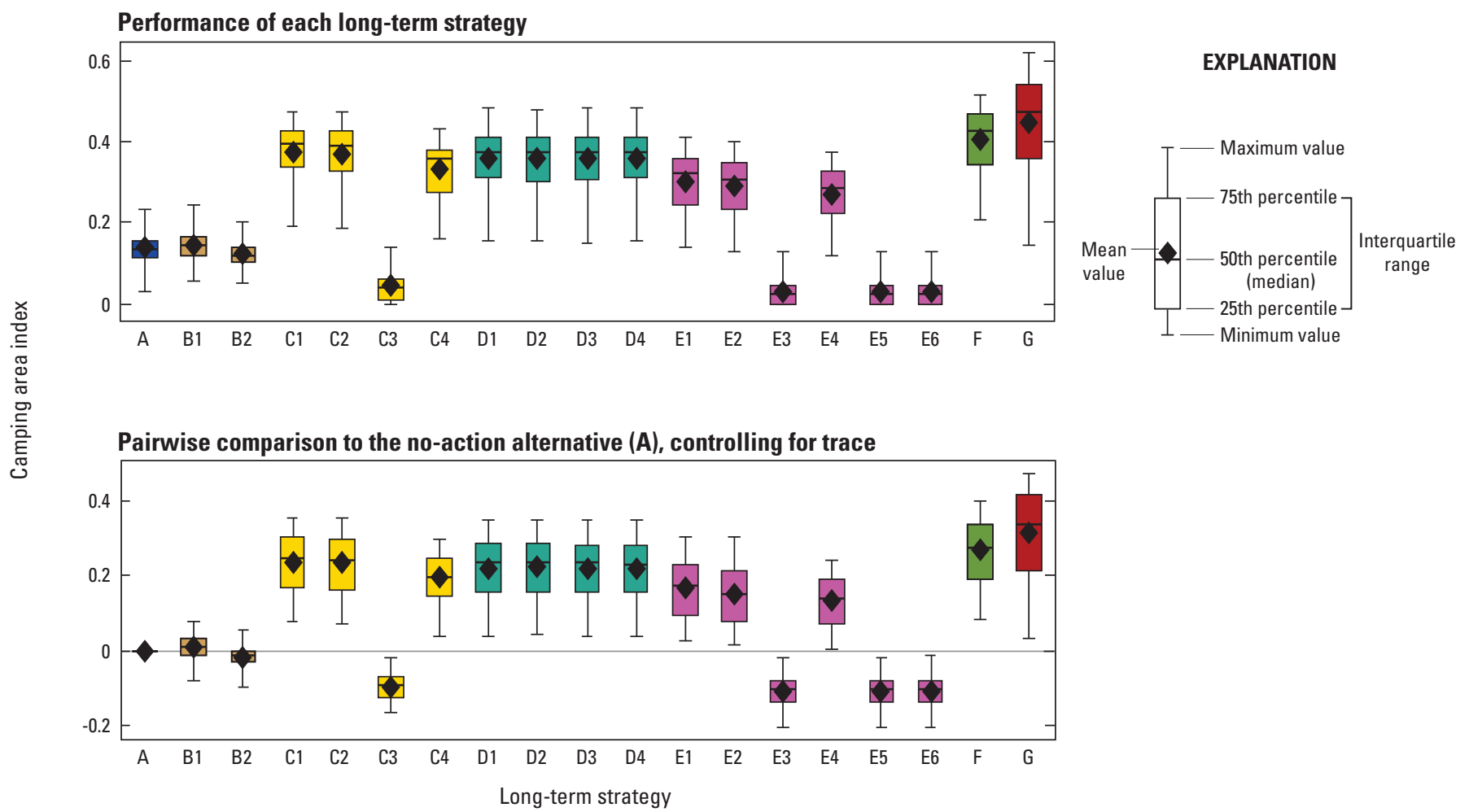

Figure 14. Camping area index (performance metric 11) forecast for 19 long-term strategies with equal weighting of traces. 


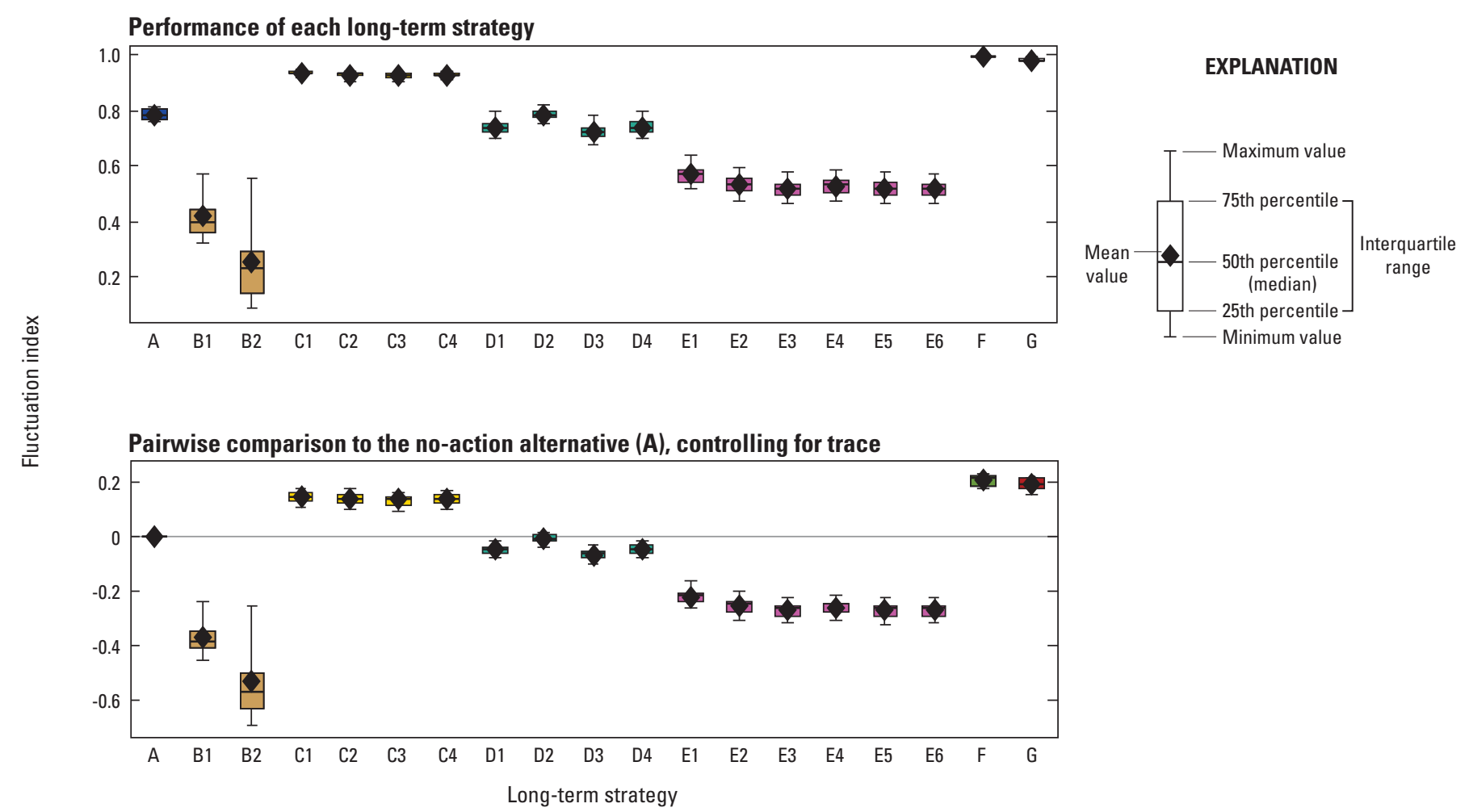

Figure 15. Fluctuation index (performance metric 12) forecast for 19 long-term strategies with equal weighting of traces.

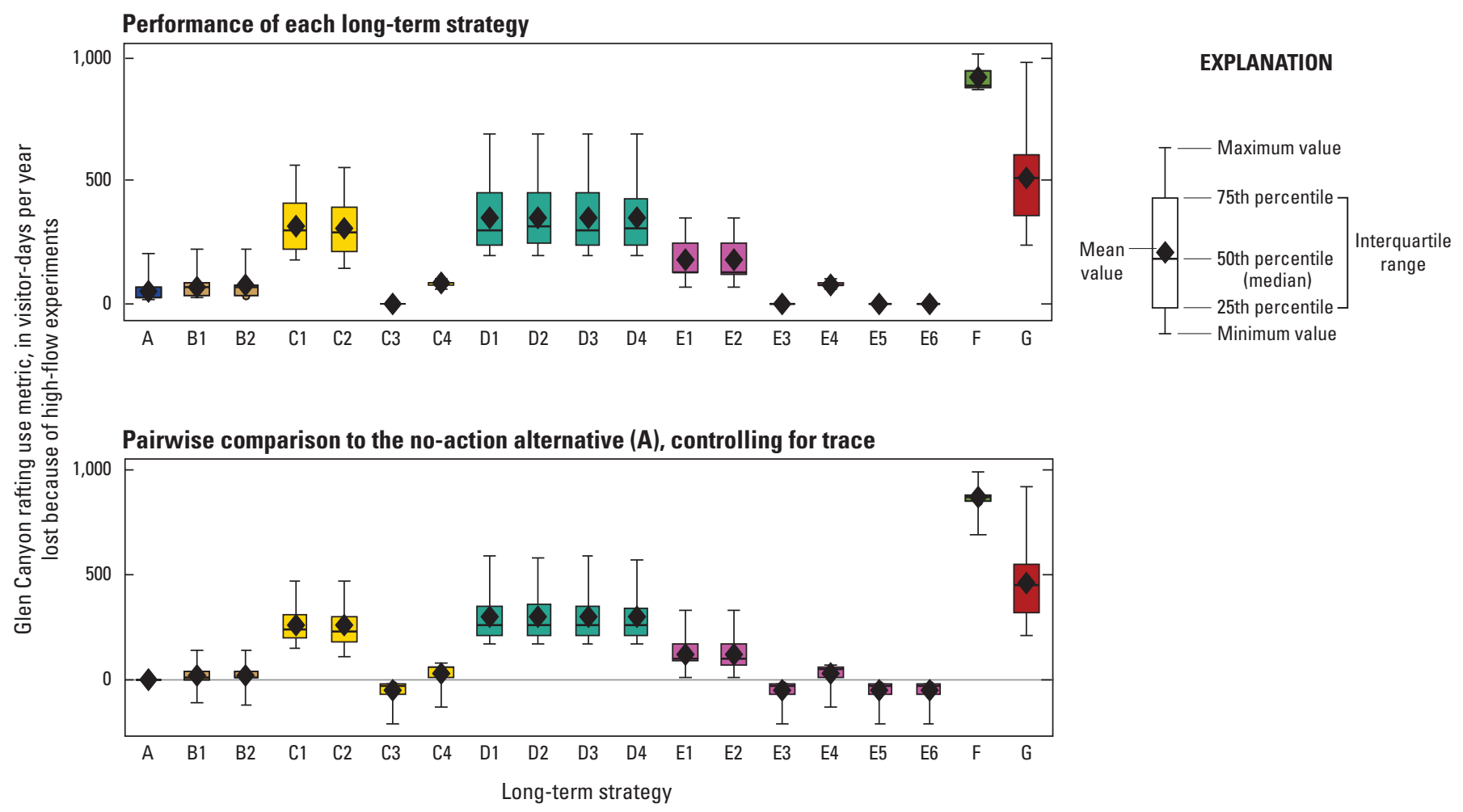

Figure 16. Glen Canyon rafting use metric (performance metric 13) forecast for 19 long-term strategies with equal weighting of traces. 
The index ranged between 2 and 6 across alternatives and traces (fig. 17), indicating a 50-percent degradation or a 50-percent improvement in vegetation conditions, respectively. The highest mean vegetation index was associated with long-term strategy D4 (riparian vegetation index, 3.954), but 13 of the 19 long-term strategies were ranked first depending on the hydrological and sediment trace. The value of information for resolving uncertainty about the hydrological and sediment trace before committing to a long-term strategy was 0.224 (an improvement of 5.66 percent; table 6). The choice of the long-term strategy was not affected, however, by any of the critical uncertainties (table 6).

\subsection{Sediment Results}

The SLI (performance metric 15) measured the potential for sand bar formation by reporting the proportion of sand transported during flows greater than $31,500 \mathrm{ft}^{3} / \mathrm{s}$. The SLI was most strongly affected by the frequency of HFEs; the longterm strategies with the highest SLI (especially C1, C2, D1, D2, F, and G) allowed frequent HFEs, and the long-term strategies with the lowest SLI (C3, E3, E5, and E6) did not permit HFEs (fig. 18). Uncertainty in the combination of hydrological and sediment trace did affect the ranking of the alternatives (EVXI, 3.57 percent; table 6) with 6 of the 19 long-term strategies favored in at least 1 trace.

\subsection{Tribal Resources Results}

Several performance metrics were developed to evaluate resources of specific importance from a tribal perspective. The marsh vegetation ratio (performance metric 16) forecast the preservation or expansion of the wetland vegetation communities along the Colorado River (fig. 19). For context, the current extent of marsh vegetation is 4.6 acres. The long-term strategy with the highest mean marsh vegetation ratio was E6 (mean marsh vegetation ratio, 1.101), representing about a 10-percent increase in marsh community area, but long-term strategy E3 was most commonly ranked first among the 63 traces. Alternatives $\mathrm{C}$, F, and $\mathrm{G}$ exhibited consistent losses of marsh vegetation compared to Alternative A, whereas Alternatives D and E exhibited modest increases (fig. 19). The variance in the index induced by variation in hydrology was larger than the variance across alternatives (fig. 19). The value of information for resolving hydrological and sediment uncertainty before committing to a long-term strategy was 3.20 percent (table 6).
The frequency of mechanical removal (performance metric 17) was 0 for those long-term strategies that do not permit this management tool $(\mathrm{C} 1, \mathrm{C} 2, \mathrm{E} 1, \mathrm{E} 2, \mathrm{E} 5, \mathrm{E} 6$, and F) and varied between 0 and 6 years out of 20 for the other long-term strategies (fig. 20). For those long-term strategies that permitted mechanical removal, the frequency was influenced by the emigration rate of RBT from Glen Canyon (performance metric 4), which in turn was influenced by the frequency of HFEs. Because the long-term strategies with the lowest frequency were determined simply by whether mechanical removal was allowed or not, the identification of the top-ranked strategy was not influenced by any of the uncertainties.

The frequency of trout management flows (performance metric 18) was 0 for those long-term strategies that did not allow their use (10 out of the 19 long-term strategies) and varied between 0 and 20 years out of 20 for the remaining strategies (fig. 21). Under Alternative G, TMFs were triggered on average more than one-half of the years, and sometimes in all 20 years, depending on the hydrological trace. For the strategies that allowed TMFs, the frequency of their use was correlated with RBT abundance and, hence, with the RBT catch rate (performance metric 3 ) and emigration rate (performance metric 4). Again, because the long-term strategies with the lowest frequency of TMFs were determined by the admissible tools in the strategy, the value of information associated with the various uncertainties was 0 .

\subsection{Full Consequence Table}

A summary of the performance of the 19 long-term strategies against the 18 performance metrics is represented in a consequence table (table 7). There is neither a single long-term strategy that performs best for all performance metrics (such a strategy would be shaded in yellow across the corresponding row), nor a single long-term strategy that performs worst for all performance metrics (such a strategy would be shaded dark blue across the row); furthermore, no long-term strategy is either consistently better or consistently worse than Alternative $\mathrm{A}$ across all performance metrics. Interestingly, the strategies that are worst for a number of performance metrics (for example, B2, C3, E5, F, and G) are also best for other performance metrics. Other long-term strategies are neither best nor worst on any performance metrics (for example, B1, C4, D1, D2). This pattern of performance indicates that there are important tradeoffs among the long-term strategies, and the best alternative cannot be identified without considering the relative value of the resource goals and performance metrics. 


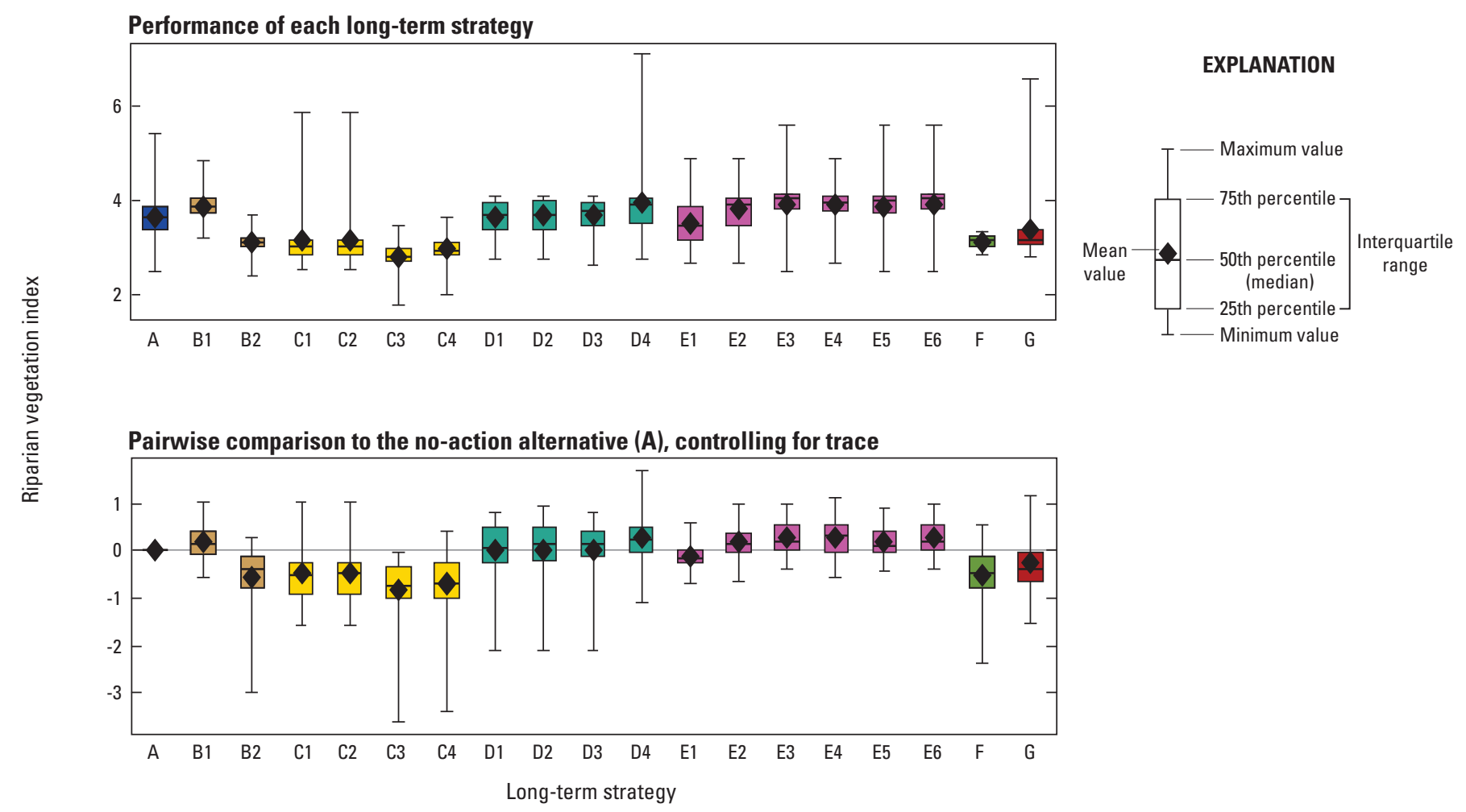

Figure 17. Riparian vegetation index (performance metric 14) forecast for 19 long-term strategies with equal weighting of traces.

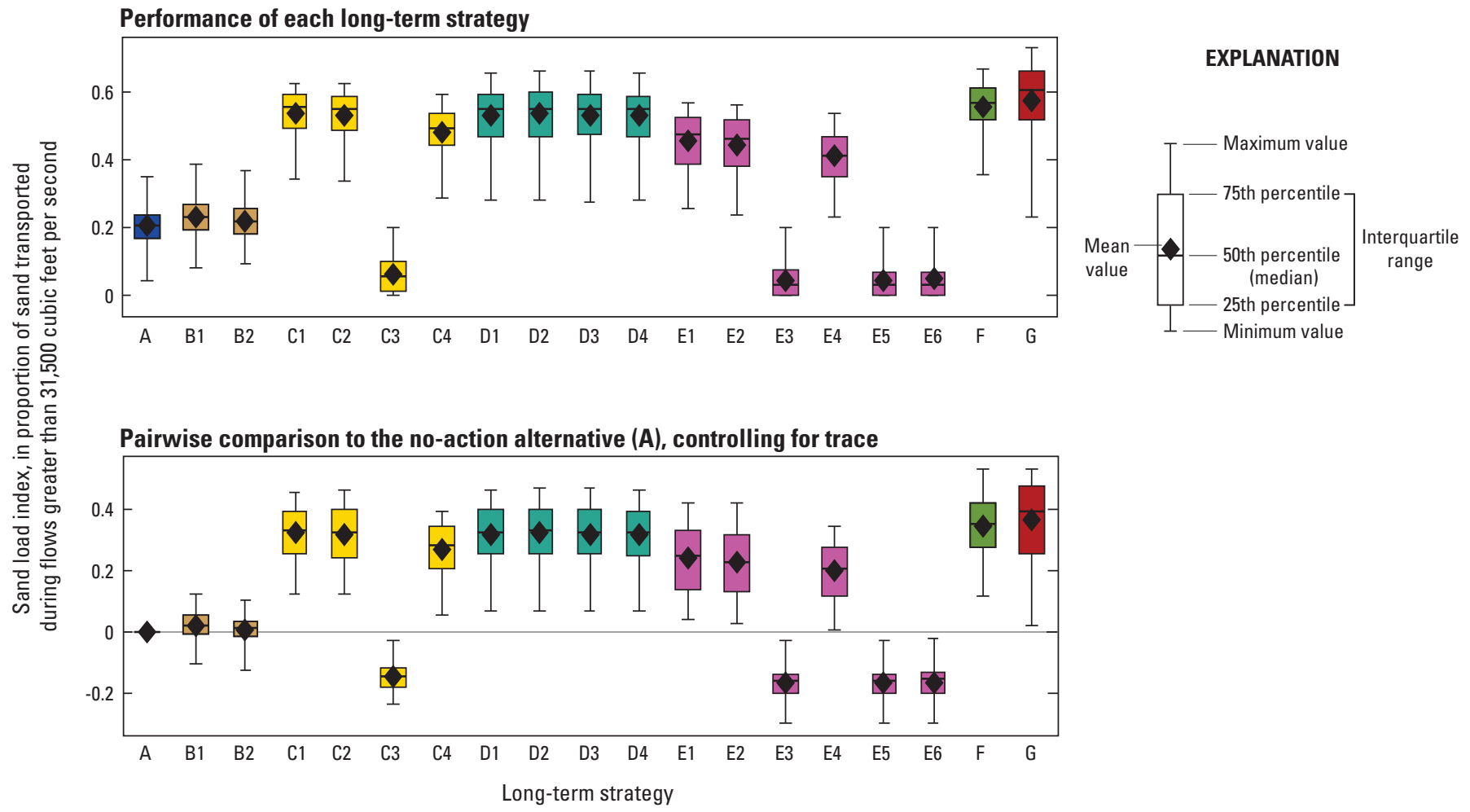

Figure 18. Sand load index (performance metric 15) forecast for 19 long-term strategies with equal weighting of traces. 


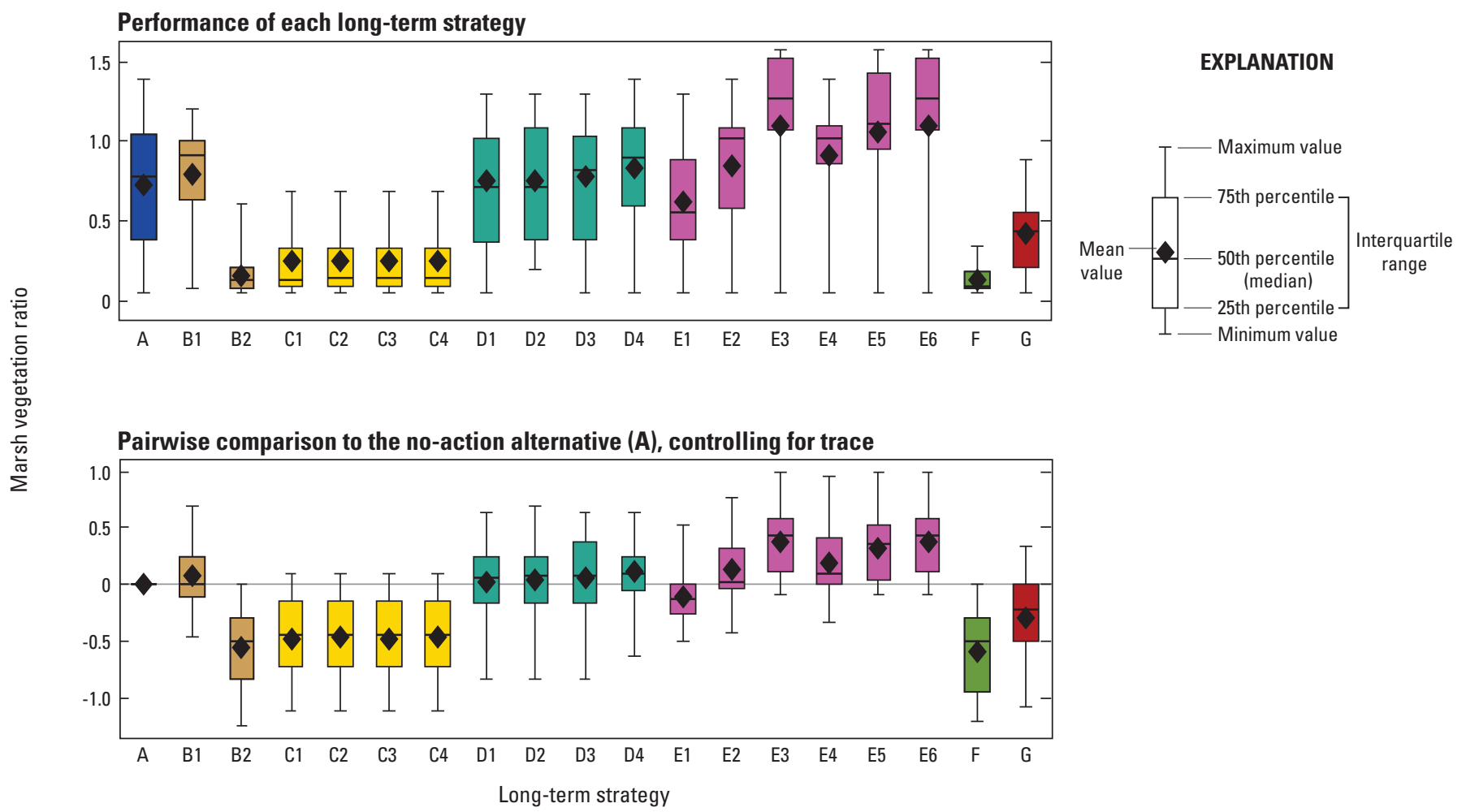

Figure 19. Marsh vegetation ratio (ratio of average marsh cover over 20-year period to current marsh cover, performance metric 16) forecast for 19 long-term strategies with equal weighting of traces.

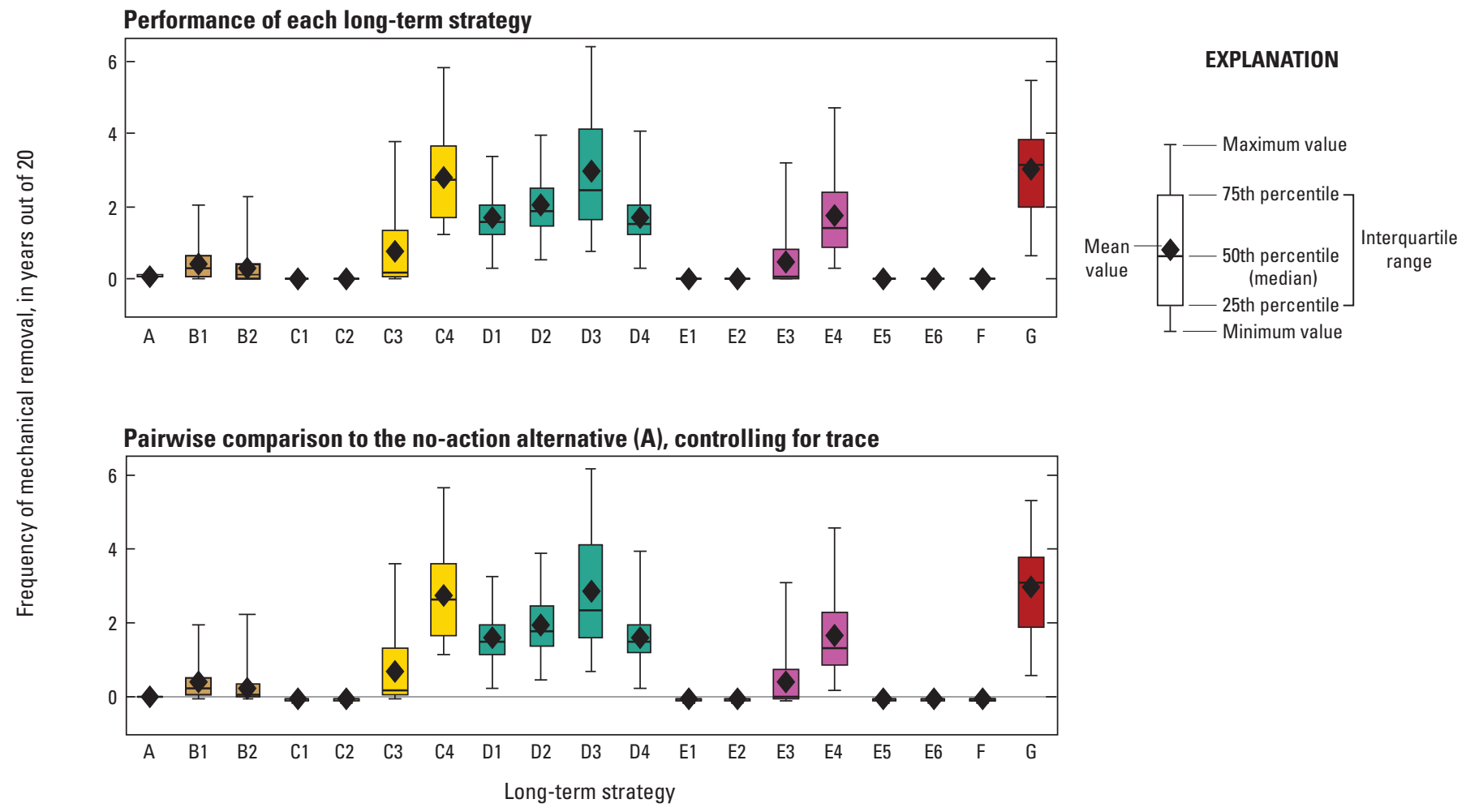

Figure 20. Frequency of mechanical removal (performance metric 17) forecast for 19 long-term strategies with equal weighting of traces. 


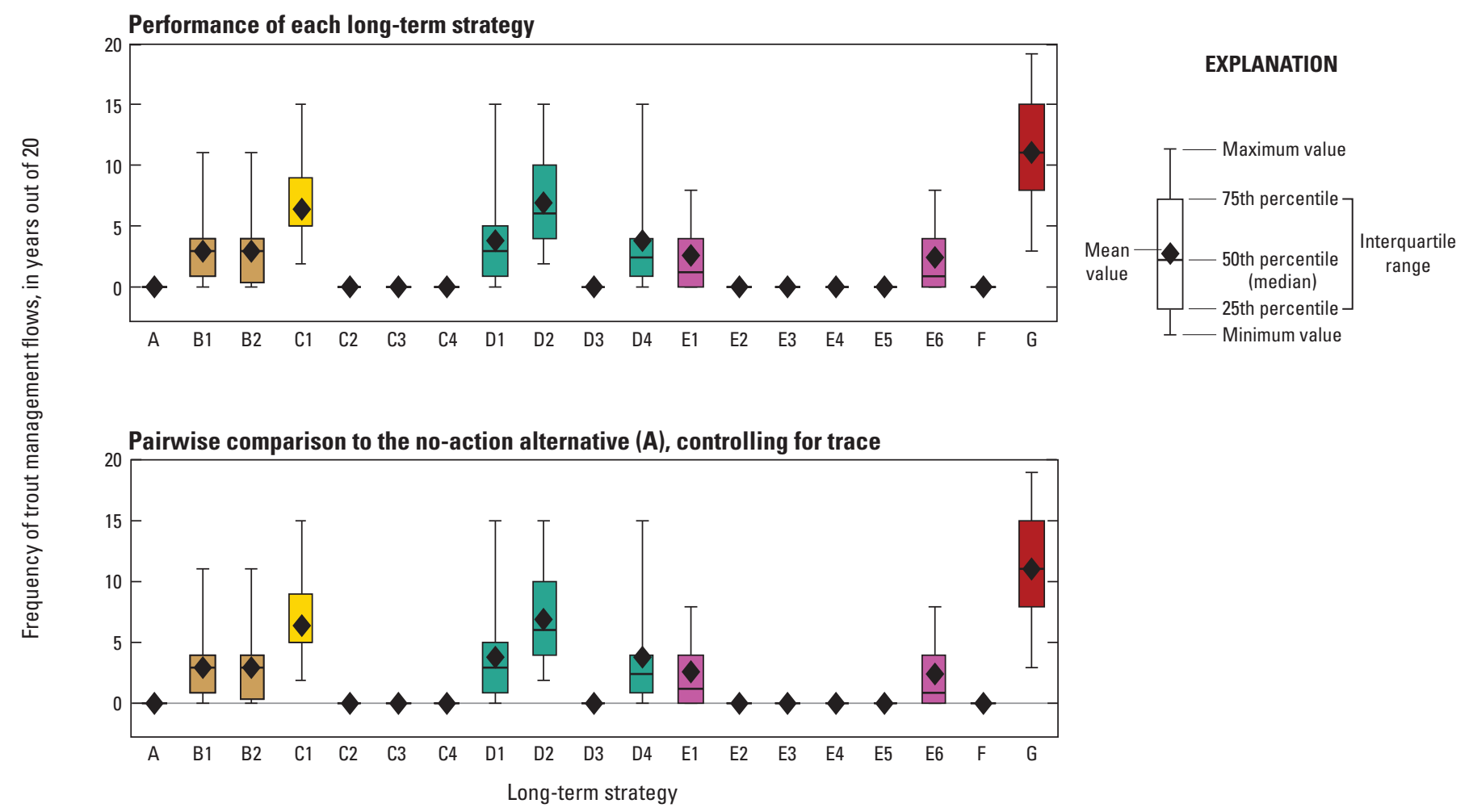

Figure 21. Frequency of trout management flows (performance metric 18) forecast for 19 long-term strategies with equal weighting of traces. 


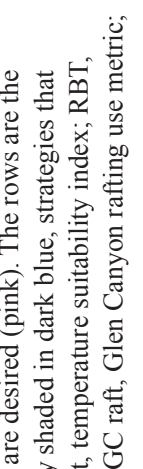

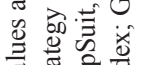

迎 言:

它署苍言

is b

E을 율

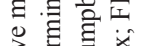

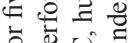

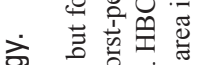

(3)

응 을

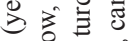

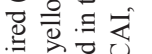

.

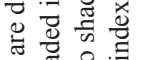

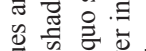

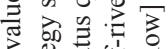

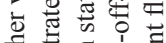

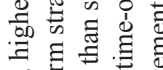

co

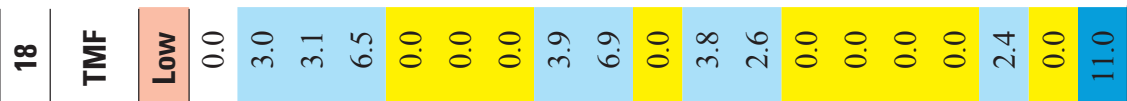

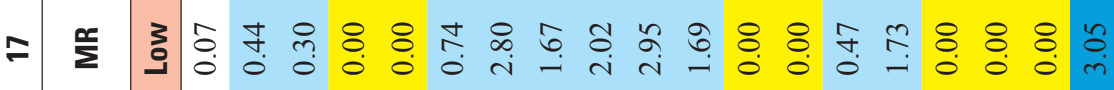

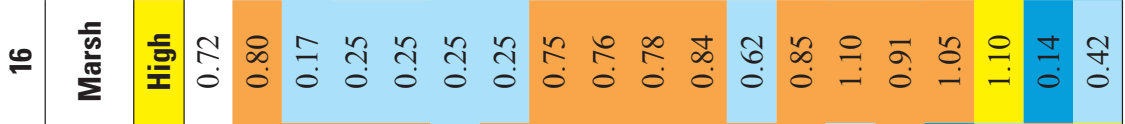

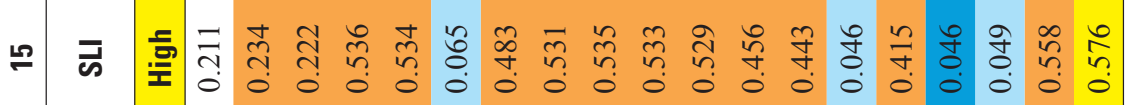

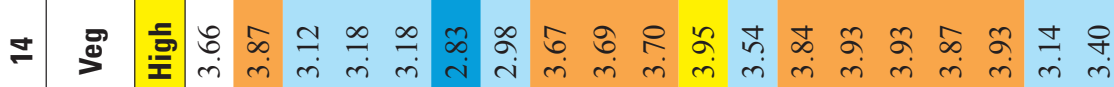

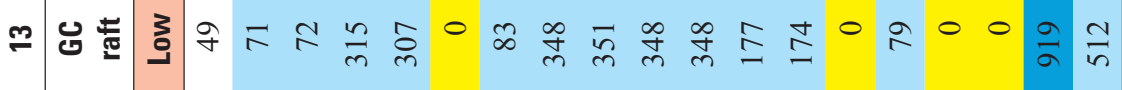

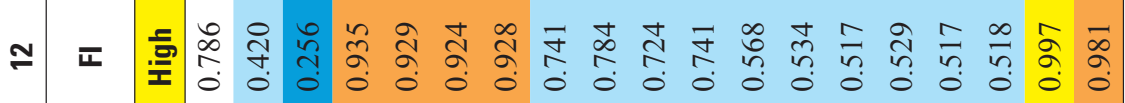

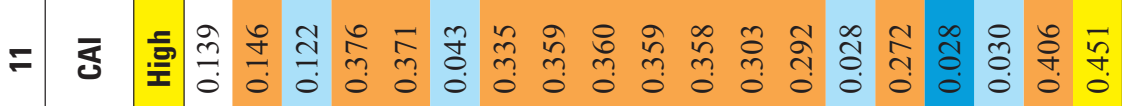

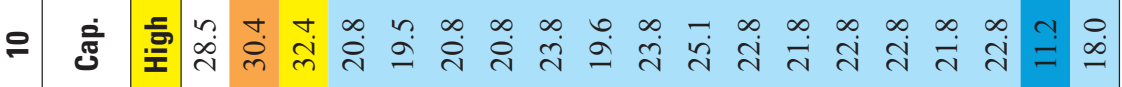

$\exists$

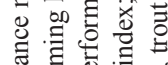

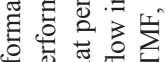

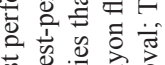

पै

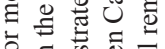

党焉焉

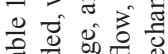

远

品

总

政

言方鬲票

o : 8

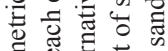

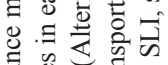

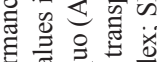

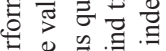

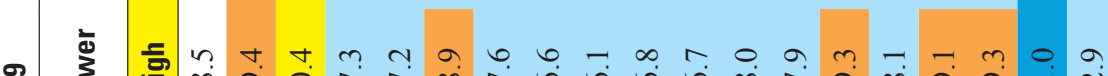

a d a

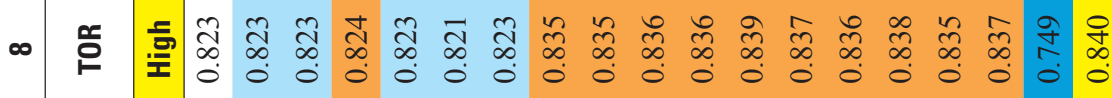

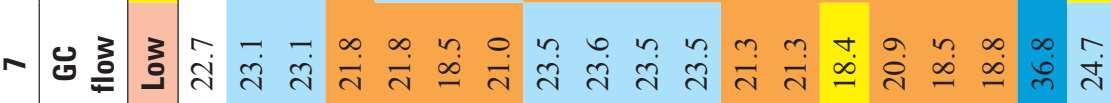

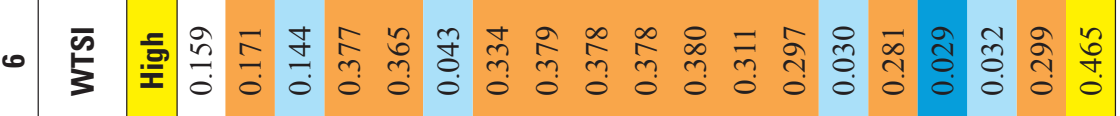

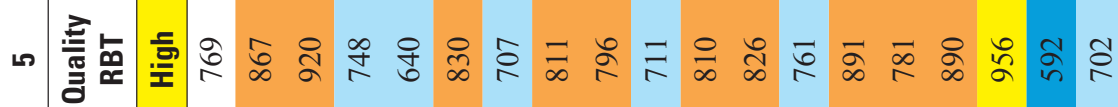

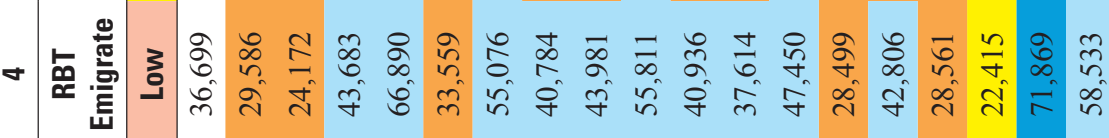

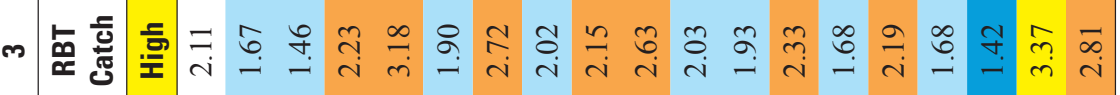

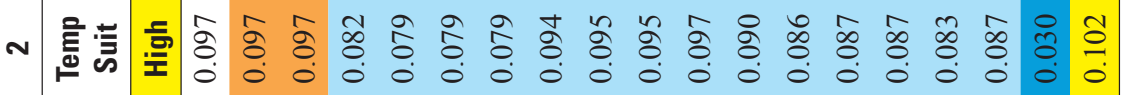

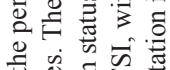

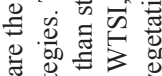

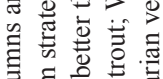

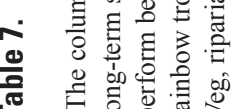

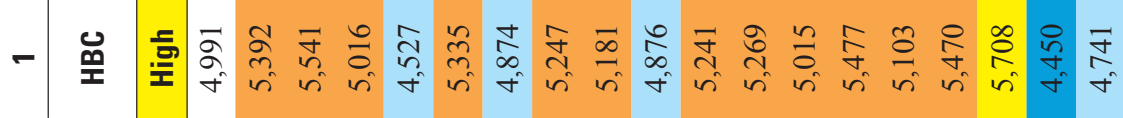

高高离 


\section{Decision Analysis Results}

The purposes of completing a formal decision analysis as a component of the evaluation in the LTEMP EIS was to explicitly examine the influence of the relative importance assigned to the resource goals on the ranking of the alternatives and long-term strategies, and to understand the effect of uncertainty on this same ranking. As described in section 3, "Decision Analysis," the two primary tools used to support this investigation were MCDA and the expected value of information.

\subsection{Swing-Weighting Method and Results}

The swing-weighting method (Winterfeldt and Edwards, 1986) was used to develop weights for the performance metrics, reflecting individual stakeholder expressions of the relative importance of those metrics. In April 2014, a 2-day workshop was held to present a preliminary analysis of the long-term strategies against the performance metrics to interested stakeholders. After discussion of the meaning and interpretation of each of the performance metrics, the stakeholders were given a swing-weighting response form with instructions (table 8) to complete within several weeks. The swing-weighting method asks a decision maker or stakeholder to consider each resource goal, the performance metric that reflects it, and the range over which the performance metric varies; and to compare the relative importance of the performance metrics by evaluating how valuable it would be to change the performance of an alternative from the worst score for a performance metric to the best score. The stakeholders were first asked to rank the performance metrics in this manner and then to assign a score between 0 and 100 to each metric to reflect a more nuanced interpretation of the ranking. Because it is difficult to evaluate 18 performance metrics simultaneously, and because there were natural groupings of the metrics, the swing-weighting exercise used a two-level structure. The 18 performance metrics were assigned to 8 higher-level groups (table 8). The stakeholders first ranked and scored the metrics within each group. Then, to rank and score the higher-level groups, the stakeholders were asked to think about the importance of changing the scores of all the metrics within a group for their worst levels to their best levels at the same time. While completing this exercise, the stakeholders had access to a preliminary consequence table (similar to table 7) and a spreadsheet that automatically calculated the weights on the performance metrics as the swing-weighting sheet was filled in.

A total of 27 Federal, State, tribal, and private agencies and organizations were invited to participate in the decision analysis by expressing their view of the relative importance of the performance metrics using the swing-weighting method (Winterfeldt and Edwards, 1986). The invitations were sent to agencies that were either members of AMWG or Cooperating
Agencies for the LTEMP EIS; 14 agencies, including the 2 joint-lead agencies, elected to participate (table 9).

From the responses to the swing-weighting exercise, weights were calculated for the 18 performance metrics separately for each participating stakeholder. To compare these vectors of weights, principal components analysis was used to reduce the dimension of the comparison from 18 to 2 . The first two principal components explained 52.6 percent of the variation in weights across stakeholders. The first principal component was positively correlated with the weight on the frequency of mechanical removal, SLI, WTSI, fluctuation index, and riparian vegetation index; and negatively correlated with hydropower generation and capacity (fig. 22A). The second principal component was positively correlated with HBC population size, Glen Canyon rafting use, and the camping area index; and negatively correlated with RBT emigration and the Glen Canyon flow index (fig. 22A). The differences among the participating stakeholders can then be plotted with these two components (fig. 22B). Representatives from the utility industry (CREDA, UAMPS, and SRP) tended to put more weight on the hydropower generation and capacity metrics than other stakeholders. The agencies concerned with management of the RBT fishery (International Federation of Fly Fishers [IFFF] and Arizona Game and Fish Department [AZGFD]) were in the middle of the spectrum on the first component but had strong positive values for the second component, reflecting an emphasis on $\mathrm{HBC}$, high-quality RBT, and RBT catch rate. The FWS, Arizona Department of Water Resources (ADWR) and the Hopi, Hualapai, and Navajo Tribes placed relatively more emphasis on increasing vegetation and minimizing RBT emigration than other stakeholders. The principal components for two of the nongovernment organizations (Grand Canyon River Guides [GCRG] and National Parks Conservation Association [NPCA]) placed an emphasis on camping area index, SLI, and WTSI. Note that the joint-lead agencies (Reclamation and NPS) separately completed the swing-weighting exercise, and their separate weights were used as input to the principal components analysis, but they elected to average their weighting vectors for presentation and discussion. The joint-lead principal components fall near the center of the spectrum of stakeholders. Although some of these patterns compare well with the expressed views of the stakeholder agencies, others are harder to explain; it is important to note that the higherorder principal components still contained explanatory power, so not all the differences among agencies can be summarized with the first two components.

\subsection{Multicriteria Decision Analysis}

The weights on the performance metrics, unique to each agency, tribe, or organization, were combined with the consequence table to generate a weighted performance metric for each long-term strategy, allowing a comparison of the long-term strategies that integrates the differences in response across performance metrics and the relative value 

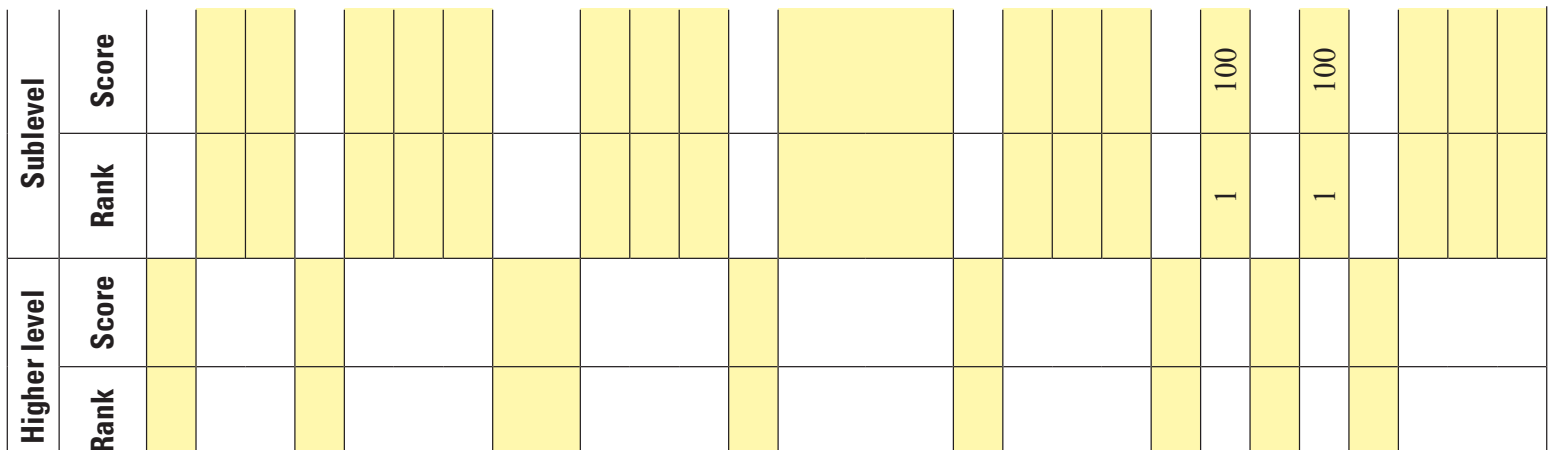

.

ัํํ 高 訔

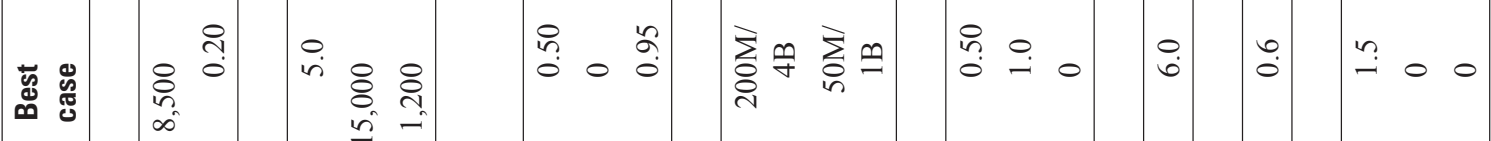

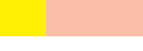

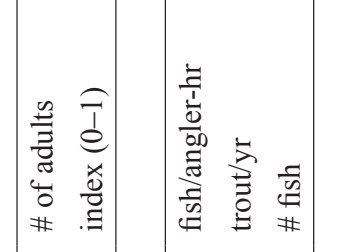

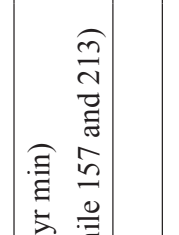

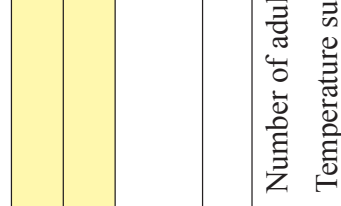

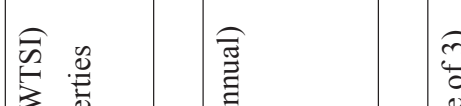

.

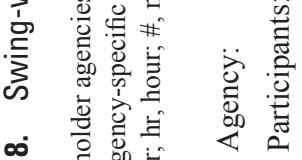

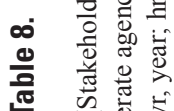
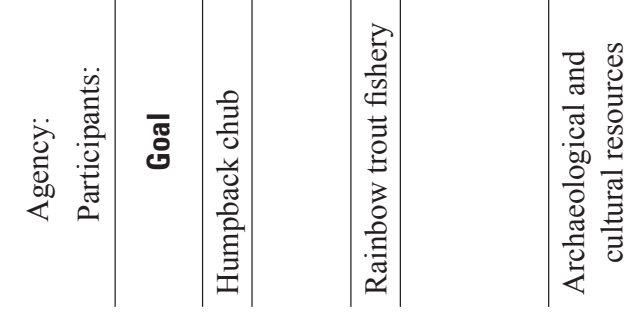
Table 9. Agencies participating in the swing-weighting exercise.

[Representatives from 27 Federal, State, tribal, and private agencies were invited to participate in the swing-weighting exercise. The set of invited agencies included the Adaptive Management Working Group and cooperating agencies for the Long-term Experimental and Management Plan Environmental Impact Statement. Of the 27 agencies invited, 14 participated. AMWG, Adaptive Management Working Group; CA, cooperating agency; NGO, non-governmental organization]

\begin{tabular}{lcccc}
\hline \multicolumn{1}{c}{ Agency } & Affiliation & AMWG & CA & Participant \\
\hline Bureau of Indian Affairs & Federal & Yes & Yes & No \\
\hline National Park Service & Federal & Yes & Yes & Yes \\
\hline Bureau of Reclamation & Federal & Yes & Yes & Yes \\
\hline U.S. Fish and Wildlife Service & Federal & Yes & Yes & Yes \\
\hline Western Area Power Administration & Federal & Yes & Yes & No \\
\hline Havasupai Tribe & Tribe & No & Yes & No \\
\hline Hopi Tribe & Tribe & Yes & Yes & Yes \\
\hline Hualapai Tribe & Tribe & Yes & Yes & Yes \\
\hline Navajo Nation & Tribe & Yes & Yes & Yes \\
\hline Pueblo of Zuni & Tribe & Yes & Yes & No \\
\hline Southern Paiute Consortium & Tribe & Yes & No & No \\
\hline Fort Mojave Indian Tribe & Tribe & No & Yes & No \\
\hline National Parks Conservation Association & NGO & Yes & No & Yes \\
\hline International Federation of Fly Fishers & NGO & Yes & No & Yes \\
\hline Grand Canyon River Guides & NGO & Yes & No & Yes \\
\hline Arizona Department of Water Resources & State & Yes & No & Yes \\
\hline Arizona Game and Fish Department & State & Yes & Yes & Yes \\
\hline Colorado River Board of California & State & Yes & Yes & No \\
\hline Colorado Water Conservation Board & State & Yes & No & No \\
\hline Colorado River Commission of Nevada & State & Yes & Yes & No \\
\hline New Mexico Interstate Stream Commission & State & Yes & No & No \\
\hline Wyoming State Engineer's Office & State & Yes & No & No \\
\hline Utah Division of Water Resources & State & Yes & No & No \\
\hline Salt River Project & Public power utility & No & Yes & Yes \\
\hline Upper Colorado River Commission & State and Federal & No & Yes & No \\
\hline Colorado River Energy Distributors Association & Power purchase contractor & Yes & No & Yes \\
\hline Utah Associated Municipal Power Systems & Power purchase contractor & Yes & Yes & Yes \\
\hline
\end{tabular}

the particular agency places on those performance metrics. For the joint-lead agencies, using their average set of weights, Alternative D (and specifically, long-term strategy D4) performed better than the other alternatives (fig. 23). Alternatives C, D, E, F, and G all substantially outperformed Alternative A (status quo), provided HFEs were implemented. The long-term strategies that did not implement HFEs (C3, E3, E5, and E6) were all demonstrably poorer than Alternative $\mathrm{A}$, as measured by the weighted performance. The weighted performance of Alternative B was similar to that of Alternative A, with longterm strategy B1 slightly better than long-term strategy B2.

Alternative D was created after a preliminary analysis of the other alternatives. In the April 2014 preliminary analysis, the results of which were discussed by the joint-lead agencies and the Cooperating Agencies, Alternative $\mathrm{C}$ and $\mathrm{E}$ exhibited roughly equivalent performance with some differences in ranking across stakeholders. Alternative $\mathrm{D}$ was created as a hybrid between Alternative $\mathrm{C}$ and $\mathrm{E}$, taking features of each that had contributed to positive performance in the preliminary analysis. One of the advantages of separating objective weighting from alternative evaluation in MCDA is that the weights only depend on the ranges of the performance metrics, not on the alternatives under consideration, so new alternatives can be evaluated without having to re-elicit the swing weights. Because Alternative D was created from the insights gained in the preliminary analysis of alternatives, it stands to reason that Alternative D outperformed Alternatives $\mathrm{C}$ and $\mathrm{E}$. It is interesting, however, that the gain in performance is fairly small, suggesting that only marginal gains in performance remain with the management tools available, against the backdrop 
A. Loading plot

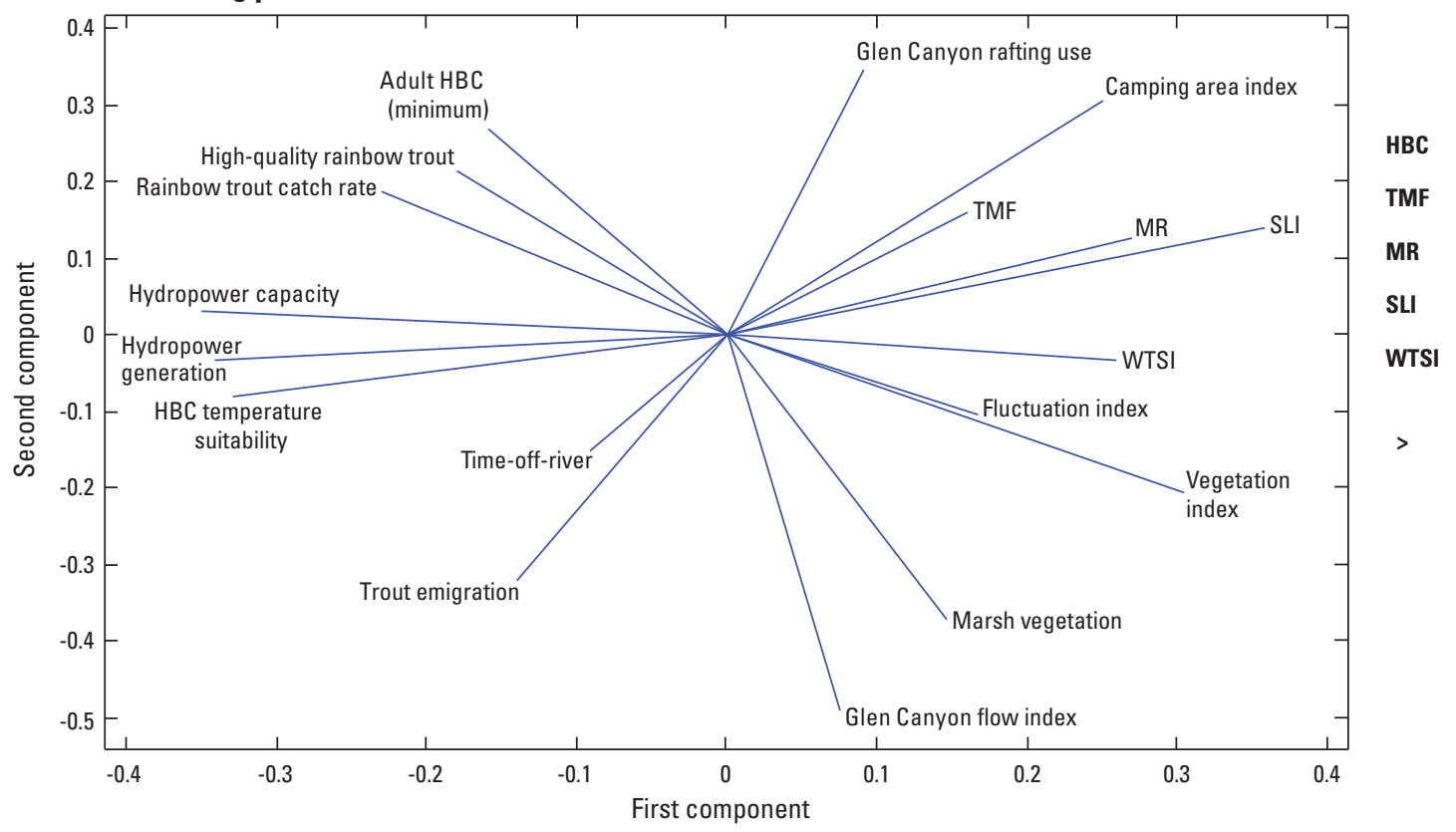

EXPLANATION

HBC Humpback chub

Trout management flow

Mechanical removal

Sand load index

Wind transport of sediment index

Greater than

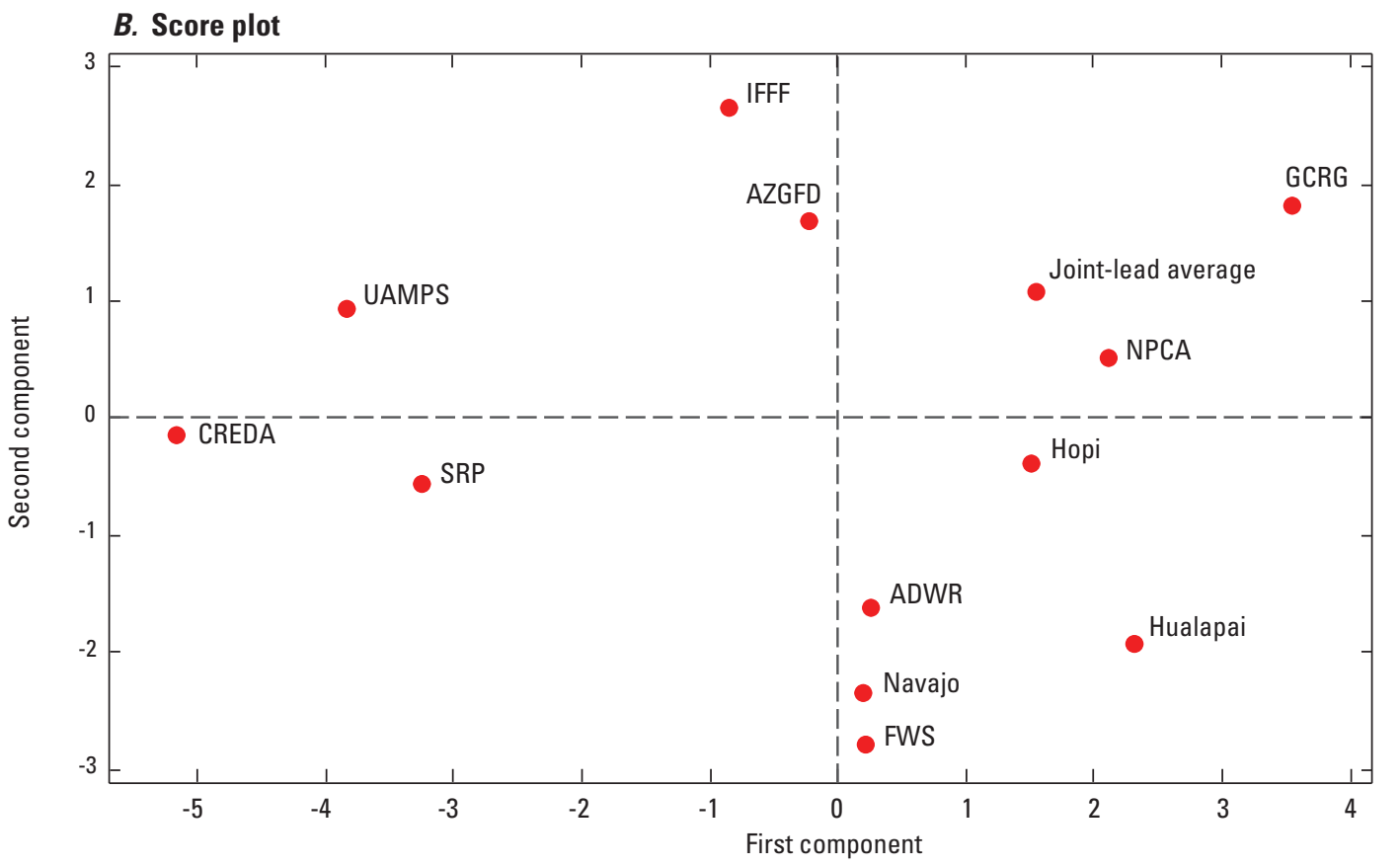

EXPLANATION

$\begin{array}{llll}\text { UAMPS } & \text { Utah Associated Municipal Power Systems } & \text { CREDA } & \text { Colorado River Energy Distributors Association } \\ \text { IFFF } & \text { International Federation of Fly Fishers } & \text { SRP } & \text { Salt River Project } \\ \text { AZGFD } & \text { Arizona Game and Fish Department } & \text { ADWR } & \text { Arizona Department of Water Resources } \\ \text { GCRG } & \text { Grand Canyon River Guides } & \text { FWS } & \text { U.S. Fish and Wildlife Service } \\ \text { NPCA } & \text { National Parks Conservation Association } & & \end{array}$

Figure 22. Principal components analysis of the weights on the performance metrics across stakeholder agencies. $A$, loading plot; and, $B$, score plot. 


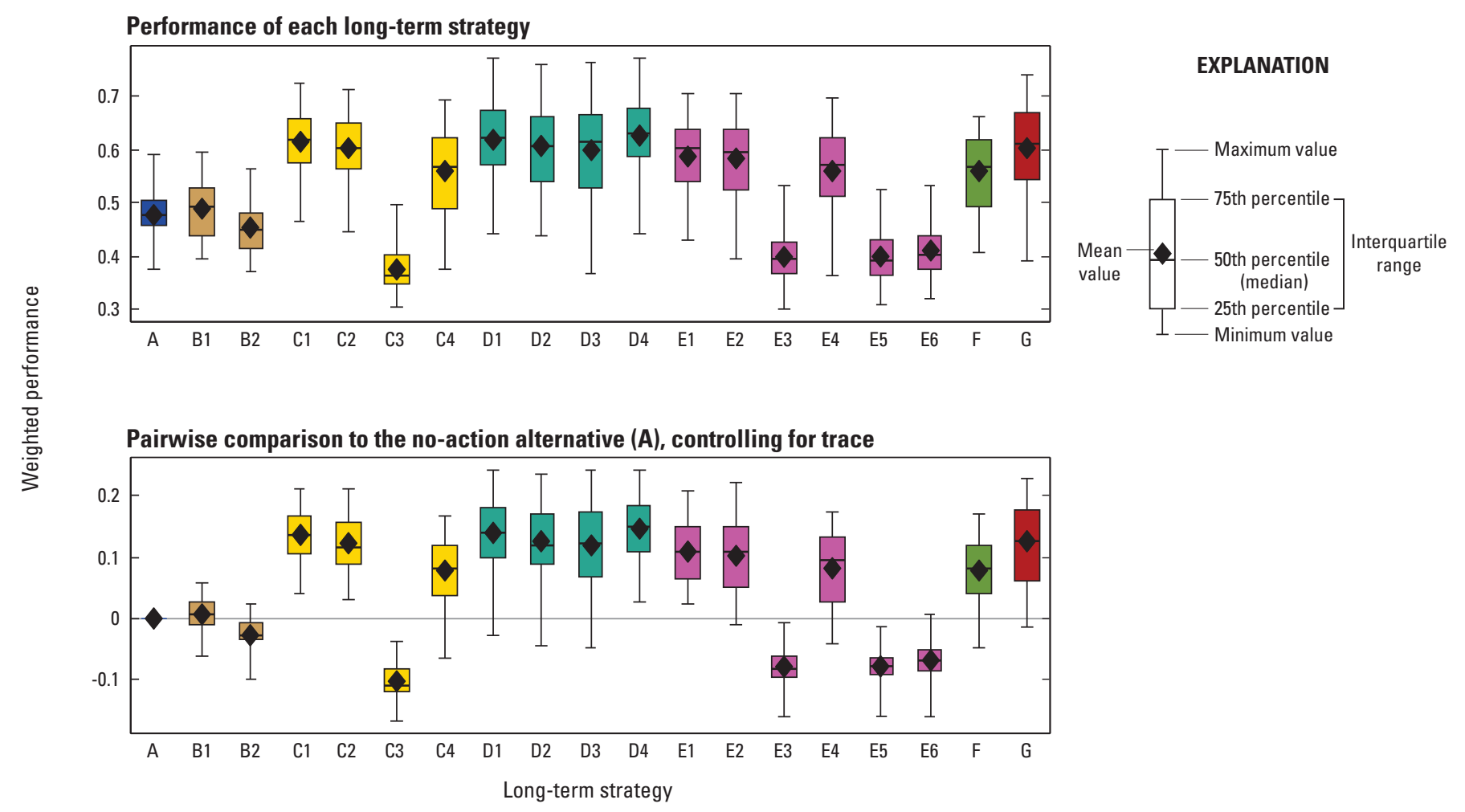

Figure 23. Joint-lead agency weighted performance across 18 metrics forecast for 19 long-term strategies using equal weighting of hydrological traces.

of uncertainty in hydrology and the complex set of tradeoffs among the resource goals.

One of the important motivations for MCDA was the opportunity to include and analyze differing viewpoints from stakeholder agencies regarding the importance of the various resource goals and their performance metrics. The agencyspecific weightings did affect the ranking of alternatives (table 10). For most of the participating agencies, long-term strategy D4 had the highest mean-weighted performance (with the mean taken over hydrology and sediment traces and critical uncertainties). For two of the agencies (UAMPS, CREDA), long-term strategy B2 had the highest weighted score, and for one organization (GCRG), Alternative G had the highest weighted score. For all participating agencies except CREDA, long-term strategy D4 outperformed Alternative A. For all agencies, long-term strategy $\mathrm{C} 3$ performed worse than Alternative A, and for most of those agencies, it was the worst-performing long-term strategy. Alternative F was a polarizing strategy: for three agencies it was the worst-performing strategy, whereas for four others, it performed better than the status quo. Most of the differences across stakeholders in the MCDA ranking of the long-term strategies can be explained by the first principal component in the weighting (fig. 22). For those agencies that placed more weight on the performance metrics on the left side of the diagram (fig. 22A), Alternative $\mathrm{B}$ performed very well because it performs best for power generation and capacity; for those agencies that placed more weight on the performance metrics on the right side of the diagram (fig. 22A), Alternative B was outperformed by Alternative $\mathrm{D}$. Across all participating stakeholders, the mean values for the long-term strategies in Alternative $\mathrm{D}$ were greater than those for Alternatives $\mathrm{C}$ and $\mathrm{E}$, suggesting that the improvements made in crafting Alternative $\mathrm{D}$ are robust to the weights on the performance metrics.

Across stakeholders, the top-ranked long-term strategy was effectively tied with a number of other long-term strategies, against the backdrop of uncertainty induced by the hydrology and sediment traces; for example, using the jointlead agency weights on the objectives, Alternative D4 had the highest mean performance, but the differences between D4 and next nine long-term strategies (D1, C1, D2, G, C2, D3, E1, E2, and E4) had ranges that included zero (fig. 24, bottom panel); that is, based on the results of the MCDA, alternatives $C, D, E$, and $G$ were nearly indistinguishable using the joint-lead agency weights. This pattern held for the weights from most stakeholders as well (fig. 25), with between 2 and 11 long-term strategies effectively tied. For all stakeholders except CREDA, long-term strategies D4 and D1 were either the best-performing or effectively tied with the best-performing long-term strategy.

The differences among the long-term strategies within Alternative D are difficult to discern (fig. 23). The tradeoffs associated with using TMFs are marginal (compare D1 to D3). Similarly, the tradeoffs associated with "bug flows" do not 


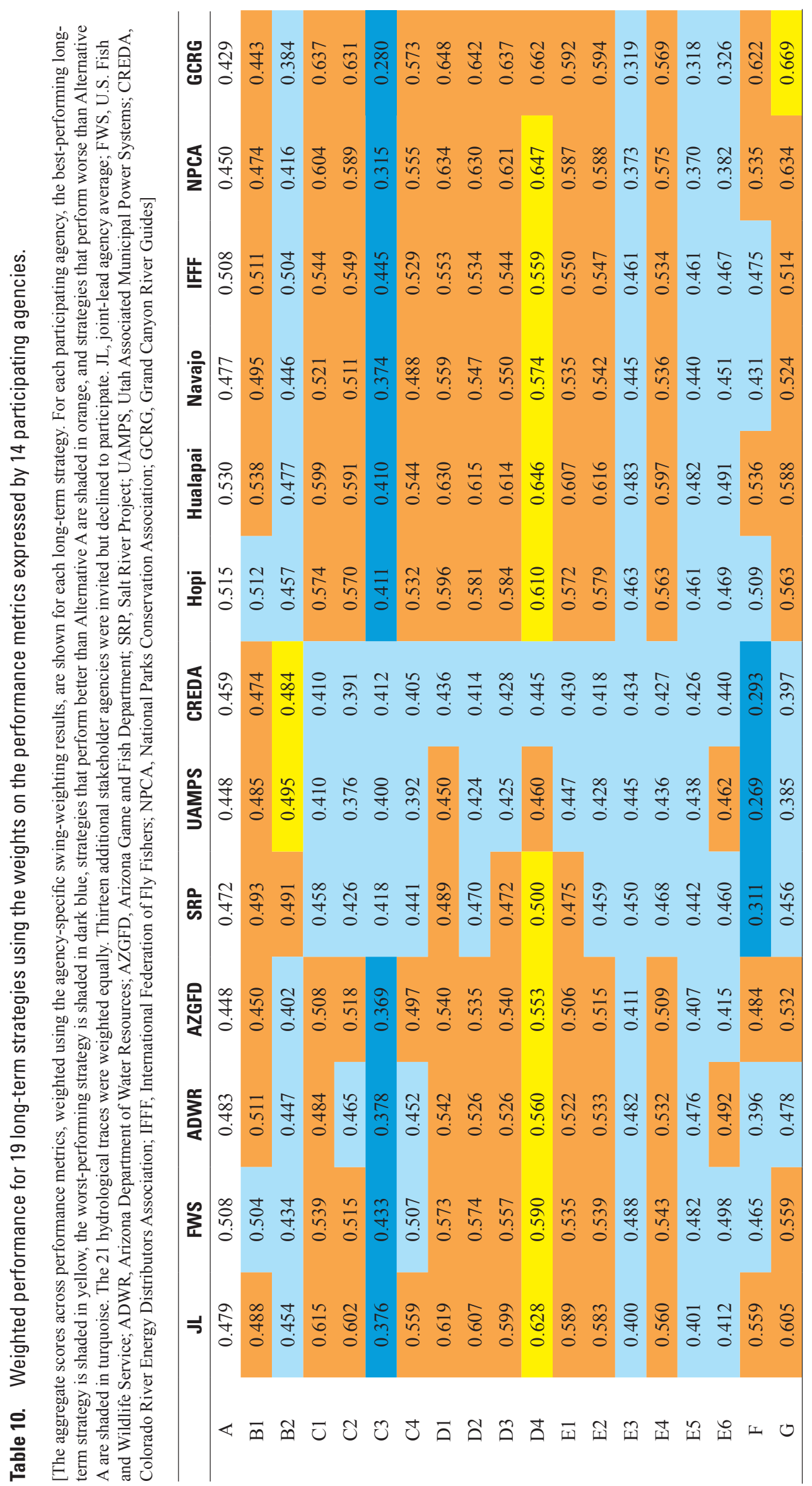



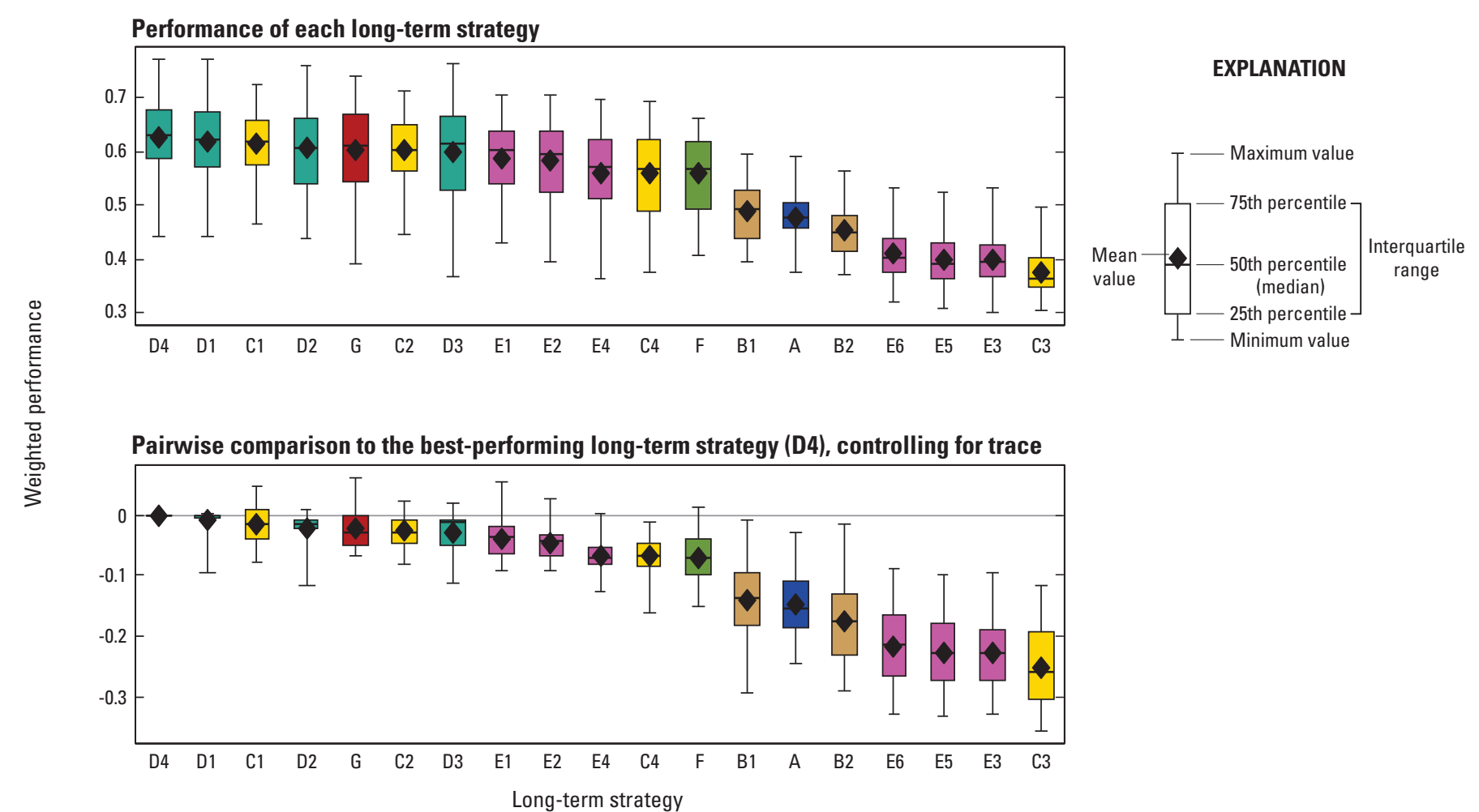

Figure 24. Joint-lead agency weighted performance across 18 metrics, sorted by mean performance, forecast for 19 long-term strategies using equal weighting of hydrological traces.

produce a clear favorite (compare D1 to D2). Finally, although there is the suggestion that the costs of low summer flows outweigh the benefits (compare D1 to D4), the difference is small against the backdrop of the variation driven by hydrology. The patterns within Alternative D are shown for the joint-lead agency weighting (figs. 23-24) but hold for the other stakeholder weightings as well (fig. 25).

\subsection{Expected Value of Information}

A second important purpose for the use of formal decision analysis tools was to examine the effect of uncertainty on the ranking of the alternatives. Although the effect of uncertainty on the ranking of alternatives based on single performance metrics was generally small (table 6), it is conceivable that the weighted performance could be more sensitive to uncertainty if the effects of the uncertainties affect the subtle balancing of tradeoffs. The analysis of the value of information on the weighted performance, however, revealed that the effect of the uncertainties was nearly 0 (table 11). For the joint-lead agency weighting and all but two of the participating stakeholders, the best-performing long-term strategy was the same across the 16 hypotheses that represented critical uncertainty (table 11); for example, long-term strategy D4 was preferred in the joint-lead agency weighting regardless of whether fall HFEs have an effect on RBT recruitment or not, regardless of whether TMFs are 10 or 50 percent effective in reducing RBT recruitment, and regardless of the relative influence of temperature and RBT on juvenile HBC survival and growth. For two stakeholders, there was a very small effect of the critical uncertainty: for IFFF, C2 was preferred more than D4 in 2 of the 16 hypotheses; and for GCRG, D4 was preferred more than $\mathrm{G}$ in 1 of the 16 hypotheses (table 11). Even in these two cases, however, the expected value of information for resolving the uncertainty represented by the 16 hypotheses was less than 0.1 percent.

At first glance, these results may seem puzzling. Many intense discussions within AMWG through the years have focused on concern that uncertainty about the response of the system to management prevents the identification of a best management strategy, and differences concerning recommendations for management have been explained as differences in interpretation of the scientific evidence. The uncertainties examined in this analysis (effect of fall HFEs, effectiveness of TMFs, and relative influence of temperature and RBT on juvenile HBC) have been central to previous discussions. But the results of this analysis do not support the conclusions that resolution of this uncertainty is important in choosing among the long-term strategies examined. There are several explanations for these results. First, there is less uncertainty than informal conversations imply. After several decades of intense study of the resources affected by the operation of Glen Canyon Dam, the AMWG partners have learned a great deal. Uncertainty remains, of course, but it is bounded; for 


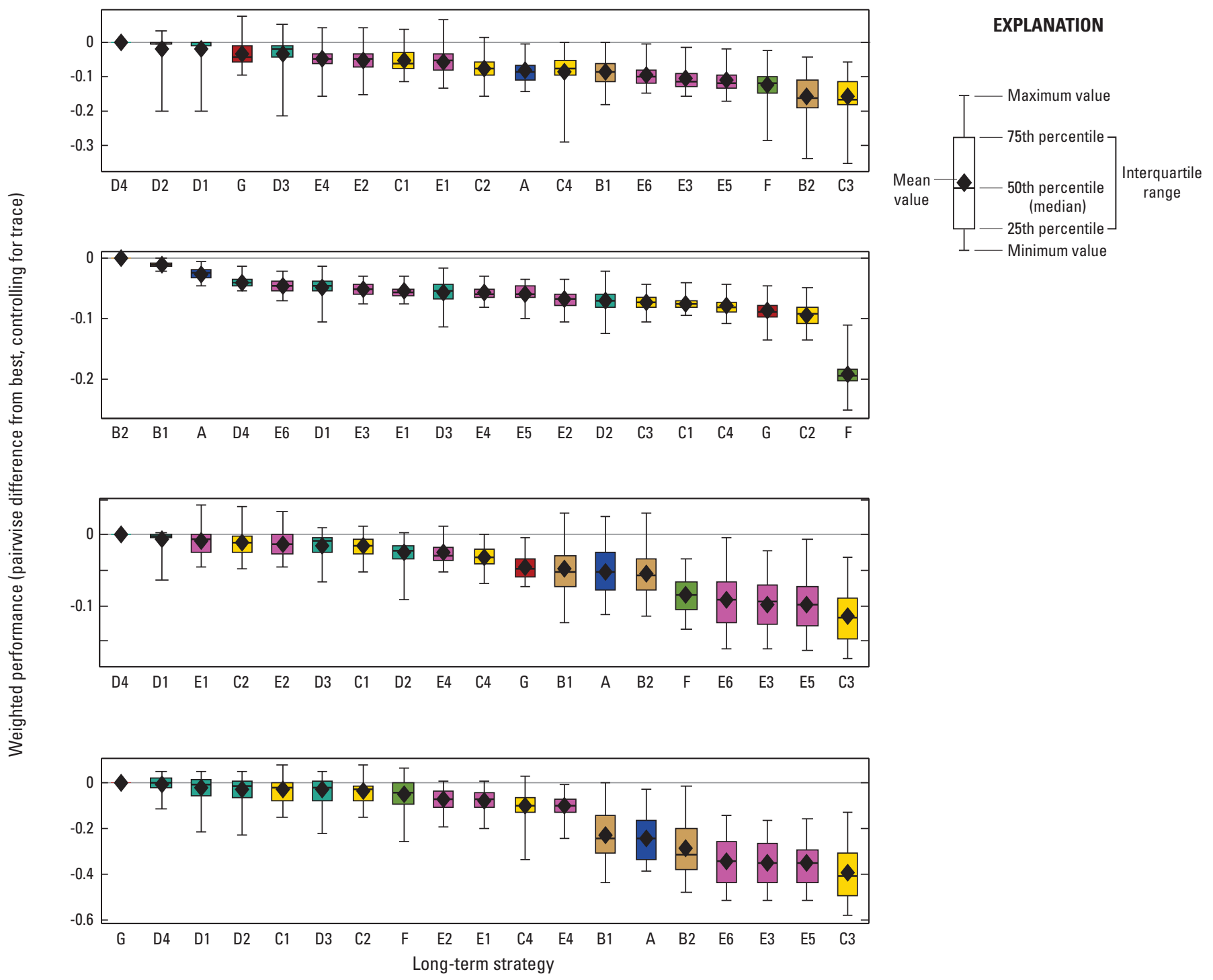

Figure 25. Weighted performance across 18 metrics, for four stakeholder agencies, sorted in descending order of mean performance. The four panels show the results for the stakeholders at the outer boundary of the score plot (fig. 22B; U.S. Fish and Wildlife Service, Colorado River Energy Distributors Association, International Federation of Fly Fishers, and Grand Canyon River Guides). 


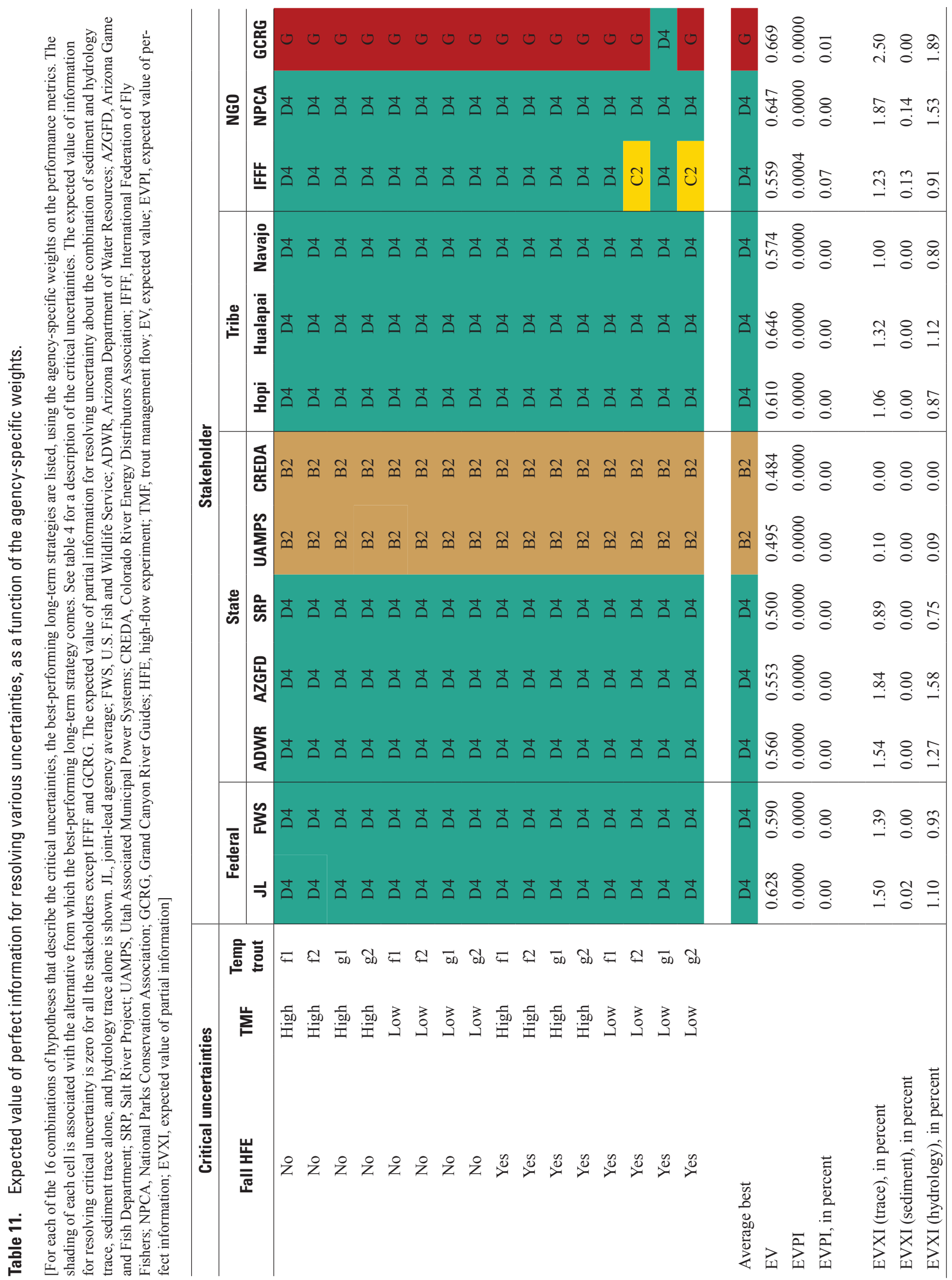


example, the uncertainty in the effect of temperature and RBT on juvenile HBC is large, in the sense that the parameters governing those relations are uncertain by a factor of two (fig. $3 \mathrm{~A}$ and $3 B$ ); the trout effect on survival could be as small as -0.15 or as large as -0.4 . But, the decades of study of the interactions of RBT and HBC have indicated conclusively that there is an effect of RBT on juvenile HBC survival, and there are effects of both RBT and temperature on juvenile HBC growth. Second, the value of information is strongly affected by the set of alternatives considered. It only asks if the uncertainty impedes the choice of a best alternative from among the set evaluated. It does not ask if there could be another alternative, not yet identified, that would be sensitive to the uncertainty. So, for example, it was thought that the value of low summer flows would be sensitive to the effect of temperature on HBC growth; therefore, C2, for example, might be favored compared to $\mathrm{C} 1$ if model $\mathrm{fl}$ holds, but $\mathrm{C} 1$ might be favored compared to $\mathrm{C} 2$ if model $\mathrm{f} 2$ holds. This presumes, though, that low summer flows are triggered in enough years and involve flows low enough to lead to substantial changes in the temperature in the Colorado River at the confluence with the Little Colorado River to produce a demonstrable difference between models $\mathrm{f} 1$ and $\mathrm{f} 2$; this was not the case. But, if there were another alternative that could produce large differences in temperature (for example, a temperature control device on Glen Canyon Dam), these uncertainties may have played a greater role. Third, in a multiple-objective decision, the influence of the weights on the objectives might override the effect of uncertainties; for example, the costs associated with low summer flows (on recreation and hydropower, for example) may override the potential benefits (to HBC) enough that the effect of the uncertainty does not matter.

\subsection{Effects of Climate Change}

Although the value of information associated with resolving critical uncertainty was small, there was an indication that the uncertainty associated with hydrological input had some influence on the ranking of the long-term strategies (table 11). For the joint-lead agency weighting, foreknowledge of the hydrological and sediment trace could lead to a 1.5 percent improvement in the weighted performance across objectives (table 11). Such knowledge is not possible because it would require accurate prediction of the monthly precipitation in the Colorado Basin over the next 20 years. But in demonstrating that hydrological input might be important in the selection of a long-term strategy, it raises the question about the potential influences of climate change.

The 21 reconstructed historical hydrological traces that were used in the LTEMP analysis represent possible 20-year sequences if the future is like the recent past (1906-2010). The 112 hydrological traces generated as part of the Basin Study (Bureau of Reclamation, 2012) represent the best current understanding of what might happen because of climate change. Mean annual inflow to Lake Powell is quite different under these two sets of traces (fig. 26). The median flow over the climate-change traces is lower than for the historical traces, although it is within the interquartile range of the historical traces. About 30 percent of the potential future distribution of flows, however, is not captured by the distribution of the historical traces. The historical 20-year trace with the lowest mean inflow has an annual flow of about 8.5 million acre-feet; 30 percent of the climate-change traces fall below this point, suggesting that the set of historical traces may not be representative of future conditions.

To examine part of the potential influence of climate change, a reweighting of the historical traces was calculated to better match the mean and variance of Lake Powell inflow seen in the climate-change traces. The climate-change weighing put about 18 percent of the weight on the single hydrology trace with the lowest input to Lake Powell. This reweighting of the hydrological traces was then used in all the MCDA calculations to examine the effect of those weights on the performance of the long-term strategies. For the joint-lead agency weights on the performance metrics, the weights on the hydrological traces had a small effect on the aggregate performance but did not change the rankings of alternatives (fig. 27). A similar pattern was seen for other stakeholder weightings. Although this result suggests the ranking of alternatives is robust to uncertainty about climate change, it is important to
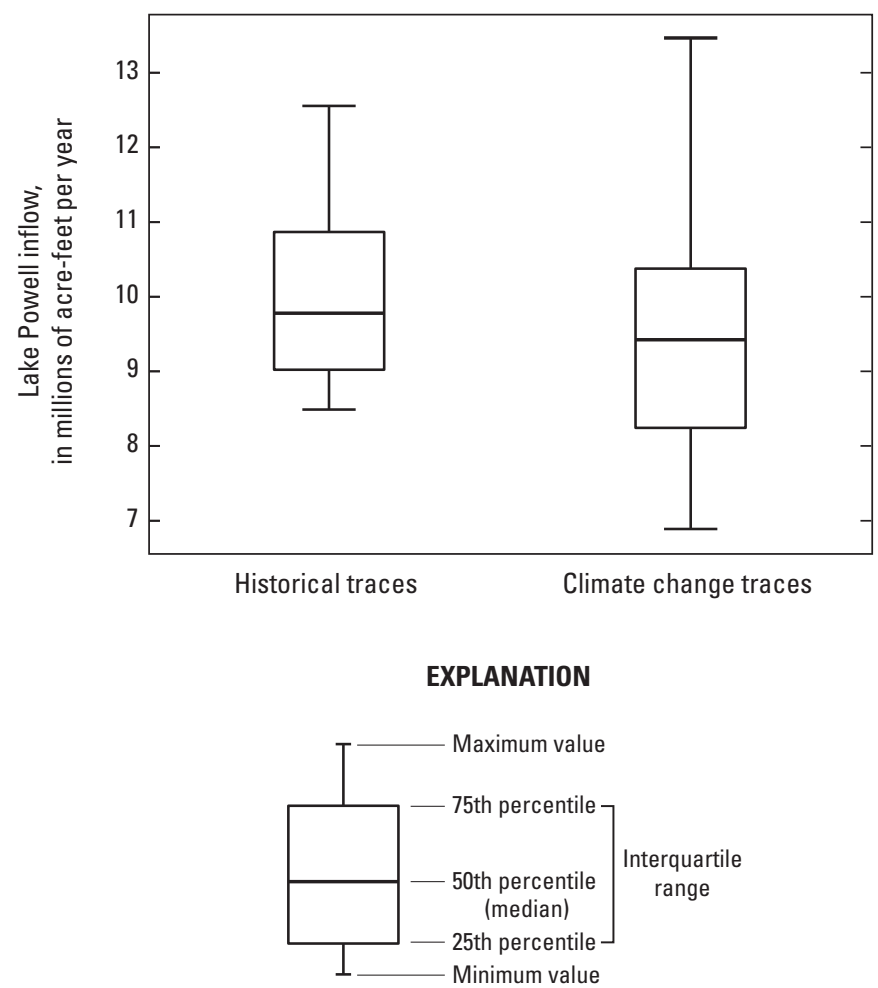

Figure 26. Mean annual inflow to Lake Powell during the 20-year period of the Long-Term Experimental and Management Plan for 21 historical hydrological traces and 112 climate-changeinfluenced hydrological traces. 


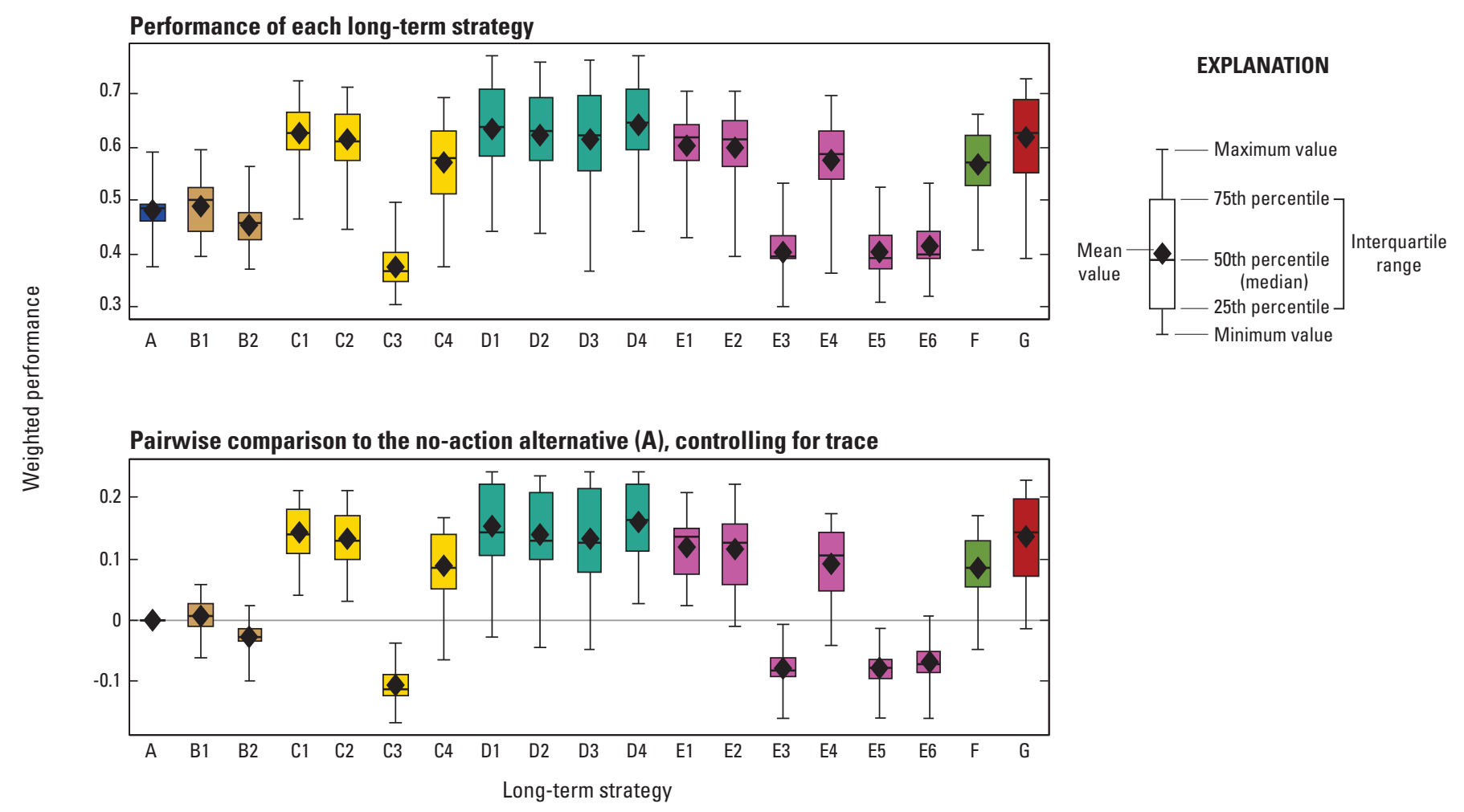

Figure 27. Joint-lead agency weighted performance across 18 metrics forecast for 19 long-term strategies using the climate-change weighting of hydrological traces.

keep in mind that the traces that were run through the modeling did not include plausible scenarios from the low end of the climate-change distribution.

\section{Discussion}

The analysis in this report is meant to add to the analysis in the LTEMP EIS itself. For those resource goals that could be evaluated with quantitative performance metrics, the tools of decision analysis allowed us to integrate the consequence analysis with the value judgments of stakeholders to formally evaluate the tradeoffs among the resource goals and to examine the influence of uncertainty on the performance of the long-term strategies. It is important to note, however, that not all the resource goals of importance could be evaluated quantitatively. The LTEMP EIS contains a narrative analysis of a greater number of resource goals than were included in the decision analysis, and this greater set of goals may be influential for the stakeholders and joint-lead agencies.

\subsection{Evaluation of Alternatives}

The alternatives examined in the LTEMP EIS and their long-term strategies differed in performance across the metrics considered. The full consequence table (table 7) shows strong tradeoffs: long-term strategies that perform well on any one performance metric may not perform well on others; thus, the choice of a preferred alternative will require the Secretary of Interior to weigh the importance of the various resource goals. The MCDA was designed as one way to provide input to the Secretary in her decision, by allowing the joint-lead agencies and stakeholders to express their interpretation of the importance of those resource goals and trace that interpretation through to the rankings of the alternatives. The best-performing long-term strategy did depend on the weights given to the performance metrics. Among the participating agencies, three alternatives rose to the top: Alternatives B, D, and G. Alternative B (especially long-term strategy B2) was favored by those agencies that emphasized the importance of the hydropower resource. Alternative $\mathrm{G}$ was the top- or second-ranked alternative for those agencies that emphasized restoration of natural processes, like beach building and native vegetation. For the remainder of the participating agencies, the analysis ranked Alternative D (especially long-term strategy D4) the highest. Alternative D was created after preliminary analysis revealed the strengths and weaknesses of the other alternatives and performs marginally better than the alternatives from which it was designed ( $\mathrm{C}$ and $\mathrm{E})$.

A number of other suggestions arise from the decision analysis regarding the long-term strategies. For most of the stakeholders, the benefits of HFEs seem to outweigh the costs, even in the face of uncertainty about their effects, at least as 
measured by the performance metrics included in this analysis. The other modifications (for example, TMFs, mechanical removal, low summer flows, and bug flows) produce equivocal results; their inclusion is neither convincingly demonstrated nor precluded by the decision analysis.

Several caveats are warranted in interpreting this report. First, the performance metrics evaluated represent only a subset of the resource goals that might be influenced by the alternatives. The LTEMP EIS provides a fuller discussion of other goals, and the stakeholders and decision makers will need to judge if the formal decision analysis represents a sufficient degree of completeness. Second, not all stakeholders with an interest in the LTEMP EIS chose to participate in the decision analysis; thus, the array of viewpoints represented (for example, fig. 22 and table 10) may not capture the full range or appropriate distribution of viewpoints. Third, even for those stakeholders that participated, it may be difficult to express a nuanced set of values through the swing-weighting process. The set of MCDA methods used assumes the resource goals can be traded against each other in a linear, additive, and independent fashion. In fact, the value a stakeholder places on one objective might depend on how well an alternative is also performing on another objective; such dependencies require other decision analysis methods that were not used here. Fourth, some of the performance metrics may not have directly captured the resource goals they were meant to represent. For instance, the SLI is a proxy for sediment deposition and retention but not necessarily directly correlated with it. Fifth, some of the performance metrics (like hydropower generation) were expressed on natural scales that can be readily understood, but some of the performance metrics were expressed on proxy scales (for example, SLI) or constructed scales (for example, fluctuation index) that are difficult to understand; this mixture of scales makes the swing-weighting judgments challenging.

The structuring of objectives and the development of appropriate performance metrics are critical steps in MCDA and require diligence to meet the assumptions of a linear, additive value model (the form of MCDA used in this analysis). One of the concerns is the possible inclusion of means objectives, leading to possible double counting in the weighting process; for example, there was considerable discussion about the inclusion of the RBT emigration rate (performance metric 4) - was it fundamental or merely a means to conserving native fish populations? For some stakeholders, it was fundamental as an expression of the conservation of natural processes. But for other stakeholders, weight may have been placed on this objective as an expression of the effect of trout on native fish, thus, leading to possible double counting. Another concern is the possible inclusion of preferentially dependent objectives; for example, were RBT catch rate (performance metric 3) and abundance of high-quality RBT (performance metric 5) treated as independent in the swingweighting exercise, or did the participants assume that if you had one, you would have the other and so assign weight based on simultaneous achievement? The two-stage swing-weighting may have helped reduce this concern, but with the large number of performance metrics being evaluated, cognitive mistakes in the swing-weighting exercise could still have happened. When applying decision theory to real problems, with all their subtleties and complexities, it is difficult to achieve perfect adherence to the assumptions of the analysis, but diligence toward those assumptions is needed.

All these caveats are fair, and the interpretation of the results should account for them. But the analysis also represents an effort to use the best available science to explicitly examine the ranking of alternatives as influenced by an analysis of consequences and the relative values placed on the resource goals.

\subsection{Motivation for Adaptive Management}

The purpose of doing the EVPI calculation was to understand the importance of resolving uncertainty (and the relative importance of resolving the different sources of uncertainty) before beginning experimental design. This puts the focus of uncertainty on its value to the decision maker, rather than its value as a point of scientific discovery. Although much has been written about the many scientific uncertainties about how the Colorado River ecosystem responds to management, less has been documented about how resolution of those uncertainties would explicitly affect and improve management decisions. The value of information analysis identifies the following: what long-term management alternative is best assuming each of the competing hypotheses, what long-term management alternative is best in the face of uncertainty (if uncertainty cannot be resolved), how much long-term management can improve through resolution of uncertainty, and which components of uncertainty contribute most to the value of information. Of course, what constitutes "best" depends on how the decision maker values the multiple resource goals within their statutory framework, so the analysis includes the sensitivity of the value of information to the weights on the objectives.

The results presented in this report (including the MCDA and EVPI analyses) provide valuable information for the construction of an experimental or adaptive design that is targeted to the most importance sources of uncertainty and has the best chance of resolving that uncertainty. The design of an adaptive strategy needs to consider three important elements: the value of the information being sought, the power of any experimental or adaptive design to resolve that uncertainty, and the short-term costs to the resource goals of pursuing the reduction of uncertainty. Although there are optimization algorithms to derive adaptive strategies taking these factors into account, for example, active adaptive stochastic dynamic programming (Williams, 1996), such tools are difficult to use in such a complex system.

Interestingly, the EVPI analysis suggests that there is not much advantage in an experimental approach because the resolution of the uncertainties articulated is not expected to alter the choice of long-term strategy. This suggestion, however, 
hinges on the assumption that the uncertainties examined are a complete set. What about the "unknown unknowns," the uncertainties that we cannot yet articulate, but which we might nevertheless discover? We cannot analyze their importance, without being able to estimate their effect, and we also cannot design a monitoring system to detect them reliably. But, ongoing monitoring of the important resource goals, coupled with experimental implementation of the novel elements of any chosen alternative, is likely to reveal any surprises that would affect the achievement of the resource goals.

\subsection{Decision Analysis and the National Environmental Policy Act}

A typical analysis under the NEPA looks quite a bit like a formal decision analysis: resource goals (objectives) are articulated, alternatives are designed and described, and alternatives are evaluated against the individual resources of concern. These analyses are often qualitative, but a mix of qualitative and quantitative tools is also common. What is often missing from such analyses is a formal way to synthesize the results across the resources of concern. To the extent that NEPA is meant as a way to disclose to the public the environmental effects of the considered actions, such a synthesis is not needed. What decision analysis adds is a formal, quantitative way for the decision maker to consider and express the relative importance of the various resource goals in choosing a preferred alternative. In our view, then, decision analysis provides a useful companion to the analyses completed in an EIS.

The use of formal decision analysis in the context of a NEPA process was unfamiliar to a number of the Cooperating Agencies and other stakeholders, and several noted their discomfort with its use in comments to the joint-lead agencies. One-half of those stakeholders invited to participate in the swing-weighting exercise chose not to do so (table 9). They cited a number of concerns: skepticism that all the resources could be evaluated quantitatively, distrust of the methods of MCDA generally, a preference for providing input in a format they felt comfortable with, and a desire not to be forced to make an explicit value judgment on all the resource goals. Underlying the concerns was a stated fear that the decision analysis methods would be used to make the decision rather than just support an understanding of the alternatives. At all points, the joint-lead agencies and DOI leadership assured the stakeholders that the decision analysis was an effort to explore the performance of the proposed alternatives as deeply as possible with quantitative tools but was being used as only one of many sources of input in the transparent, deliberative process sought under NEPA. The effective use of decision analysis tools in the context of future NEPA processes will benefit from the insights of additional case studies, and from improved communication and training with regard to the theory, practice, justification, and benefits of decision analysis.

\section{Summary}

This report describes a formal decision analysis led by the U.S. Geological Survey, in cooperation with the Bureau of Reclamation, National Park Service, and Argonne National Laboratory, to support the development and evaluation of alternatives for the Glen Canyon Dam Long-Term Experimental and Management Plan. A set of 12 resource goals formed the basis of this evaluation, with 18 performance metrics used to provide quantitative measures of the resource goals. A total of 19 long-term strategies associated with 7 alternatives were evaluated against the performance metrics using a series of linked simulation models. Stakeholder input was elicited using the swing-weighting method, and this input was coupled with the quantitative evaluation of the alternatives in a multicriteria decision analysis. For 10 out of 13 stakeholder weightings presented, Alternative D (in particular, long-term strategy D4) outperformed the other alternatives. For the remaining stakeholder weightings, Alternatives B and G were the top performers. These rankings were robust to the uncertainties examined; the value of resolving uncertainty was never greater than 7.5 percent for any performance metric, and never greater than 2.5 percent for any stakeholder-weighted performance. This analysis is not a substitute for the full qualitative analysis found in the Long-Term Experimental and Management Plan Environmental Impact Statement, but does provide a transparent way to synthesize the analyses that could be quantified.

\section{References Cited}

Bishop, R.C., Boyle, K.J., Welsh, M.P., Baumgartner, R.M., and Rathbun, P.R., 1987, Glen Canyon Dam releases and downstream recreation-An analysis of user preferences and economic values: Flagstaff, Ariz., Glen Canyon Environmental Studies, Report No. GCES/27/87, 398 p. [Also available at http://www.gcmrc.gov/library/reports/cultural/ Recreation/Bishop1987.pdf.]

Bureau of Reclamation, 1995, Final Environmental Impact Statement - Operation of Glen Canyon Dam, Colorado River Storage Project, Arizona: Washington, Bureau of Reclamation, $337 \mathrm{p}$.

Bureau of Reclamation, 1996, Record of decision-Operation of Glen Canyon Dam-Final environmental impact statement: Washington, Bureau of Reclamation, $15 \mathrm{p}$.

Bureau of Reclamation, 2007, Final Environmental Impact Statement-Colorado River interim guidelines for lower basin shortages and the coordinated operations for Lake Powell and Lake Mead: Boulder City, Nev., Bureau of Reclamation, Upper and Lower Colorado Regions. 
Bureau of Reclamation, 2011a, Environmental assessment-Development and implementation of a protocol for high-flow experimental releases from Glen Canyon Dam, Arizona, 2011 through 2020: Salt Lake City, Utah, Bureau of Reclamation, Upper Colorado Region.

Bureau of Reclamation, 2011b, Environmental assessmentNon-native fish control downstream from Glen Canyon Dam: Salt Lake City, Utah, Bureau of Reclamation, Upper Colorado Region.

Bureau of Reclamation, 2012, Colorado River Basin water supply and demand study-Study report: Washington, Bureau of Reclamation, $85 \mathrm{p}$.

Bureau of Reclamation and National Park Service, 2014, Alternatives for consideration in the Glen Canyon Dam Long-term Experimental and Management Plan Environmental Impact Statement: Salt Lake City, Utah, Bureau of Reclamation, Upper Colorado Region; Denver, Colorado, National Park Service, Intermountain Region.

Bureau of Reclamation and National Park Service, 2015, Draft Environmental Impact Statement_-Glen Canyon Dam Long-term Experimental and Management Plan: Salt Lake City, Utah, Bureau of Reclamation, Upper Colorado Region; Denver, Colorado, National Park Service, Intermountain Region.

Castle, Anne, 2010, Direction to desired future conditions ad hoc group: Washington, D.C., U.S. Department of the Interior, $3 \mathrm{p}$.

Cole, T.M., and Wells, S.A., 2006, CE-QUAL-W2-A twodimensional, laterally averaged, hydrodynamic and water quality model (ver. 3.5): Vicksburg, Miss., U.S. Army Engineering and Research Development Center, Instruction Report EL-06-1.

Edwards, W., 1971, Social utilities, in Lesser, Arthur, ed., Decision and risk analysis-Powerful new tools for management: Hoboken, N.J., Engineering Economist for American Society of Engineering Education, Proceedings of the Triennial Symposium sponsored by Engineering Economy Divisions, American Society for Engineering Education, and American Institute of Industrial Engineers, 6th, U.S. Naval Academy, Annapolis, Md., June 19-20, 1971, p. 119-129.

Felli, J.C., and Hazen, G.B., 1998, Sensitivity analysis and the expected value of perfect information: Medical Decision Making, v. 18, no. 1, p. 95-109.

Figueira, José, Greco, Salvatore, and Ehrogott, M., eds., 2005, Multiple criteria decision analysis - State of the art surveys: New York, Springer, v. 78, no. 1, 1,045 p.
Flug, Marshall, Seitz, H.L.H., and Scott, J.F., 2000, Multicriteria decision analysis applied to Glen Canyon Dam: Journal of Water Resources Planning and Management, v. 126, no. 5, p. 270-276. [Also available at http://dx.doi.org/10.1061/ (ASCE)0733-9496(2000)126:5(270).]

Goodwin, Paul, and Wright, George, 2004, Decision analysis for management judgment (3rd ed.): West Sussex, United Kingdom, John Wiley \& Sons, 477 p.

Gregory, Robin, Failing, Lee, Harstone, Michael, Long, Graham, McDaniels, Tim, and Ohlson, Dan, 2012, Structured decision making - A practical guide for environmental management choices: West Sussex, United Kingdom, WileyBlackwell, $312 \mathrm{p}$.

Gregory, Robin, Keeney, Ralph, and Winterfeldt, Detlof von, 1992, Adapting the environmental impact statement process to inform decision makers: Journal of Policy Analysis and Management, v. 11, no. 1, p. 58-75. [Also available at http://dx.doi.org/10.2307/3325132.]

Herath, Gamini, and Prato, Tony, eds., 2006, Using multicriteria decision analysis in natural resource management: Hampshire, United Kingdom, Ashgate Publishing Limited.

Howard, R.A., 1966, Information value theory: IEEE Transactions on Systems Science and Cybernetics, v. 2, no. 1, p. 22-26. [Also available at http://dx.doi.org/10.1109/ TSSC.1966.300074.]

Johnson, F.A., Moore, C.T., Kendall, W.L., Dubovsky, J.A., Caithamer, D.F., Kelley, J.R., Jr., and Williams, B.K., 1997, Uncertainty and the management of mallard harvests: Journal of Wildlife Management, v. 61, no. 1, p. 202-216. [Also available at http://dx.doi.org/10.2307/3802429.]

Keeney, R.L., 1996, Value-focused thinking - A path to creative decisionmaking: Cambridge, Mass., Harvard University Press, 432 p.

Kiker, G.A., Bridges, T.S., Varghese, A., Seager, T.P., and Linkov, Igor, 2005, Application of multicriteria decision analysis in environmental decision making: Integrated Environmental Assessment and Management, v. 1, no. 2, p. 95-108. [Also available at http://dx.doi.org/10.1897/ IEAM_2004a-015.1.]

Kimbrough, Sue, Vallero, Dan, Shores, Richard, Vette, Alan, Black, Kevin, and Martinez, Victoria, 2008, Multi-criteria decision analysis for the selection of a near road ambient air monitoring site for the measurement of mobile source air toxics: Transportation Research Part D-Transport and Environment, v. 13, no. 8, p. 505-515. [Also available at http://dx.doi.org/10.1016/j.trd.2008.09.009.] 
Korman, Josh, Kaplinski, Matthew, and Melis, T.S., 2011, Effects of fluctuating flows and a controlled flood on incubation success and early survival rates and growth of age- 0 rainbow trout in a large regulated river: Transactions of the American Fisheries Society, v. 140, no. 2, p. 487-505. [Also available at http://dx.doi.org/10.1080/00028487.2011.5720 15.]

Korman, Josh, Martell, S.J.D., Walters, C.J., Makinster, A.S., Coggins, L.G., Yard, M.D., and Persons, W.R., 2012, Estimating recruitment dynamics and movement of rainbow trout (Oncorhynchus mykiss) in the Colorado River in Grand Canyon using an integrated assessment model: Canadian Journal of Fisheries and Aquatic Sciences, v. 69, no. 11, p. 1827-1849. [Also available at http://dx.doi. org/10.1139/f2012-097.]

Kulkarni, R.B., Burns, R.L., Wright, John, Apper, Bryan, Baily, T.O., and Noack, S.T., 1993, Decision analysis of alternative highway alignments: Journal of Transportation Engineering, v. 119, no. 3, p. 317-332. [Also available at http://dx.doi.org/10.1061/(ASCE)0733947X(1993)119:3(317).]

Linkov, Igor, Satterstrom, F.K., Kiker, G.A., Batchelor, C.J., Bridges, T.S., and Ferguson, E.A., 2006a, From comparative risk assessment to multi-criteria decision analysis and adaptive management: Recent developments and applications: Environment International, v. 32, no. 8, p. 1072-1093. [Also available at http://dx.doi.org/10.1016/j. envint.2006.06.013.]

Linkov, Igor, Satterstrom, F.K., Kiker, G.A., Bridges, T.S., Benjamin, S.L., and Belluck, D.A., 2006b, From optimization to adaptation: shifting paradigms in environmental management and their application to remedial decisions: Integrated Environmental Assessment and Management, v. 2, no. 1, p. 92-98. [Also available at http://dx.doi. org/10.1897/1551-3793(2006)2[92:FOTASP]2.0.CO;2.]

Linkov, Igor, Satterstrom, F.K., Kiker, G.A., Seager, T.P., Bridges, T.S., Gardner, K.H., Rogers, S.H., Belluck, D.A., and Meyer, A., 2006c, Multicriteria decision analysis: a comprehensive decision approach for management of contaminated sediments: Risk Analysis, v. 26, no. 1, p. 61-78. [Also available at http://dx.doi.org/10.1111/j.15396924.2006.00713.x.]

Marcot, B.G., Thompson, M.P., Runge, M.C., Thompson, F.R., McNulty, Steven, Cleaves, David, Tomosy, Monica, Fisher, L.A., and Bliss, Andrew, 2012, Recent advances in applying decision science to managing national forests: Forest Ecology and Management, v. 285, p. 123-132. [Also available at http://dx.doi.org/10.1016/j.foreco.2012.08.024.]
Martin, T.G., Burgman, M.A., Fidler, Fiona, Kuhnert, P.M., Low-Choy, Samantha, McBride, Marissa, and Mengersen, Kerrie, 2012, Eliciting expert knowledge in conservation science: Conservation Biology, v. 26, no. 1, p. 29-38. [Also available at http://dx.doi.org/10.1111/j.15231739.2011.01806.x.]

Maurer, E.P., Brekke, Levi, Pruitt, Tom, and Duffy, P.B., 2007, Fine-resolution climate projections enhance regional climate change impact studies: Eos, Transactions, American Geophysical Union, v. 88, no. 47, p. 504. [Also available at http://dx.doi.org/10.1029/2007EO470006.]

McFadden, J.E., Hiller, T.L., and Tyre, A.J., 2011, Evaluating the efficacy of adaptive management approaches: Is there a formula for success?: Journal of Environmental Management, v. 92 , no. 5 , p. 1354-1359.

National Oceanic and Atmospheric Administration, 1995a, Environmental assessment for the structural restoration of the M/V Alex Owen Maitland grounding site, Key Largo National Marine Sanctuary, Florida: Cambridge, Mass., Industrial Economics, Inc.

National Oceanic and Atmospheric Administration, 1995b, Environmental assessment for the structural restoration of the M/V Elpis grounding site, Key Largo National Marine Sanctuary, Florida: Cambridge, Mass., Industrial Economics, Inc.

Nobrega, R.A.A., O'Hara, C.G., Sadasivuni, R., and Dumas, J., 2009, Bridging decision-making process and environmental needs in corridor planning: Management of Environmental Quality-An International Journal, v. 20, no. 6, p. 622-637. [Also available at http://dx.doi. org/10.1108/14777830910990744.]

Ouarda, T.B.M.J., Labadie, J.W., and Fontane, D.G., 1997, Indexed sequential hydrologic modeling for hydropower capacity estimation: Journal of the American Water Resources Association, v. 33, no. 6, p. 1337-1349. [Also available at http://dx.doi.org/10.1111/j.1752-1688.1997. tb03557.x.]

Prato, Tony, 1999, Multiple attribute decision analysis for ecosystem management: Ecological Economics, v. 30, no. 2, p. 207-222. [Also available at http://dx.doi.org/10.1016/ S0921-8009(99)00002-6.]

Raiffa, Howard, and Schlaifer, R.O., 1961, Applied statistical decision theory: Cambridge, Mass., Graduate School of Business Administration, Harvard University.

Ralston, B.E., Starfield, A.M., Black, R.S., and Van Lonkhuyzen, R.A., 2014, State-and-transition prototype model of riparian vegetation downstream of Glen Canyon Dam, Arizona: U.S. Geological Survey Open-File Report 2014-1095, 30 p. [Also available at http://dx.doi. org/10.3133/ofr20141095.] 
Runge, M.C., 2011, An introduction to adaptive management for threatened and endangered species: Journal of Fish and Wildlife Management, v. 2, no. 2, p. 220-233. [Also available at http://dx.doi.org/10.3996/082011-JFWM-045.]

Runge, M.C., Bean, Ellen, Smith, D.R., and Kokos, Sonja, 2011a, Non-native fish control below Glen Canyon DamReport from a structured decision-making project: U.S. Geological Survey Open-File Report 2011-1012, 74 p. [Also available at http://pubs.usgs.gov/of/2011/1012/.]

Runge, M.C., Converse, S.J., and Lyons, J.E., 2011b, Which uncertainty? Using expert elicitation and expected value of information to design an adaptive program: Biological Conservation, v. 144, no. 4, p. 1214-1223. [Also available at http://dx.doi.org/10.1016/j.biocon.2010.12.020.]

Russell, Kendra, and Huang, Jianchun, 2010, Sediment analysis for Glen Canyon Dam environmental assessmentUpper Colorado Region, AZ: Denver, Colo., Bureau of Reclamation, Denver Technical Services Center, 36 p.

Sheehy, Daniel, and Vik, Susan, 2002, Applying decision analysis methods to NRDA restoration planning: Proceedings of the Annual Ecosystem Restoration and Creation Conference, 29th, Hillsborough College, Plant City, Florida, May 2002, p. 113-127.

Speirs-Bridge, Andrew, Fidler, Fiona, McBride, M.F., Flander, Louisa, Cumming, Geoff, and Burgman, M.A., 2010, Reducing overconfidence in the interval judgments of experts: Risk Analysis, v. 30, no. 3, p. 512-523. [Also available at http://dx.doi.org/10.1111/j.1539-6924.2009.01337.x.]

Stich, Bethany, and Holland, J.H., 2011, Using a multiple criteria decision-making model to streamline and enhance NEPA and public participation processes: Public Works Management \& Policy, v. 16, no. 1, p. 59-89. [Also available at http://dx.doi.org/10.1177/1087724X10390227.]

Turner, N.J., Gregory, Robin, Brooks, Cheryl, Failing, Lee, and Satterfield, Terre, 2008, From invisibility to transparency-Identifying the implications: Ecology and Society, v. 13 , no. 2, art. 7, 14 p.

U.S. Energy Information Administration, 2014, Assumptions to the annual energy outlook 2014: Washington, U.S. Department of Energy, DOE/EIA-0554(2014).
Valdez, R.A., and Speas, D.W., 2007, A risk assessment model to evaluate risks and benefits to aquatic resources from a selective withdrawal structure on Glen Canyon Dam: Salt Lake City, Utah, Bureau of Reclamation, 36 p.

Walters, C.J., 1986, Adaptive management of renewable resources: New York, MacMillan Publishing Company, $374 \mathrm{p}$.

Walters, C.J., and Holling, C.S., 1990, Large-scale management experiments and learning by doing: Ecology, v. 71, no. 6, p. 2060-2068. [Also available at http://dx.doi. org/10.2307/1938620.]

Winterfeldt, D. von, and Edwards, W., 1986, Decision analysis and behavioral research: Cambridge, United Kingdom, Cambridge University Press 624 p.

Williams, B.K., 1996, Adaptive optimization of renewable natural resources-Solution algorithms and a computer program: Ecological Modelling, v. 93, nos. 1-3, p. 101111. [Also available at http://dx.doi.org/10.1016/03043800(95)00217-0.]

Wright, S.A., Anderson, C.R., and Voichick, Nicholas, 2009, A simplified water temperature model for the Colorado River below Glen Canyon Dam: River Research and Applications, v. 25, no. 6, p. 675-686. [Also available at http://dx.doi. org/10.1002/rra.1179.]

Wright, S.A., Topping, D.J., Rubin, D.M., and Melis, T.S., 2010, An approach for modeling sediment budgets in supply-limited rivers: Water Resources Research, v. 46, no. 10, p. 1-18. [Also available at http://dx.doi. org/10.1029/2009WR008600.]

Yackulic, C.B., Yard, M.D., Korman, Josh, and Haverbeke, D.R., 2014, A quantitative life history of endangered humpback chub that spawn in the Little Colorado RiverVariation in movement, growth, and survival: Ecology and Evolution, v. 4, no. 7, p. 1006-1018. [Also available at http://dx.doi.org/10.1002/ece3.990.]

Zagona, E.A., Fulp, T.J., Shane, R., Magee, T., and Goranflo, H.M., 2001, RiverWare-A generalized tool for complex reservoir system modeling: Journal of the American Water Resources Association, v. 37, no. 4, p. 913-929. [Also available at http://dx.doi.org/10.1111/j.1752-1688.2001. tb05522.x.] 



\section{Appendix 1. Disclaimers}

In preparatory discussions with the Adaptive Management Working Group (AMWG) stakeholders and Cooperating Agencies, the joint-lead agencies and U.S. Department of the Interior (DOI) wanted to be clear about the role of the decision analysis in the Long-Term Experimental and Management Plan (LTEMP) Environmental Impact Statement (EIS) process. The following disclaimer is to be included in the EIS when describing the use of formal decision analysis. (Note that during the discussions with the stakeholders, the term "structured decision analysis" was used as shorthand for the process being used. In this report, we follow the common practice in the literature and simply refer to the process as "decision analysis." The disclaimers below are reproduced verbatim, and so retain the use of the term "structured decision analysis"). A number of the participating stakeholders added disclaimers of their own when they submitted their swing-weighing results; these are also included below.

\subsection{Standard Disclaimer}

In an effort to provide multiple opportunities for interested stakeholders to provide input in the LTEMP process, the National Park Service (NPS) and Bureau of Reclamation (hereinafter referred to as "Reclamation") have decided to incorporate facilitated structured decision analysis (SDA) into the LTEMP EIS process. The SDA has been used previously for one aspect of the Glen Canyon Dam Adaptive Management Program (GCDAMP), the "Environmental Assessment for Non-Native Fish Control below Glen Canyon Dam." The use of SDA in the LTEMP process is not required by the National Environmental Policy Act (NEPA), nor does it replace the NEPA impact analysis.

Participation in the SDA process is a voluntary opportunity for stakeholder input. The NPS and Reclamation recognize that any input provided during the SDA effort does not replace the need and opportunities for formal public comment that are required steps in the NEPA process. Such formal comments on the Draft and Final EISs will be regarded as the formal and official positions of any commenting entity.

The use of SDA is an effort to cast a complex decision setting into a transparent, comprehensive but compressed form to help the decision makers and stakeholders see the essential elements; it may not, however, capture all nuances perfectly. The NPS and Reclamation recognize that the metrics for identified resource goals in the SDA do not necessarily reflect consensus or agreement among participants; moreover, the swing-weighting values to be applied to the metrics for identified resource goals may not reflect the broader policies or the importance of issues for any participant or agency. Stakeholders have had and will have formal opportunities to express their values through standard steps in the NEPA process, especially the submission of alternatives and public comments; for some stakeholders, these steps may allow them more flexibility to express their values in a familiar form than the decision analysis.

For these and other reasons, neither the co-leads nor the swing-weighting participants are bound by any outcomes or results of the SDA process. The NPS and Reclamation will use the results of the SDA process as one of multiple sources of information to inform the NEPA process, but the SDA process itself will not be used in isolation from other input to select the preferred alternative; rather, the NPS and Reclamation will choose a preferred alternative based on their statutory missions and responsibilities, giving consideration to legal, economic, environmental, technical, and other factors, as well as formal public input.

\subsection{Arizona Department of Water Resources Disclaimer}

The Arizona Department of Water Resources (ADWR) understands that the use of SDA in the LTEMP process is not required by NEPA, nor does it replace the NEPA impact analysis; furthermore, the ADWR recognizes that any input provided during the SDA effort does not replace the need and opportunity for formal public comment that are required steps in the NEPA process. Such formal comments on the Draft and Final EISs, in addition to the attached swing-weight exercise input, will be regarded as the formal and official positions of the ADWR.

The ADWR further recognizes that the swing-weighting values that have been applied to the metrics for identified resource goals do not reflect the broader policies or the importance of issues for the State of Arizona. The importance and priority of the values of ADWR are more accurately reflected within the "Resource Targeted Condition-Dependent" alternative, being necessarily incorporated during alternative creation. For these and other reasons, the ADWR is not bound by any outcomes or results of the SDA process.

Moreover, ADWR understands that the NPS and Reclamation will not solely rely on the results of the SDA process to select a preferred alternative; rather, the NPS and Reclamation will choose a preferred alternative based on their statutory missions and responsibilities, giving consideration to legal, economic, environmental, technical formal public input and other factors. 


\subsection{Arizona Game and Fish Department Disclaimer}

The Arizona Game and Fish Department (AGFD) understands that the use of SDA in the LTEMP process is not required by NEPA, nor does it replace the NEPA impact analysis; furthermore, the AGFD recognizes that any input provided during the SDA effort does not replace the need and opportunity for formal public comment that are required steps in the NEPA process. Such formal comments on the Draft and Final EISs will be regarded as the formal and official positions of the AGFD, in addition to the attached swing-weight exercise.

The AGFD further submits that the swing-weighting values that we have provided for the metrics for identified resource goals do not reflect the broader policies or the importance of issues for the State of Arizona as a whole; rather, they represent AGFD values as they relate to our specific statutory authority and mission. For these and other reasons, the AGFD is not bound by any outcomes or results of the SDA process.

The AGFD understands and expects that the NPS and Reclamation will not solely rely on the results of the SDA process to select a preferred alternative; rather, the NPS and Reclamation will choose a preferred alternative based on their statutory missions and responsibilities, giving consideration to legal, economic, environmental, technical, formal public input and other factors.

\subsection{Salt River Project Explanatory Letter}

The Salt River Project (SRP) submits the attached swingweighting exercise response under the following conditions:

- that this letter entitled "SRP's SDA Evaluation" remain attached to the SRP swing-weighting response table, and

- that the information submitted herein is not authorized for use, or attribution, beyond the purposes of this specific exercise in the current LTEMP EIS process.

1. Hydropower (100).- - The SRP believes that the hydropower resource goal is the only one that represents both societal and environmental benefits. Greater quantities of hydropower provide cost effective service to people who value electricity to support many aspects of their lives. Greater quantities of this renewable, carbon-free resource also serve to avoid emissions and water use by other electric generating facilities. In the initial round of swing weighting, energy and capacity are valued equally.

1. The energy metric does not appear to function in a consistent, intuitive manner; for example, a more flexible alternative with more energy production in higher-value months sometimes performs worse than a less flexible alternative with less energy production in higher-value months.
2. While the capacity metric currently looks at July, SRP's peak demand requirement most often occurs in August, and our understanding from the Western Area Power Administration (WAPA) is that August is a better choice for peak planning purposes from their perspective as well. The SRP believes that utilizing August for peak demand planning would produce more credible capacity metric results.

2. Humpback Chub (75).- - The SRP recognizes the environmental significance of the endangered humpback chub (HBC) (Gila cypha). The SRP supports the assembly of scientific evidence that establishes clear cause and effect relationships between flow regimes and a recovery of this endangered species. The "Number of Adult Humpback Chub" metric looks specifically at chub population, so the SRP places more emphasis on this metric than the "Temperature Suitability Index" metric.

3. Archaeological and Cultural Resources (60).- The Archeological and Cultural Resources goal represents an important societal benefit that the SRP supports; furthermore, SRP's perception is that, as presently crafted, the Archeological and Cultural Resources goal contains a more accurate representation of tribal interests than the "Tribal" resource goal. The SRP supports alternatives that science shows will preserve these resources.

1. At the April Workshop, it was mentioned that the Time-off-river index was the issue that could lead to degradation of archeological and cultural resources; thus, this metric was scored highest.

2. There has been some discussion about the wind transport of sediment index (WTSI). Specifically, some LTEMP representatives indicated that they would not want architectural and cultural sites buried by sand. This metric was, therefore, scored less highly.

3. Based on new data from high-flow experiments (HFEs), it is unclear how HFEs and sediment affect downstream architectural and cultural sites. Because there are some winners and some losers, it is uncertain how the single "GLCA flow effects of historic properties (Ninemile)" metric can be representative of all sites; for example, science shows that HFEs will not increase sand bars before river mile (RM) 30 since there is no silt inflow. Even below RM 30, some sandbars cannot be built up to previous levels because even the maximum output of GCD cannot push sand high enough; thus, the SRP is not weighing this option as heavily as the others.

4. Trout Fishery (40).- - The SRP recognizes the recreational value of the trout fishery and weighs the benefits against the environmental dangers of trout migration on downstream resources in the Grand Canyon ecosystem. 
Since science appears to show that trout stay relatively close to Lees Ferry, SRP would not weigh "Lees Ferry trout emigration estimate" metric as heavily as if trout emigrated more through the canyon. As long as trout are not affecting downstream resources, the other metrics are also important to the trout fishery; thus, the "Angler Catch Rate Index" and "Number of trout $>16$ inches total length" sublevel metrics are scored lower than the emigration metric but are still valued.

5. Recreation (20).- The SRP recognizes the societal value of recreation and believes Glen and Grand Canyons should be enjoyed by anyone who visits. While most visitors who visit the Grand Canyon do not raft down the canyon, the subset of people who do so should be considered.

1. The "GRCA camping area index" is an important metric because people need safe areas to camp for the night. This is the highest rated metric.

2. The fluctuation index is less highly rated because it does not take the time of day of the fluctuation into account.

3. The GLCA rafting use index does not appear to have enough swing from low to high values to be rated highly. The swing of 600 people per year that could not take a trip down the river is not the same scale of an impact as a 1,000 fish population increase for HBC or a $\$ 9$ million per year increase in hydropower energy value.

6. Riparian Vegetation (20).- - The SRP recognizes the effect of riparian vegetation on the ecosystem of the Grand Canyon and believes it is has valuable environmental impacts. The aggregation of all metrics into this single metric hides some of the complexities; for example, CDAS and SASF perform worst for native/ nonnative ratio but best for arrowweed. These are not able to be considered separately, which makes specific value judgments difficult.

7. Sediment (0).-The SRP observes that the effects of sediment are accounted for in the HBC, Archaeological \& Cultural, Recreation, and Riparian Vegetation metrics. The SRP's perception is that sediment is a means to an end. We believe that a separate sediment metric does not make sense in the same manner that a separate temperature or HFE metric does not make sense.

8. Tribal (0).-The SRP believes that tribal interests should be recognized as a valued dimension of the LTEMP EIS process; however, as presented assembled and stated, the Tribal Resource goal does not appear to effectively represent tribal interests. The results for "Change in Marsh Vegetation" were questioned at the April Workshop and were not changed before this swing weighting.
Trout should only be removed when they are endangering HBC, and the decision of how to remove them would preferably comply with tribal interests.

\subsection{Utah Associated Municipal Power Systems Explanatory Letter}

Utah Associated Municipal Power Systems (UAMPS) representing over 30 UAMPS members contracting for power generating output of Glen Canyon Dam is pleased to submit our response to the swing-weight exercise related to the LTEMP EIS process. The UAMPS is both an LTEMP EIS Cooperating Agency, a member of Glen Canyon Dam Adaptive Management Workgroup, and has been involved with most activities related to the operation of Glen Canyon Dam since environmental studies began in the mid-1980s. The UAMPS is grateful for the opportunity to participate in the EIS process as a member of the AMWG and as a Cooperating Agency contributor. We are appreciative of the great amount of work performed by both Federal government employees and contractors performing studies and assembling vast amounts of reporting documents, as well of those interested parties who have been following this LTEMP process.

We continue to be concerned with the valuation of the electric generation from Glen Canyon Dam and the reduction of power capacity and see this loss will be required to be replaced by resources using fossil fuels emitting carbon dioxide, which create other environmental problems and considerations. Thus far, we have not seen any expression of impacts of capacity switching except for some costs of capacity data for natural gas generation. In that regard, we wish to support the comment submitted by the Colorado River Energy Distributors Association (CREDA) that the cost estimates for natural gas combined-cycle generation in today's costs included in the performance metrics are way undervalued and should be corrected. We also hope additional cost analysis will eventually be included to address the lost power generating flexibility at Glen Canyon Dam needed for the western power grid. The flexibility provided by this hydropower is not free and will need to be made-up by some other power generating resource paid for by all utilities connected to the WECC power grid. Thus far, this loss of generating flexibly and the environmental impacts resulting from the shift to fossil fuels has only been casually addressed. We see the environmental objectives in this EIS seem to have priority over the far reaching climate change impacts that the electric industry in the west faces more and more as it struggles meet electric demands.

\subsection{Colorado River Energy Distributors Association Submittal Letter}

This letter [dated April 18, 2014] is an integral part of CREDA's SDA swing-weighting exercise submittal. CREDA members are all non-profit wholesale customers of the Salt 
Lake City Area Integrated Projects (SLCA/IP) firm electric and transmission resources, of which Glen Canyon Dams is the largest generating facility. Although all members are non-profit entities, CREDA membership is diverse. Therefore, responses provided on the attached exercise cannot be ascribed to any individual CREDA member, as individual members did not have the ability to participate in the 5 days of workshop nor complete the exercise individually. Further, the responses are submitted with the understanding that the results will be reported with participant attribution and included in the draft/final Long-Term Experimental and Management Plan (LTEMP) Environmental Impact Statement (EIS). Further, it is not clear to CREDA in what other forums this submittal is intended for use or attribution. Given those assumptions, CREDA submits its SDA swing-weighting response under the conditions that a) this letter shall remain attached to the SDA swing-weighting response table, and 2) the information submitted herein is not authorized for use or attribution beyond purposes of this specific exercise in the LTEMP EIS processes and documents.

SDA AND LTEMP: Having participate fully in the August and March-April SDA workshops, it has become clear to CREDA this this process may not lend itself readily to a system and resources as complex and interdependent as we see in the resources of interest in the LTEMP. As the performance metrics and models have been developed and evolved, CREDA still has concerns about some of the underlying Resource Goals, and their inconsistency with the AMWG-approved Desired Future Conditions. Although many comments and concerns have been expressed on some of the Goals in various forums and through various medium, the Goals have remained unchanged since LTEMP scoping, As we were advised on April 1, if a participant still has concerns with a Resource Goal, or if the participant believes the elements of a metric are contradictory, inappropriately "linked" to a Resource Goal, or a create a potential legal or policy conflict, the participant should value the metric with a very low or 0 value. We appreciate the time and effort involved in developing and facilitating the SDA process, but suggest that it may be more applicable and useful for either determining stakeholder values of individual attributes of a resource, or analyzing a reduced number of alternatives (particularly when many of the LTEMP alternatives were "split up" for this exercise). We commend the stakeholders who devoted a significant amount of time and effort to the August 2013 and this year's process.

\section{SDA, HYDROPOWER ANALYSIS AND LTEMP:}

As you are aware, CREDA is participating in this process as a member of the Glen Canyon Dam Adaptive Management Work Group (AMWG), representing "contractors for the purchase of Federal power produced at Glen Canyon Dam". As such representative, CREDA's submittal of the Balanced Resource Alternative represents the value we ascribe to the hydropower resource, notwithstanding we have some outstanding questions about how this alternative was ultimately modeled for the SDA process. Participants in the April workshop were advised that the hydropower performance metric was incomplete, and that a key component of the metric, capacity, had to be developed by Argonne in an inordinately short period of time (April 1-8), further, that the "ratepayer analysis" portion of the hydropower analysis was noted as "still under discussion" in the Performance Metrics document provided to the workshop participants. CREDA offers detailed comment herein on the energy, capacity and ratepayer analysis components of the hydropower resource, as we were invited to do as soon as possible after the April 1 workshop. We understand and expect that the electric resource flexibility component of the metric will be assessed as part of the draft/full EIS process, and that air quality impacts, such as carbon offsets will also be a part of the overall hydropower analysis. We offer the following comments and suggestions for use in assessing hydropower resources going forward in the LTEMP process.

ENERGY: The information provided to the SDA workshop participants on April 1 has results that are unintuitive. For example, one can compare RTCD4 with BR1. Both have Fall HFEs. BR1 has an average output of 14,500 cfs during July and August, while RTCD4 has an average output of 12,000 cfs and 11,000 cfs respectively. Furthermore, BR1 has an average fluctuation range that is $140 \%$ of MLFF, while RTCD4 has an average fluctuation range that is $114 \%$ of MLFF. Based on common knowledge, BR1 should perform better for energy than RTCD4. However, based on modeling results, RTCD4 performed better. This example, along with others discussed during the April 4 meeting, call the energy results into question. We urge the LTEMP co-leads to utilize the expertise of the cooperating agency utility experts in energy analysis. We would also like to see more detailed energy results, as was agreed in the April 4 conference call.

CAPACITY: The information provided to the SDA workshop participants on April 10 indicates that the capacity metric uses July as its peak month. CREDA reaffirms its suggestion on March 31 that August be used as the peak month to reflect actual utility peak demand experience, both past and as projected for the period of the LTEMP EIS. Also included in the April 10 information is a capacity value of $\$ 65,000 / \mathrm{MW}$-yr to be used in the swingweighting process, based upon the following factors:

- 620-MW natural gas combined cycle plant

- Capital cost of $\$ 917 / \mathrm{kW}$

- Fixed operation and maintenance cost of $\$ 13.17 / \mathrm{kW}$

- 30-year lifetime

- Discount rate of $3.8 \%$

CREDA believes, based on discussion with its utility members who are also cooperating agencies in the LTEMP, that a more accurate estimate of the capacity value for a large, natural gas combined cycle facility is in the range of $\$ 82,000 / \mathrm{MW}-\mathrm{yr}-\$ 132,000 / \mathrm{MW}-\mathrm{yr}$.

As a consulting service to the electric utility industry, the Electric Power Research Institute (EPRI) regularly 
prepares estimates of the costs associated with developing various types of energy resources, including gas-fired combined cycle facilities. EPRI's publicly available Generation Technology Options Report (published 2/19/2013) can be accessed at the linked site. EPRI information provided below can be found in Table 1-2 of their report.

Having worked with EPRI for a number of years with respect to resource characteristics and cost information for various electric resource technologies, a CREDA member's experience suggests that EPRI's valuations often do not fully account for the generally higher elevations and harsher ambient conditions that exist in CREDA member service regions relative to the assumptions used in EPRI's technology assessment efforts. Consequently, the CREDA member's internal cost estimates are higher. A comparison of key factors is provided below.

In summary, CREDA believes that the currently proposed values for LTEMP capacity valuation result in an understatement of Glen Canyon hydropower capacity value on the basis of a credible, publicly available, industry standard source for such information (EPRI) as well as on the basis of utility specific information and experience. We urge the LTEMP co-leads to utilize the expertise of the cooperating agency utility experts in capacity analysis.

RATEPAYER ANALYSIS: As was recently communicated to Ass't. Secretary Castle, CREDA and its electric utility members believe that this analysis must be based on and reflect impacts to the product/resource produced through the operation of Glen Canyon Dam, which is wholesale electric power and energy. On 4/1/14, we again objected to an attempt to develop and include a retail rate analysis, which is not required by NEPA, and which will likely be incorrect and misleading because it will not be possible to obtain sufficient and credible data given the time constraints and budget dollars associated with the LTEMP process. The chart below provides some perspective about the complexities involved in electric utility retail rate development. Consistent with the scope of federal agency responsibility, to the extent any ratepayer analysis is required (which we don't believe is the case under NEPA), we urge the LTEMP co-leads to focus on the wholesale level, and consider utilizing cooperating agency utility expertise.

Finally, CREDA recognizes the time and effort spent by all the SDA participants and believes that a key outcome from the workshops and exercises is the opportunity afforded the AMWG stakeholders, LTEMP co-leads, Argonne National Labs and GCMRC personnel and contractors to learn more about and appreciate the complexities and interdependencies of the resources addressed through the Adaptive Management Program, as well as the challenges faced by the Secretary of the Interior in balancing the resources associated with the operation of Glen Canyon Dam. It has also become clear through the model development and results supporting the SDA process that the resources of concern are "performing well" under the current operational and management parameters. The LTEMP co-lead and cooperating agencies should strongly consider this information.

\begin{tabular}{lllll}
\hline \multicolumn{1}{c}{ Factor } & \multicolumn{1}{c}{ LTEMP } & \multicolumn{1}{c}{ EPRI } & \multicolumn{1}{c}{ CREDA } \\
\hline 1 & Capital Cost & $\$ 917 / \mathrm{kw}$ & $\$ 1,025 / \mathrm{kw}-1,325 / \mathrm{kw}$ & $\$ 1,130 / \mathrm{kw}-\$ 1,426 / \mathrm{kw}$ \\
2 & Fixed O\&M Cost & $\$ 13.17 / \mathrm{kw}-\mathrm{yr}$ & $\$ 15 / \mathrm{kw}-\mathrm{yr}$ & $\$ 23 / \mathrm{kw}-\mathrm{yr}-\$ 25 / \mathrm{kw}-\mathrm{yr}$ \\
3 & Discount Rate (1) & $3.8 \%$ & $5 \%$ & Higher than $5 \%$ \\
4 & Resulting Capacity Cost (2) & $\$ 65,000 / \mathrm{MW}-\mathrm{yr}$ & $\$ 82,000 / \mathrm{MW}-\mathrm{yr}-\$ 101,000 / \mathrm{MW}-\mathrm{yr}$ & $\$ 108,000 / \mathrm{MW}-\mathrm{yr}-\$ 132,000 / \mathrm{MW}-\mathrm{yr}$ \\
\hline
\end{tabular}

(1) The discount rates of CREDA members are proprietary and confidential information.

(2) Lower cost represents wet cooling, higher cost represents dry cooling. 


\section{Representative Factors in Retail Rate Development}

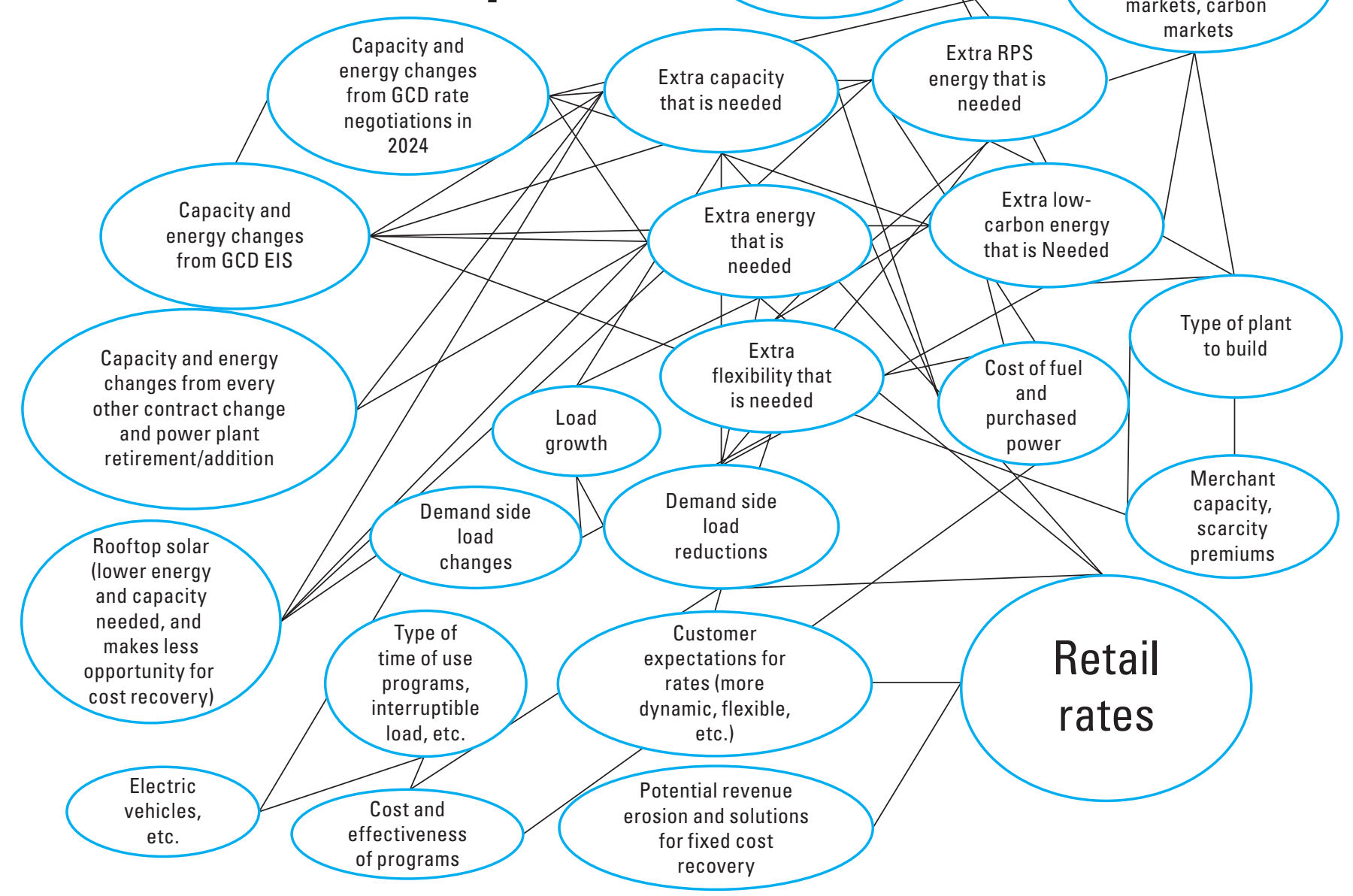

Publishing support provided by:

West Trenton, Tacoma, and Rolla Publishing Service Centers

For more information concerning this publication, contact:

Director, USGS Patuxent Wildlife Research Center

12100 Beech Forest Road, STE 4039

Laurel, MD 20708-4039

$301-497-5500$

Or visit the Patuxent Wildlife Research Center Web site at:

http://www.pwrc.usgs.gov/ 

$\frac{\pi}{20}$

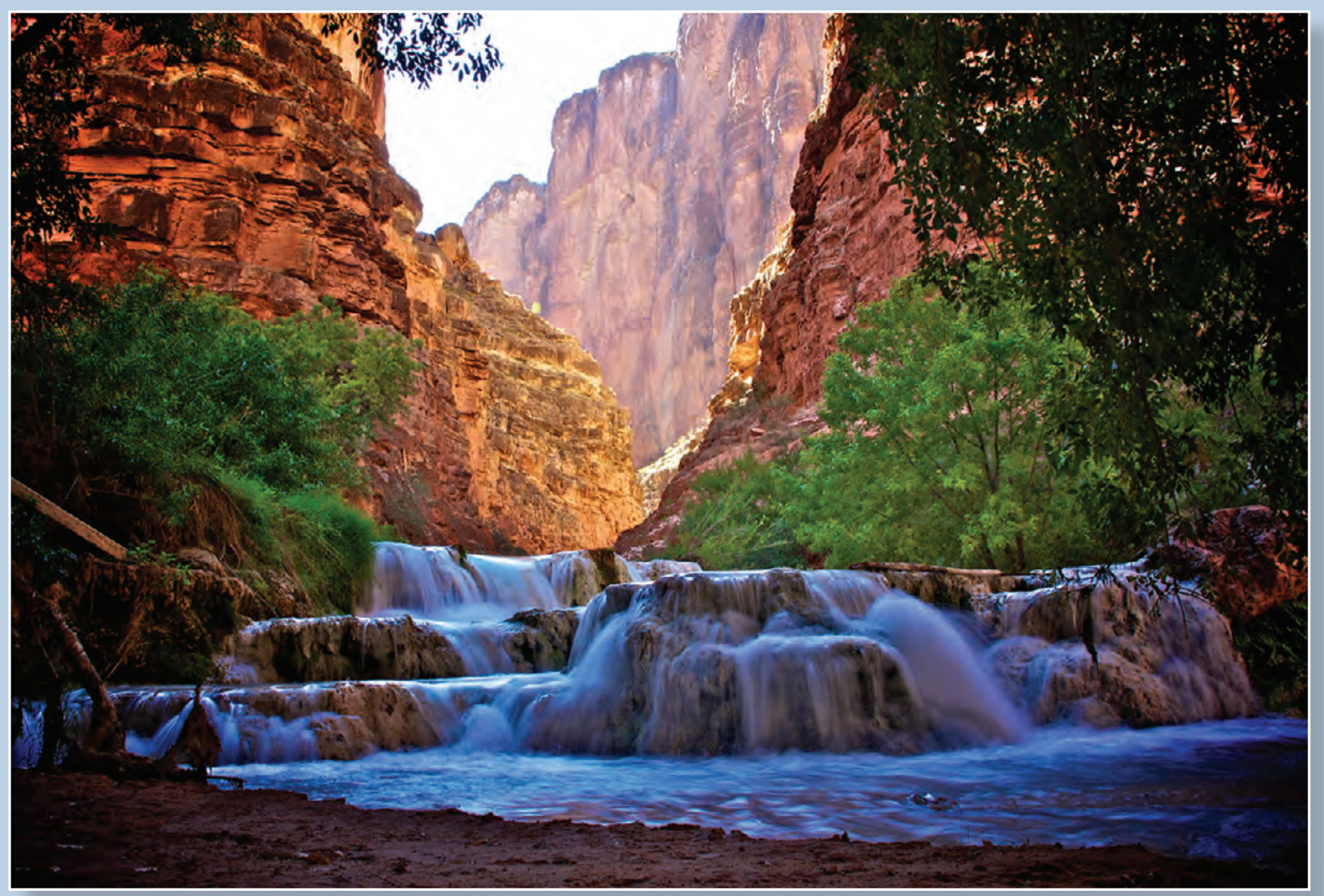

